\title{
Investigation of the Process- and System-Induced Activation of Material Reactions during Discontinuous High-Frequency Welding
}

\author{
Volker Wesling ${ }^{1, a}$, Antonia Schram ${ }^{1, b}$, Henning Wiche ${ }^{1, c}$ \\ ${ }^{1}$ Institut für Schweißtechnik und Trennende Fertigungsverfahren (ISAF), \\ Technische Universität Clausthal (TUC), Agricolastraße 2, \\ 38678 Clausthal-Zellerfeld, Germany \\ aoffice@isaf.tu-clausthal.de, 'bchram@isaf.tu-clausthal.de, cwiche@isaf.tu-clausthal.de
}

Keywords: high-frequency welding, thermomechanical treatment, welding of ultra high strength steel, skin-effect, proximity-effect

\begin{abstract}
Besides weldable component geometries for the high-frequency welding process also possible process and system induced activated material reactions during discontinuous highfrequency welding are presented in this paper. Among others such material reactions can be a locally limited thermal influence on the base metal, defined plastic derformations during the upsetting process as well as grain refinement in the weld seam, comparable to thermomechanical treatment during rolling for increasing strength or ductility.
\end{abstract}

\section{The process versions of discontinuous high-frequency welding}

Discontinuous high-frequency welding is a pressure-welding process. The process sequence consists of two steps. First, the edges to be joined are simultaneously heated over their entire length to a temperature just below the liquidus temperature by Ohmic resistance heating. After completion of the heating process, the joining edges are mutually upset in order to ensure positive material bonding. The excellent tolerance compatibility of this welding method results from the mechanical pressure-welding process. Moreover, under some circumstances, oxides which are present in the seam are pinched out into the upset metal which is formed during the upsetting operation. This excess metal must then be removed from the resulting component in an additional operational step, as dictated by the particular application involved.

As a matter of principle, a distinction is made between two types of energy input coupling for heating the edges to be joined: inductive and conductive coupling. For inductive heating of the edges to be joined, the energy is supplied to the edge by induction, as illustrated in Fig. 1. For this purpose, the components to be welded are mutually positioned in such a way that a defined gap is present between the edges. The gap is surrounded by an induction coil in a configuration which ensures the mutual electrical isolation of the two components from one another and from the highfrequency generator. The inductor consists of a single-turn winding. For maximising the efficiency, the shape of the inductor is usually designed to correspond exactly with the geometrical shape of the two partners to be joined. After switching on the high-frequency generator, a ring current flows in the inductor and generates an alternating magnetic field in the surrounding region. The alternating magnetic field induces eddy currents in the joining edges of the components to be welded. Because of the associated electrodynamic effects, the current density is restricted to a very narrow area in the immediate proximity of the surfaces to be joined. As a result, the heat input to the base metal is highly localised. The coupling distances between the induction coil and the edges to be joined can be adjusted separately for each of the two work-pieces; thus, the energy input can be controlled independently for each work-piece. In this manner, components with a large difference in wall thickness as well as materials with different electrical and thermal properties (such as aluminium and steel) can also be welded together $[1,2]$. 

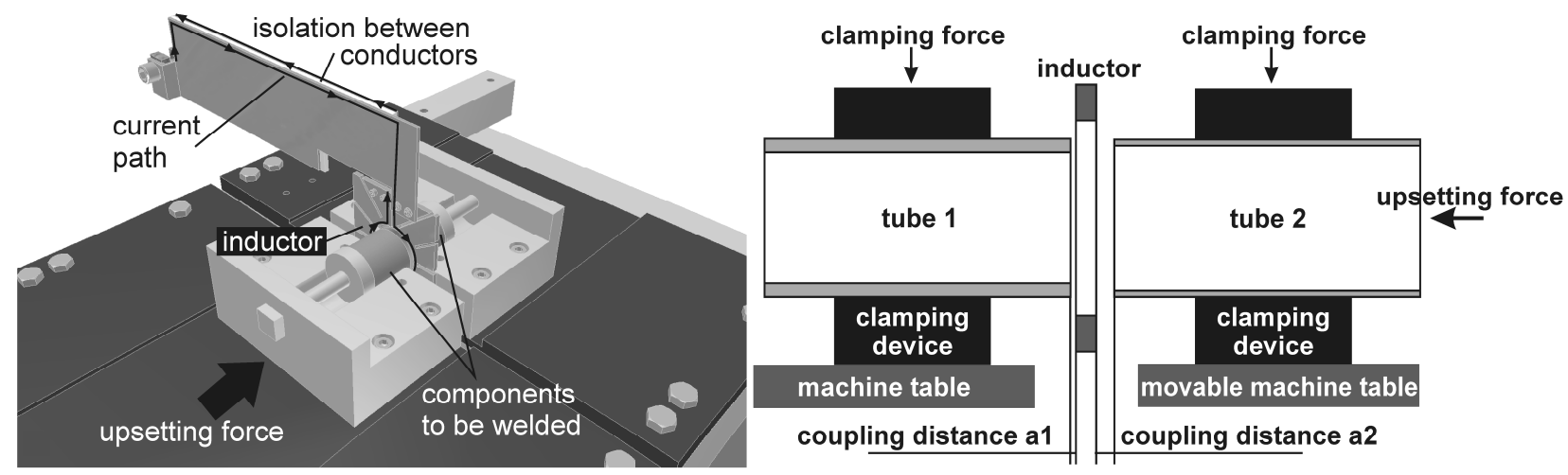

Fig. 1: Operating principle of inductive high-frequency welding, including an illustration of the essential process parameters

In the case of conductive high-frequency welding, the semifinished goods to be joined are electrically in contact with the high-frequency generator; see Fig. 2. Electrical contact bars function as connecting elements and are simultaneously employed as clamping devices for the work-pieces. In this process version, too, the components are mutually positioned with a defined gap. The current is routed through the connecting elements and through a connecting bridge in such a way that the direction of current flow through one component is opposed to that in the other component. With the use of high-frequency alternating current, this configuration results in the occurrence of a pronounced proximity effect. This electrodynamic effect describes the current concentration in two neighbouring current-carrying conductors on the side facing the respective neighbour. This effect results from the decrease in impedance on the interior sides of the two conductors, which in turn is caused by alternating magnetic fields acting in this arrangement of conductors. Furthermore, a frequency-dependent skin effect is always associated with alternating current. The combination of these two effects causes a restriction of the conductive cross-section to a very narrow area in the immediate proximity of the surfaces to be joined. As a result, the thermal exposure of the base metal is very low with this process version, too. By means of the separate adaptation of the exposed work-piece length (distance between the joining edge and clamping device), the energy input into the work-pieces to be joined can be adjusted. In this manner, materials with different electrical as well as thermal properties can also be welded. Furthermore, semifinished goods of different wall thickness can be welded [3]. Besides the aforementioned version-specific process parameters, the generator output power and the current-on period as well as the upset pressure can be employed as welding parameters with both energy-input methods. Moreover, open structural components, such as A-columns for motor vehicles, can be also welded by appropriate geometrical adaptation of the copper clamping devices; thus, the process is not limited to sheet-steel blanks $[1,4,5]$. 

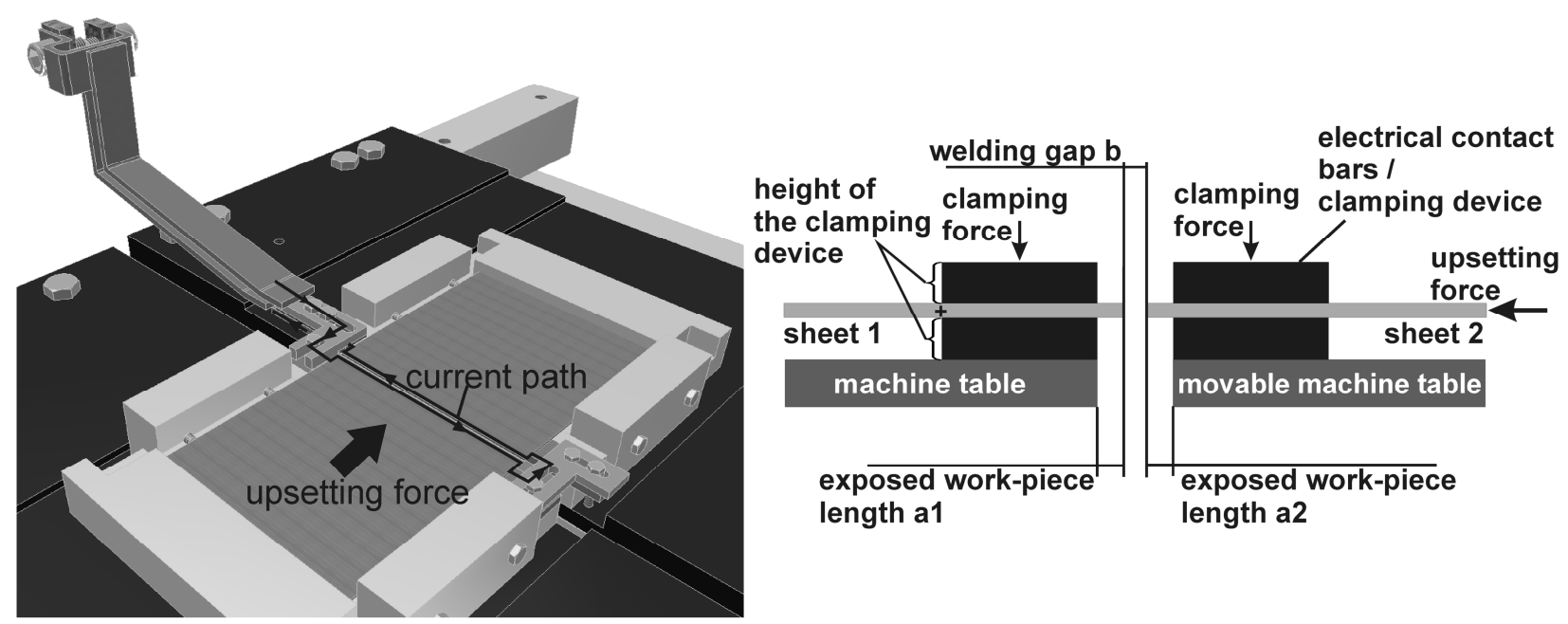

Fig. 2: Operating principle of conductive high-frequency welding, including an illustration of the essential process parameters

\section{Geometrical criteria for discontinuous high-frequency welding}

Introduction. The fields of application and limits on applicability of discontinuous high-frequency welding have been investigated [6]. For this purpose, the possible fields of application as well as the limitations have been considered on the basis of standard geometrical shapes, which can be classified in the categories of planar elements, rod-shaped elements, and nodular elements.

The different energy-input methods involved in the two HF processes impose decisive limitations on the geometry of work-pieces which can be joined by the respective process version and thus represent a fundamental distinction between the two processes. Closed structures can be welded only by the inductive HF process. For sheet-steel blanks and open structures, on the other hand, the conductive process version provides the more favourable alternative because of its higher efficiency. This information constitutes the basis for selecting the energy-input version which is appropriate for the shape of the prototype component to be joined.

Two criteria were applied for specifying limits on the applicability of discontinuous highfrequency welding. On the one hand, the energy input into the edges to be joined must be specifically controllable and uniform. On the other hand, sufficiently high upsetting pressure must be applicable over the entire length of the weld in a direction orthogonal to the surfaces to be joined [1].

Limitations on the weldability of planar elements with nonlinear seams. To date, the conductive HF weldability of tailored blanks with linear seams as well as open contour sections with twodimensional seams has been demonstrated in detail at the Institute ISAF [1,4,5,7]. Examples of such applications include columnar structures for automotive components of deep-drawn steels. Furthermore, weldability has been demonstrated for sheet blanks of micro-alloyed fine-grained steels, polyphase steels, ultrahigh-strength martensitic steels, as well as for diverse aluminium alloys $[3,8,9,10]$. At the same time, sheets with nonlinear seams have also been successfully welded. The motivation for welding of nonlinear seams is the possibility of achieving structural stiffening with simultaneous weight reduction.

In a further step, concepts must now be established for analytically estimating the weldability as a function of both the seam geometry and the material concerned. The reason for the efforts to develop such methods is the necessity of providing geometrically matched clamping devices and welding tools for each particular concrete case. Furthermore, an experimental determination of the process limits for welding of nonlinear seams would be extremely expensive.

The starting point for the analytical estimate of weldability is the knowledge that a certain minimal surface pressure must be applied in the direction orthogonal to the surface to be joined, in order to obtain a pressure weld which is free of defects. In the case of nonlinear seam geometry, 
however, the applied upset force is subdivided into two components, one of which acts in the direction tangential to the surface to be joined. If the orthogonal component of force decreases locally to a value below the necessary minimum because of the seam geometry, a defect is formed as a result. Edges with this kind of geometry cannot be welded by these methods.

Hence, the minimal orthogonal surface pressure necessary for obtaining a joint with positive material bonding must be employed for estimating the weldability. The process limits are then determined by a comparison of the calculated upset-force curve along the joining surface with the necessary minimal upset-force component.

The minimum is determined experimentally by a simple series of tests. For this purpose, sheetsteel blanks are welded with linear seams; for each successive weld, the upset pressure is decreased stepwise, whereas the electrical parameters are kept constant. The joints thus obtained are then subjected to a transverse tension test after removal of the excess upset metal. If the specific upset pressure has decreased to a value below the permissible minimum, sample failure occurs at the weld. The necessary lower limit thus determined for the surface pressure can now be employed as initial value in the calculations for estimating the weldability.

In the following, the concept is illustrated for the example of a corrugated contour section. This seam geometry has been intentionally selected, since it offers considerable potential for further enhancing the stiffness of components by local hardening in the form of welded seams. Deep-drawn steel DC04 with a thickness $\mathrm{t}=1,5 \mathrm{~mm}$ was employed for the welding tests. The values of the welding parameters employed as standard for this test material are compiled in Table 1; the length of the weld was $140 \mathrm{~mm}$.

Table 1: Standard welding parameters for material DC04

\begin{tabular}{|l|l|}
\hline generator output power & $70 \%$ of $85 \mathrm{~kW}$ \\
\hline current-on period & $0,46 \mathrm{~s}$ \\
\hline upset force & $10 \mathrm{kN}$ \\
\hline specific upset pressure & $47,62 \mathrm{~N} / \mathrm{mm}^{2}$ \\
\hline exposed work-piece length & $5 \mathrm{~mm}$ \\
\hline gap width & $2 \mathrm{~mm}$ \\
\hline
\end{tabular}

For determining the necessary minimal orthogonal upset component of the upset pressure, the specific upset pressure for the welding tests was decreased in steps of $5 \mathrm{~N} / \mathrm{mm}^{2}$ from an initial value of $45 \mathrm{~N} / \mathrm{mm}^{2}$. The results of the transverse tension test on the samples welded with specific upsetpressure values of 30 and $25 \mathrm{~N} / \mathrm{mm}^{2}$ are shown in Fig. 3.
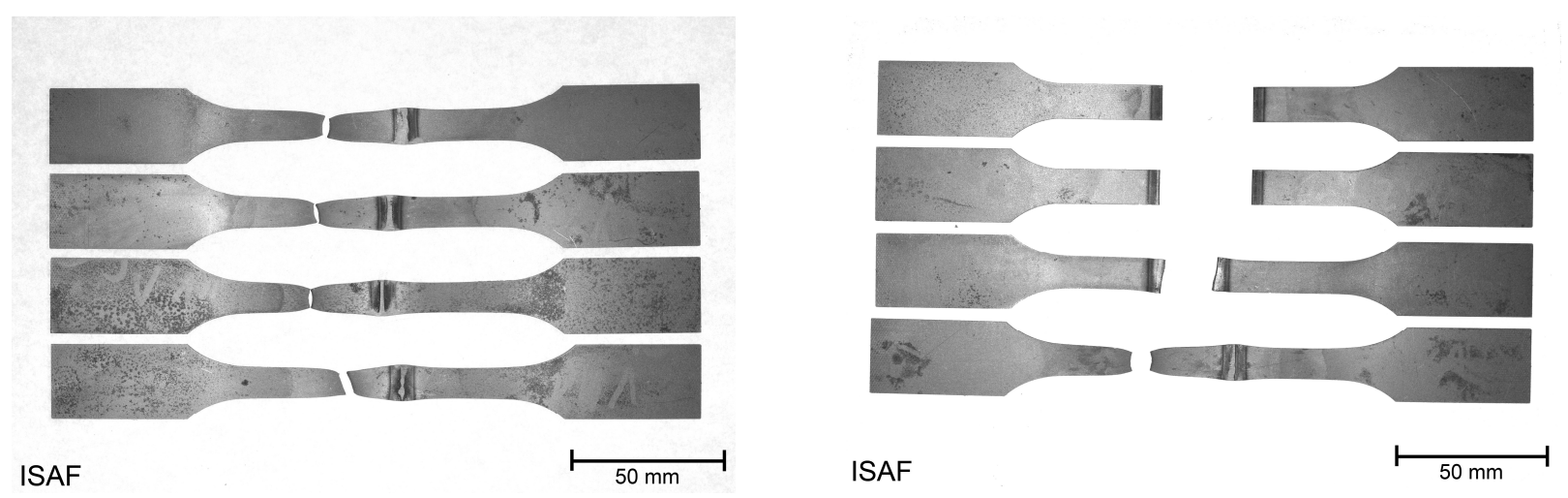

Fig. 3: Welds on material DC04 subjected to the transverse tension test with specific upset-pressure values of 30 (left) and 25 (right) $\mathrm{N} / \mathrm{mm}^{2}$ 
As shown in Fig. 3, sample failure occurs in the weld for the first time at an upset pressure of $25 \mathrm{~N} / \mathrm{mm}^{2}$, whereas an increase in upset pressure by $5 \mathrm{~N} / \mathrm{mm}^{2}$ is sufficient for obtaining good joints. Correspondingly, three upset-pressure ranges can be defined for the following analyses, Table 2 .

Table 2: Weldability ranges for material DC04 as a function of the specific upset pressure

\begin{tabular}{|l|l|l|}
\hline Range & Specific upset pressure & Weldability \\
\hline A & $\geq 30 \mathrm{~N} / \mathrm{mm}^{2}$ & Weldable \\
\hline B & $>25 \mathrm{~N} / \mathrm{mm}^{2}$ und $<30 \mathrm{~N} / \mathrm{mm}^{2}$ & Transition range \\
\hline C & $\leq 25 \mathrm{~N} / \mathrm{mm}^{2}$ & Not weldable \\
\hline
\end{tabular}

With the use of this information, sample calculations can now be performed for estimating the weldability of two sheet-steel blanks with a variable corrugated contour. The constant width of the sheet-steel blanks is $140 \mathrm{~mm}$, and the sheet thickness is $\mathrm{t}=1,5 \mathrm{~mm}$. A constant upset force of $10 \mathrm{kN}$ is applied for joining. A sinusoidal power function (Eq. 1), which has been adapted to match the sheet width of $140 \mathrm{~mm}$, is employed for the mathematical description of the contour.

$$
y=\frac{k}{a} \sin ^{2,5}(a \cdot x)
$$

The factor $k \in[0 ; \infty]$ represents the corrugation of the contour, from which certain angles of curvature result for the function. The value of the constant factor $a$ is equal to $\pi / 140$ and serves to transform the function to the contour width of $140 \mathrm{~mm}$. In Fig 4, the geometry which results from the use of this function is plotted for different values of the form factor $k$.

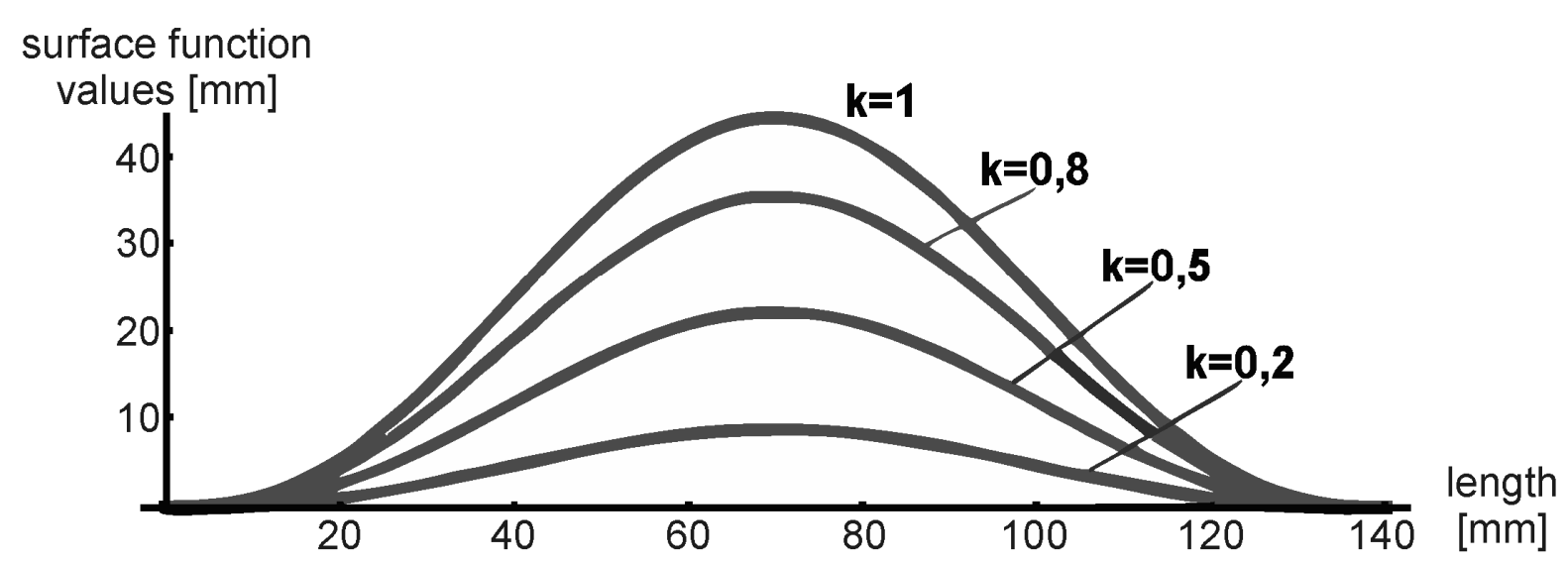

Fig. 4: Development of the corrugated contour under investigation as a function of the geometrical parameter $\mathrm{k}$

For values $k \rightarrow 0$, the function represents the ideal case of a linear seam. With increasing value of $\mathrm{k}$, the curvature of the corrugated contour increases steadily, and the component of the upset force orthogonal to the joining surface decreases locally as a result. At the same time, the specific upset force decreases further because of the increasing $k$-value and the associated increase in the arc length of the contour. However, the resulting increase in the surface area of the sheet edge has deliberately not been compensated by adaptation of the total upset pressure. Such a measure would have caused excessive mechanical stress on the supporting points at the centre and at the external sides and was therefore expressly avoided. The increased application of force at these weld sites is a direct consequence of the sliding between nonlinear weld regions past one another. 
In the following consideration, the limiting geometry is now determined as a function of the $\mathrm{k}$ value; with this geometry, the specific upset pressure which acts in the direction orthogonal to the joining surface decreases to the critical range between 25 and $30 \mathrm{~N} / \mathrm{mm}^{2}$ or below.

The angle of incidence for the component which is locally effective at the joining surface is given by:

$$
\alpha=\arctan \left(y^{\prime}\right)
$$

With the angle of incidence, the component of force acting in the orthogonal direction can be determined as follows:

$$
p_{y^{\prime}}(x)=\frac{F}{A^{*}} \cos (\alpha)
$$

with $A^{*}=\left[\int_{0}^{140} \sqrt{1+y^{\prime 2}} d x\right] \cdot t$, the resulting surface area of the weld, which depends on the factor k. With the use of Eq. 3, the resulting upset force which acts in the direction orthogonal to the sheetedge surface can be calculated over the entire length of the weld. In Fig. 5, the specific upset pressure effective in the orthogonal direction is plotted as an example for the value $k=1$.

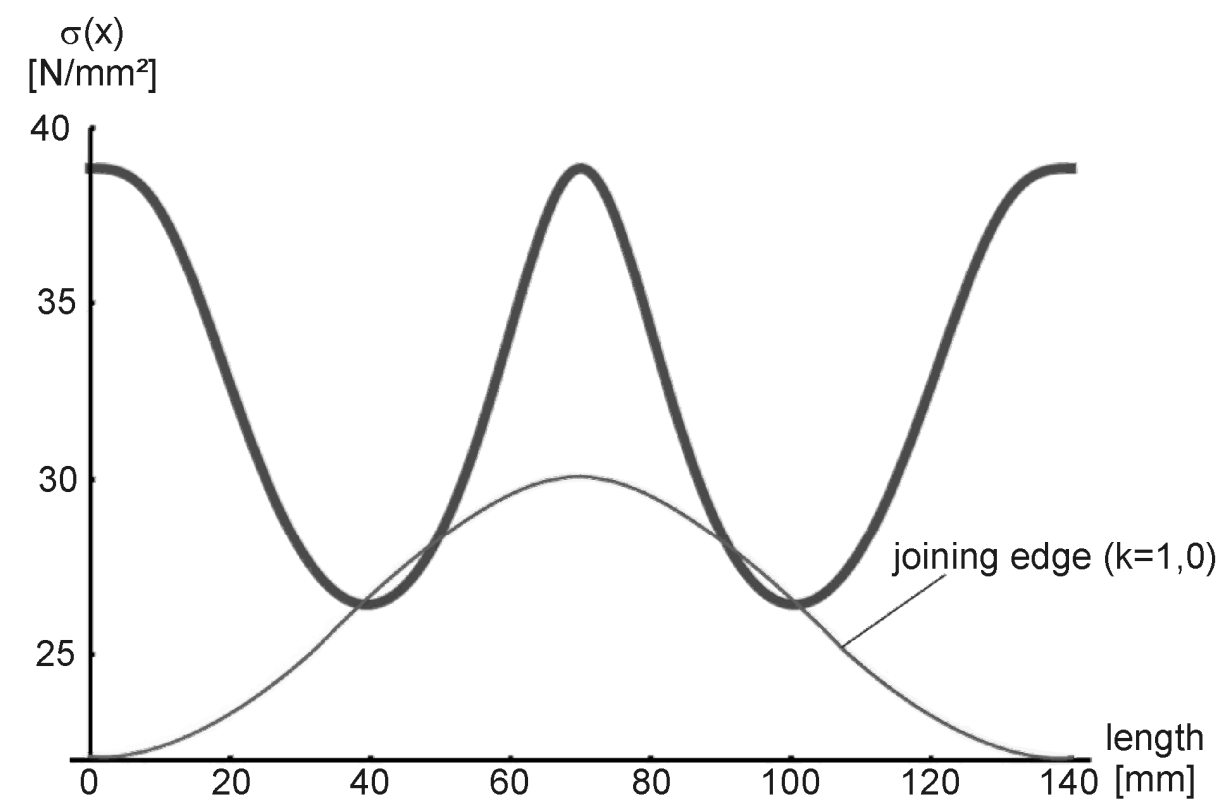

Fig. 5: Development of the specific upset pressure in the direction orthogonal to the joining edge over the length of the weld for a $\mathrm{k}$ value of 1

From Fig. 5, it is evident that the position of the upset-pressure minimum concurs with the points for the maximal slope of the contour, as expected. This slope, in turn, can be very easily calculated by setting the third derivative of the sine function equal to zero, since the maximal contour slope is located at the inflection points of the function.

$$
y^{\prime \prime}=3,75 a k \cos ^{2}(a x) \sin ^{0,5}(a x)-2,5 a k \sin ^{2,5}(a x)=0 .
$$

For this mathematical problem, the numerical calculation yields the interesting values, $\mathrm{x}_{\mathrm{W} 1}=38,48666$ and $\mathrm{x}_{\mathrm{W} 2}=100,513$. Moreover, as can be seen from equation Eq. 4, the position of the inflection points is independent of the form factor $k$. Consequently, the variation of the upset force at the critical points can be calculated as a function of the form factor with the use of Eq. 3 . 
In Fig. 6, the variation of the orthogonal component of the upset force is plotted as a function of the form factor $k$ at the inflection points of the contour function. Furthermore, the associated upsetpressure ranges are indicated in the plot.

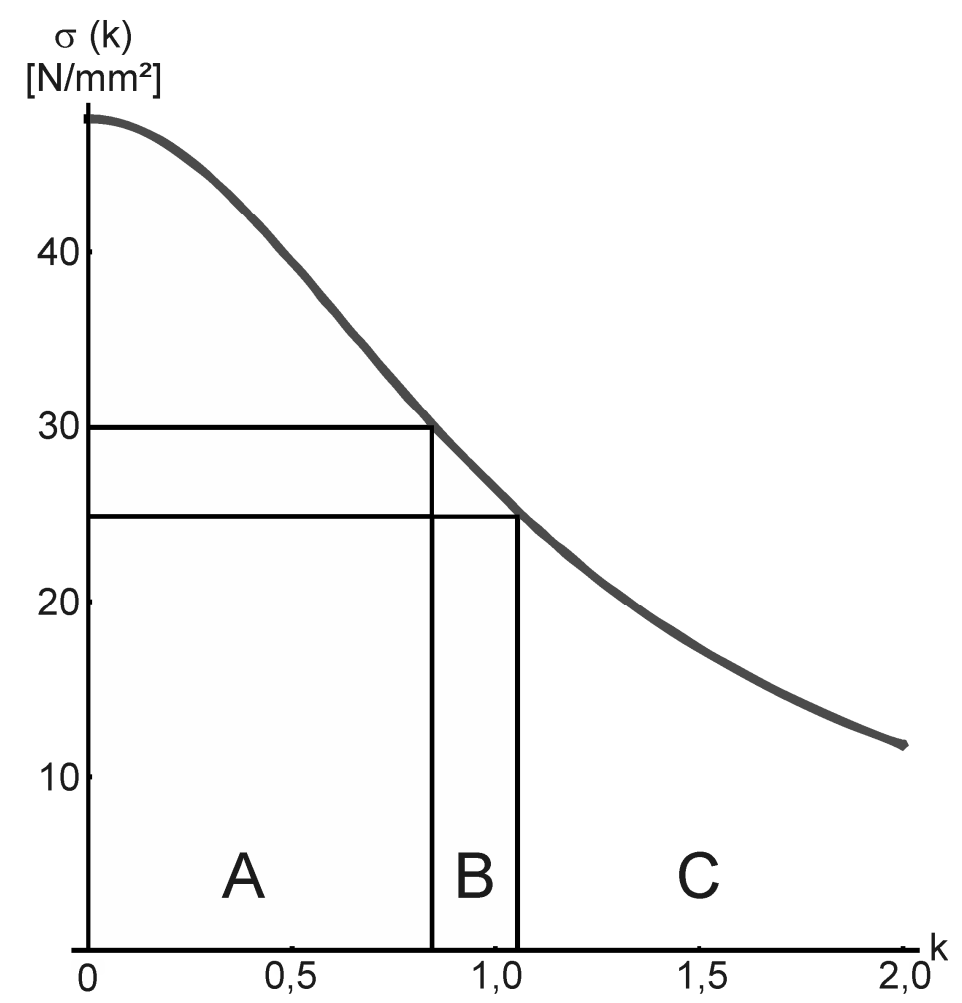

Fig. 6: Dependence of the orthogonal upset-pressure component on the form factor $\mathrm{k}$ at the points of maximal slope for the corrugated contour

The resulting $\mathrm{k}$ values for the previously defined upset-pressure ranges, including the associated slope angles, are summarised in Table 3.

Table 3: Correlation of the geometry factor $\mathrm{k}$ as well as the resulting maximal slope angle $\alpha$ of the corrugated contour with the defined weldability ranges

\begin{tabular}{|l|l|l|}
\hline Range & K value & Slope angle $\alpha$ \\
\hline A (weldable) & $0 \leq \mathrm{k} \leq 0,853$ & $0 \leq \alpha \leq 33,13$ \\
\hline $\mathrm{B}$ (transition range) & $0,853<\mathrm{k} \leq 1,066$ & $33,13<\alpha \leq 38,09$ \\
\hline $\mathrm{C}$ (not weldable) & $1,066<\mathrm{k} \leq \infty$ & $38,09<\alpha \leq \infty$ \\
\hline
\end{tabular}

In correspondence with the model introduced for the calculation, $\mathrm{k}$ values larger than 0,853 are not admissible, if the total upset pressure is not appropriately adapted to compensate for the increasing length of the weld. This value corresponds to a maximal contour slope of $33,13^{\circ}$.

Production of rod-shaped elements, for the example of hollow angular profile sections. To date, rod-shaped elements have been produced at the Institute of Welding and Machining exclusively by welding of tubular elements to form square-butt joints. Besides pipes with equal wall thicknesses, pipe-to-pipe joints with a pronounced difference in wall thickness have also been successfully welded by this technique [2]. Inductive high-frequency welding has been applied for all investigations.

In a further step, the objective is to determine the extent to which rod-shaped elements can also be produced by inductive welding at the edge of non-round, hollow elements which are not rotationally symmetric. With components of this kind, the current flow differs fundamentally from that for the case previously considered, see Fig. 7. In rotationally symmetric components, the 
current flows along a circular path in correspondence with the shape of the component. Consequently, the change in the direction of the ring current is uniform and moderate. In contrast, the changes in the direction of current flow in hollow angular profile sections are abrupt and of short duration. Hence, the purpose of the investigation is to determine whether or not such discontinuous changes in flow direction locally affect the current density and the associated heat generation. If the temperature difference along the edge to be joined is too large, weldability is not completely ensured. In this case, the geometrical design of the inductor must be appropriately adapted, or magnetic-field concentrators must be employed. Such measures are necessary for actively controlling the process of heat generation and thus ensuring uniform heating of the edges to be joined.
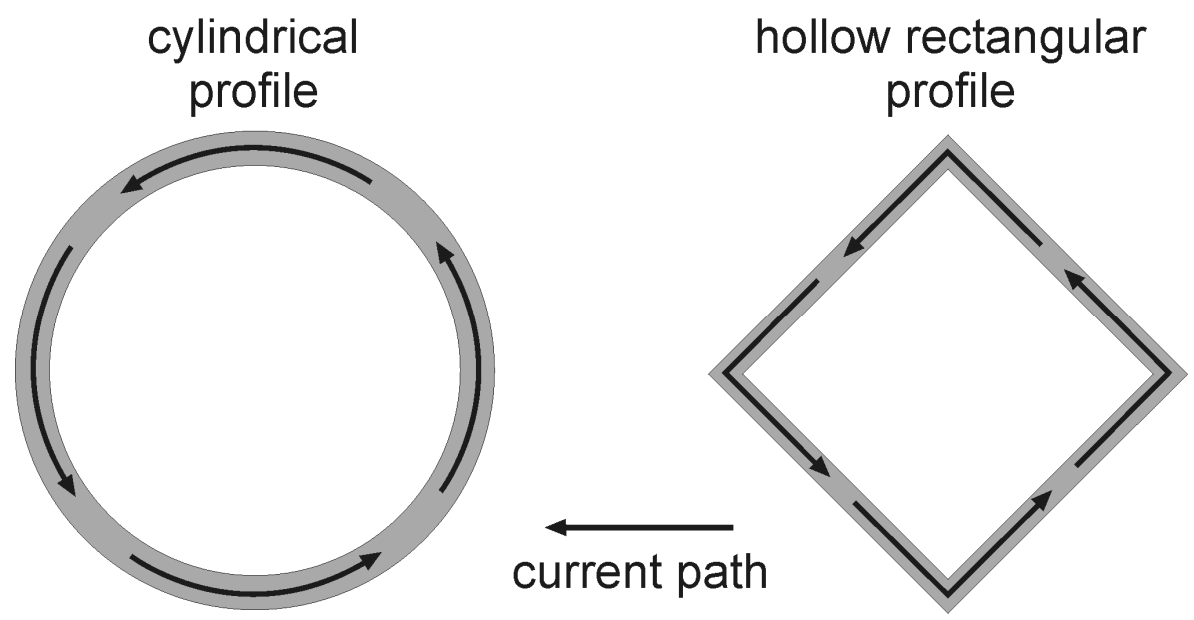

Fig. 7: Comparison of the current-flow directions in the joining edges for a cylindrical profile and a hollow rectangular profile

For testing components which are not rotationally symmetric for weldability, square profile sections have been welded by the inductive high-frequency process. Before welding, the semifinished square profile sections were prepared by milling, in order to simulate the extreme case of current flow with a 90-degree change in direction (see Fig. 7, right-hand side). The edge length of the square profile sections of unalloyed structural steel was $36 \times 36 \mathrm{~mm}$, and the wall thickness was $2 \mathrm{~mm}$. During the welding operation, the temperature distribution along the edge to be joined was monitored with the use of thermographic as well as pyrometric measuring techniques. The typical arrangement of the two work-pieces to be joined by the inductive HF welding process, with a defined gap between the two edges and with a surrounding induction coil, is shown in Fig. 8.

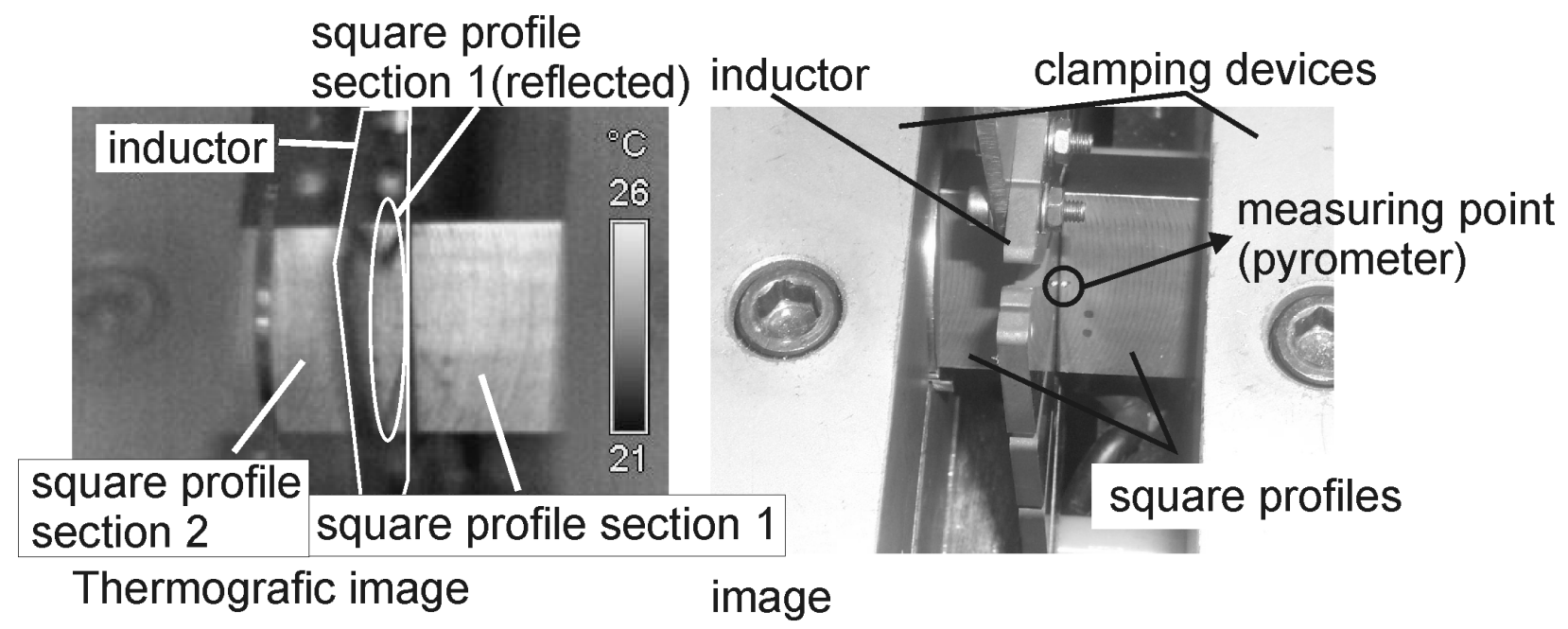

Fig. 8: Process set-up for inductive welding of square profile sections in a thermographic image and a photographic close-up view 
The thermographic image illustrated in Fig. 8 was recorded at room temperature; even in this case, all relevant details are clearly visible, in analogy with the photograph. Reflections are present only on the shiny surface of the copper induction coil (Fig. 8, left-hand side). However, these reflections are of no consequence for the quality of the thermographic measurements on work-piece 1 in the proximity of the surfaces to be joined. Thermographic images recorded in a temperature range from 350 to $1050{ }^{\circ} \mathrm{C}$ during inductive heating of the joining edges are shown in Fig. 9 for the same viewing angle as that already employed for the thermograph at room temperature. Reflections by the shiny surface of the inductor are clearly visible in the thermographs recorded at elevated temperatures, too, but the reflected joining-edge region is clearly separated from the real work-piece area by a black gap (see especially Fig. 9, $t=0,167 \mathrm{~s}$ ). In this series of images, the stepwise increase of the peak temperature at the edge to be joined is indicated graphically. The expansion of the heataffected zone as the heating time progresses is also clearly recognisable in the figure.
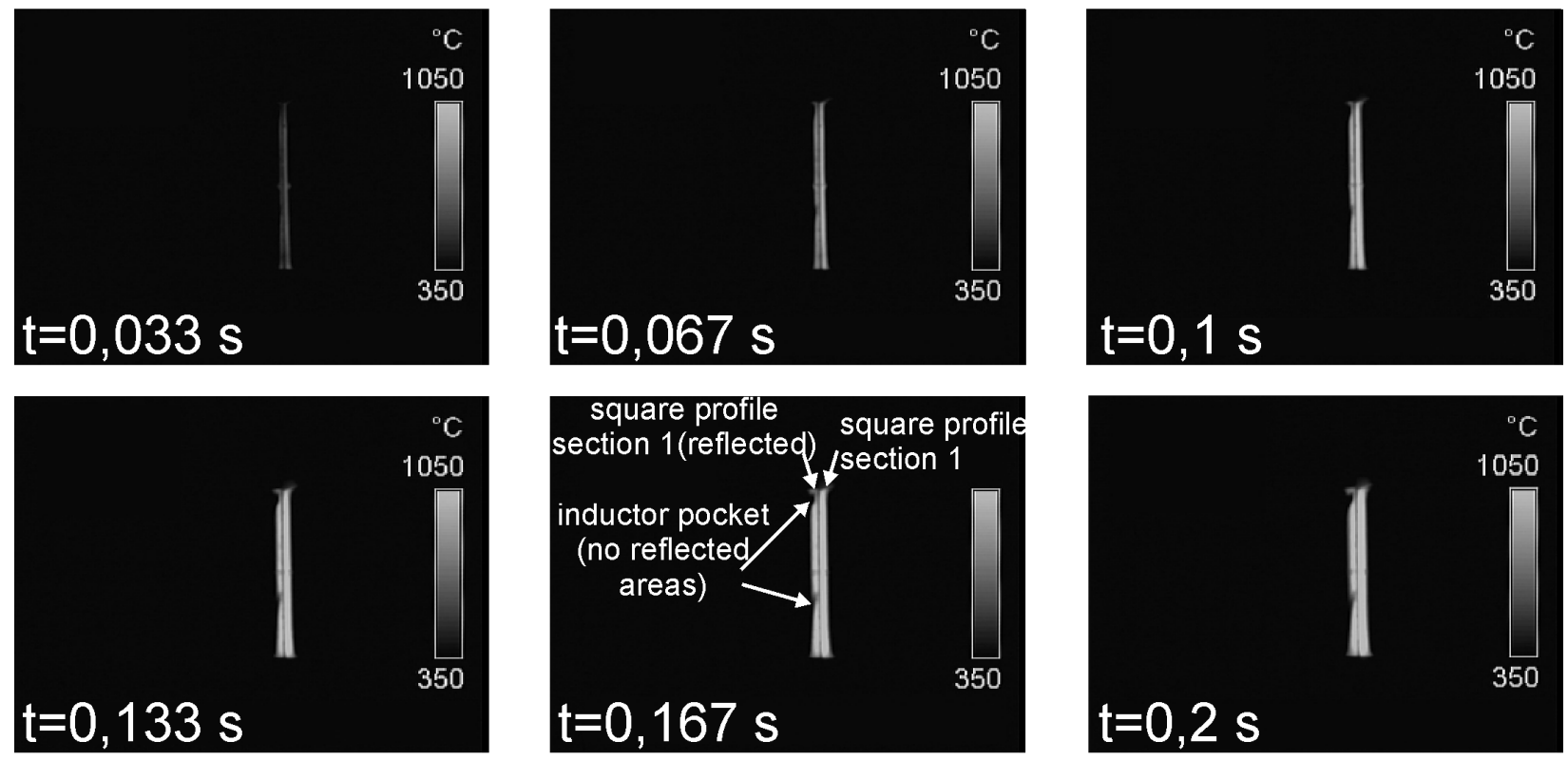

Fig. 9: Heating phase of a joining edge in a thermographic image

The thermographic images thus obtained were quantitatively evaluated with the use of software developed within the scope of Sonderforschungsbereich 675. This software allows the read-out of the recorded temperature data in a simple and expedient manner, and thus the extraction of individual measuring points or measuring-point-path curves as functions of the time, Fig. 10.

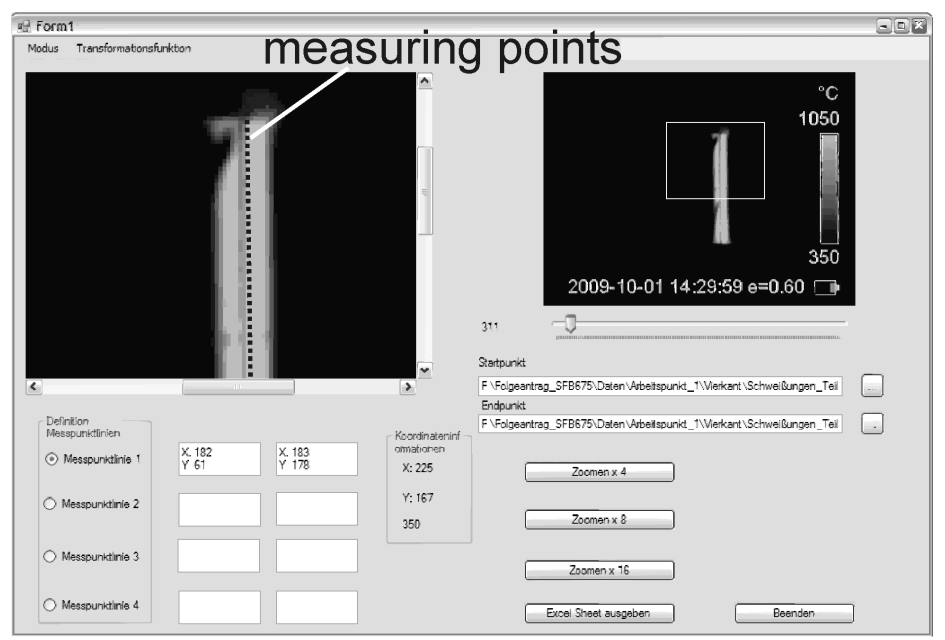

Fig. 10: User interface of the software developed for the automatic evaluation of recorded thermographic images 
A temperature-versus-time curve derived from thermographic images with the use of the evaluation software is compared with a measured pyrometric curve in Fig. 11. The curves were determined on the joining edge at the midpoint of the square profile section (see Fig. 8). The nearly congruent curve behaviour in the measuring range between 350 and $1050{ }^{\circ} \mathrm{C}$ demonstrates the extraordinary accuracy of the thermographic temperature measurement.

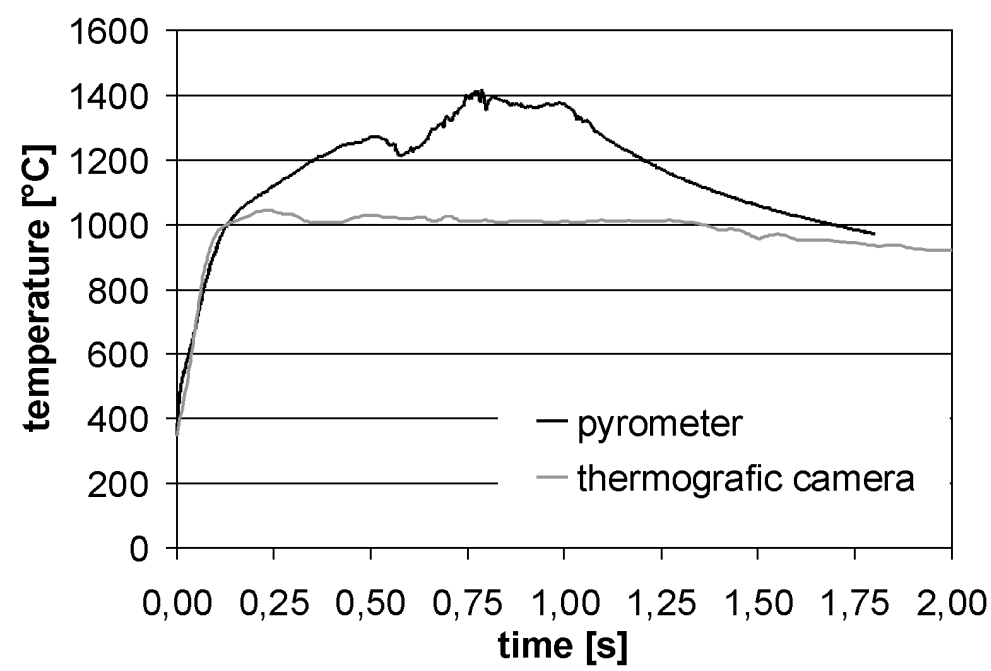

Fig. 11: Temperature-versus-time curve determined at the joining edge of a square profile section, measured with a pyrometer and with the thermographic camera employed for the investigation

For appraising the heating quality at the edge to be joined, the recorded thermographic images were evaluated along the line (red) of measuring-points illustrated in Fig. 12 (left side). The resulting temperature-path curves between the corners of the square profile section at discrete instants from $0,033 \mathrm{~s}$ to $0,133 \mathrm{~s}$ are likewise plotted in Fig. 12 (right side). At the beginning of the heating phase, heating of the corner zones is decidedly less effective than that at the midpoint. As time passes, the existing temperature differences are compensated by thermal conductivity in the area of the joining edge of the work-piece. As a result, a uniform temperature distribution is established along the joining edge beyond a temperature level of $1050{ }^{\circ} \mathrm{C}$.
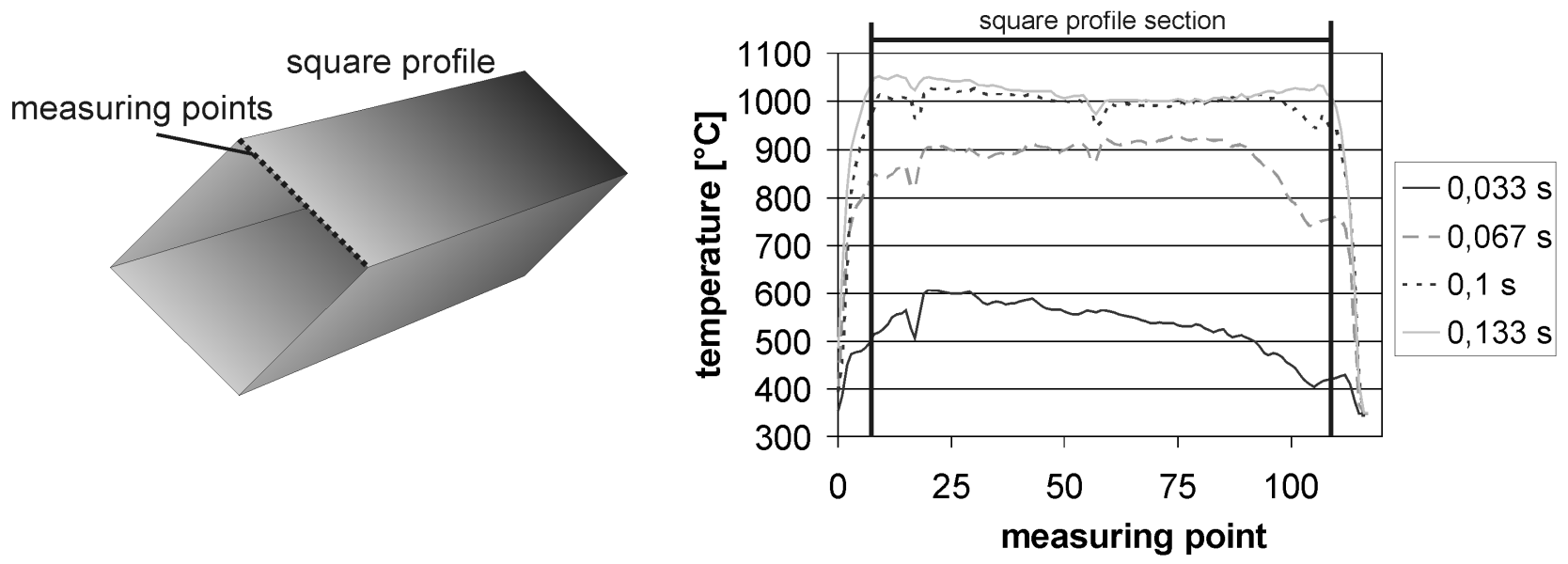

Fig. 12: Temperature distribution along the joining line on a selected side of the square profile section during the heating phase of inductive HF welding 
Thus, the flow of current at the corner points, where the direction changes by $90^{\circ}$, is not regarded as critical for the welding process with the geometry under investigation. The joint area of a square rod-shaped element which has been welded by the inductive HF process is shown in Fig. 13.

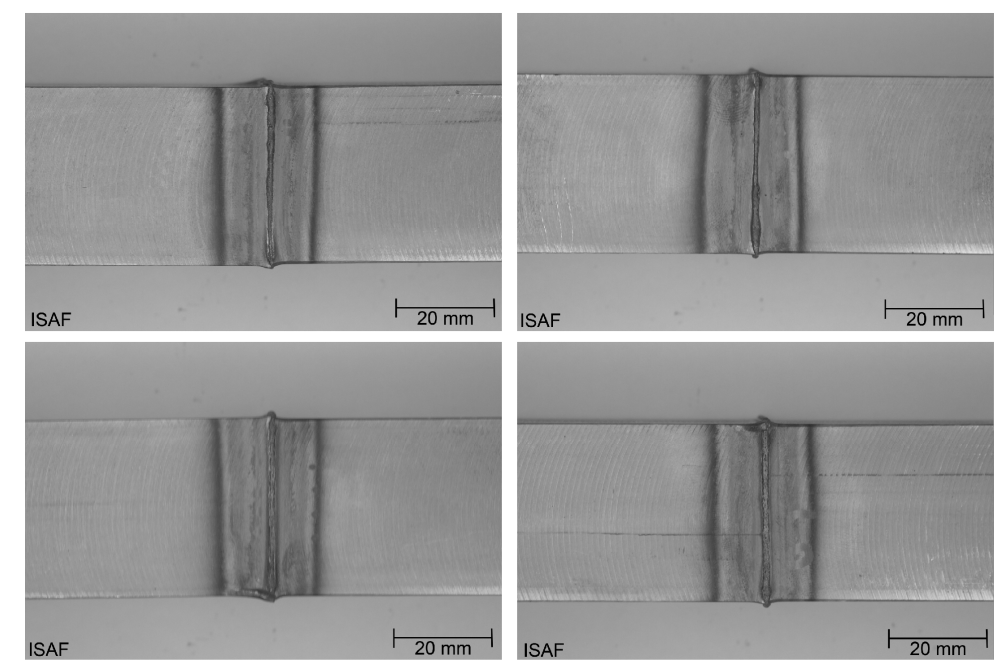

Fig. 13: HF-welded joint in a square profile section

The uniform appearance of the heat-affected zone as well as the constant presence of a melt seam along the joining line, both clearly visible in the photographs, confirm the conclusions reached on the basis of the thermographic measurements. That is, no appreciable temperature differences occur along the joining line during the heating phase. The structural constitutions present in the transverse section of the HF-welded joint are shown in Fig. 14.
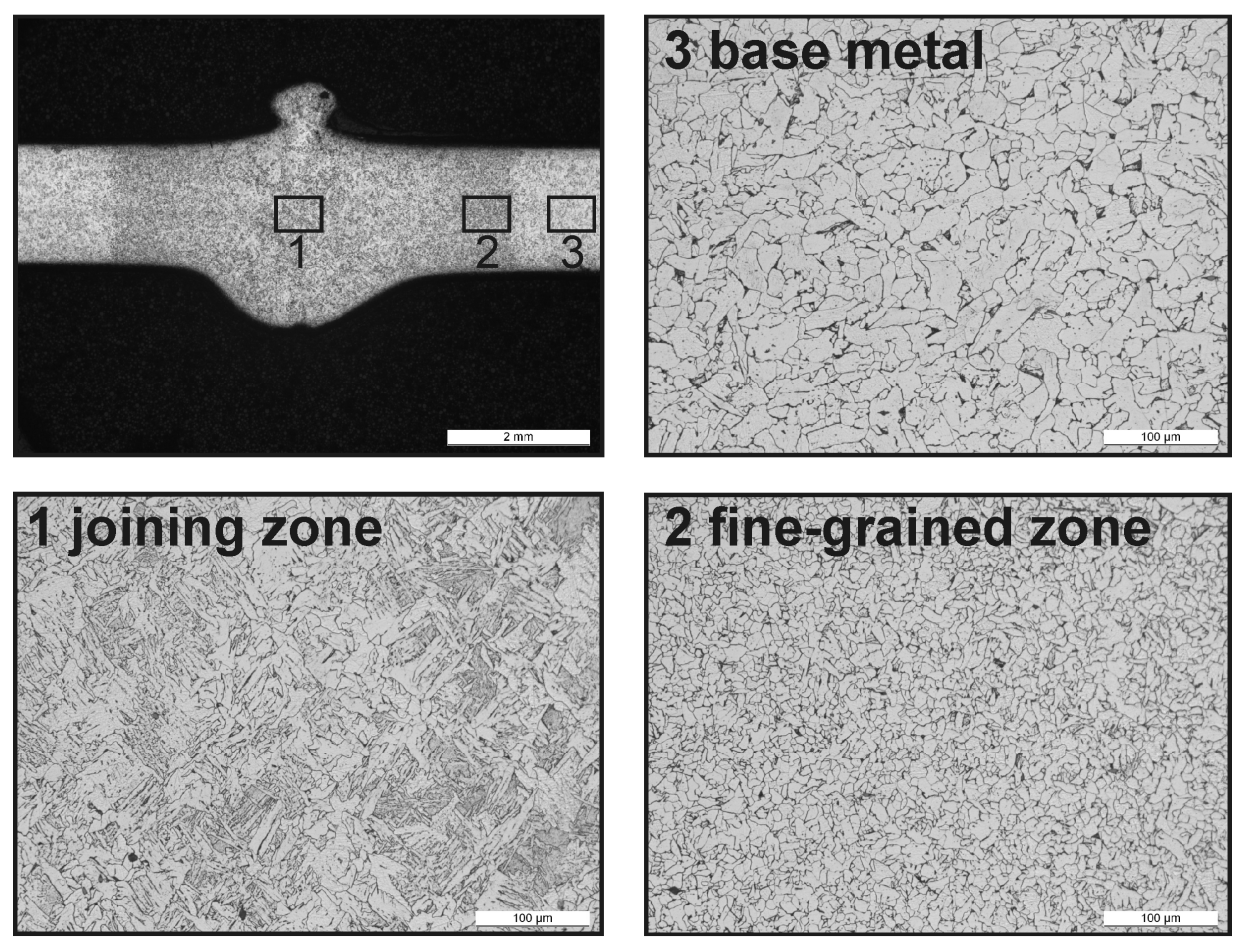

Fig. 14: Structural zones in the HF-welded joint in the square profile section of unalloyed steel

The fine-grained zone situated in the area of low austenitising temperatures is adjacent to the thermally unaffected base metal consisting of ferrite and pearlite. The fine-grained zone is likewise characterised by a ferritic-pearlitic microstructure. The coarse-grained zone is located in the area of higher austenitising temperatures. This zone exhibits a ferritic-bainitic microstructure with low pearlitic content. 
For demonstrating the static strength of the welded joints, one transverse-tension test sample was taken from each side of the welded square profile sections. The excess upset metal was removed from all samples by machining, in order to exclude any supporting effects of the upset material volume. The tested specimens failed in the base metal or in the coarse-grained zone, as shown in Fig. 15. The strength of the welded specimens was within the same range as that of the unwelded base metal.

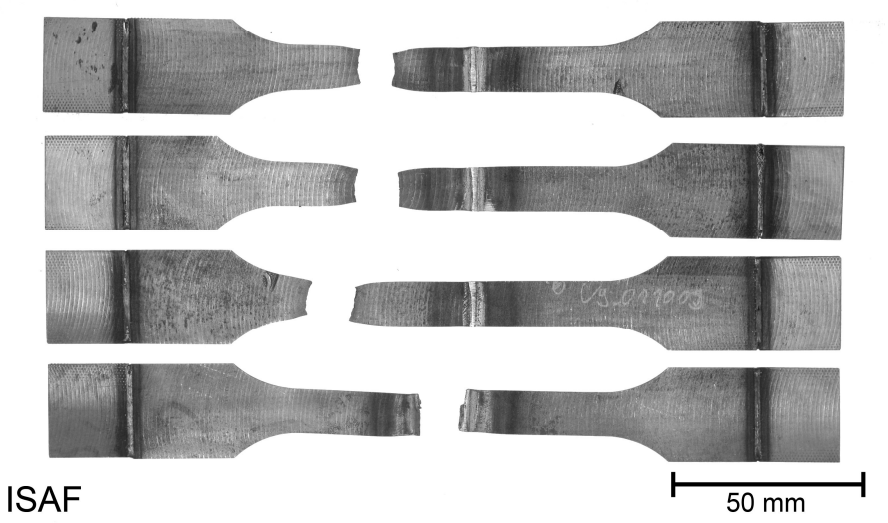

Fig. 15: Samples of inductively welded square profile section subjected to the transverse-tension test

Production of nodular structures by inductive high-frequency welding after preparatory shaping operations. The objective of these investigations was the production of nodular elements in the form of pipe-to-sheet-steel-blank joints by T-butt welding. For this application, however, the initial semifinished goods are not suited for welding, since they present two insurmountable problems, see Fig. 16.

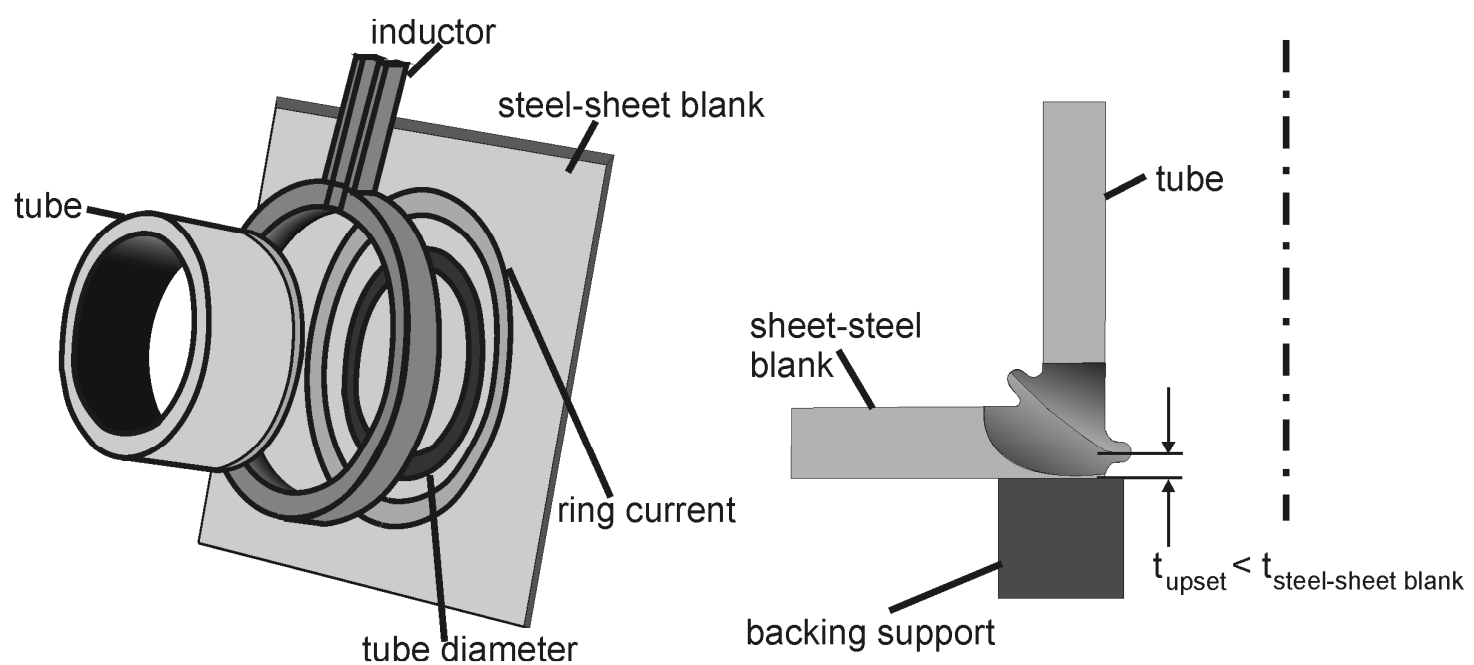

Fig. 16: Problems presented by the production of nodular structures by inductive high-frequency welding

On the one hand, the energy input into the side of the steel-sheet blank cannot be sufficiently localised, regardless of whether or not a hole has already been punched in the blank. The diameter of the ring current which flows in the work-piece is too large. A sufficiently concentrated energy input is feasible only with the use of an internal induction coil; however, this arrangement would severely impair the efficiency of the process. Moreover, the application of the necessary upset force for the joining process also presents problems with the configuration described. There is a risk of excessively severe reduction in the thickness of the steel-sheet blank, see Fig. 16. In the extreme 
case, the pipe could even be pushed through the cross-section of the sheet in the joining zone, with consequent upsetting of the pipe end on the backing support.

For solving these problems, the present application was transformed to a task of edge welding two pipes by appropriate modifications. For this purpose, the steel-sheet blank was provided with a projecting collar in the welding zone by means of a preparatory shaping operation. The principle of the resulting inductive welding process is illustrated in Fig. 17.

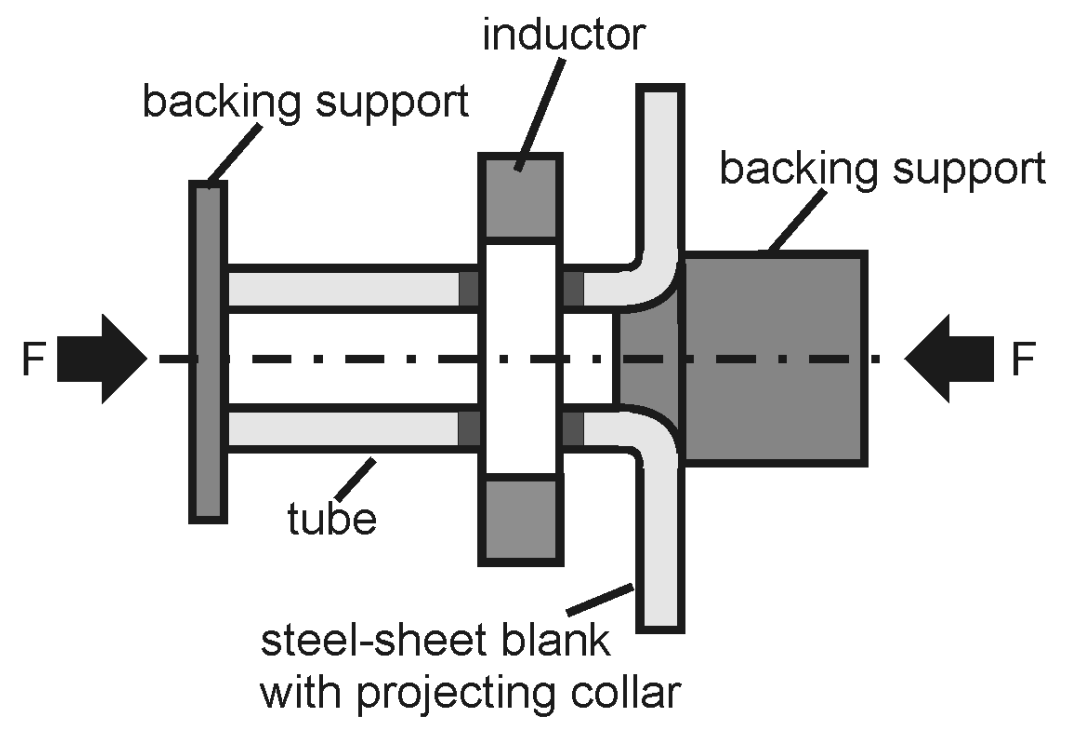

Fig. 17: Process set-up for producing nodular structures by inductive high-frequency welding

The appropriate transformation of the application for allowing edge welding of two pipes provides the most favourable configuration for inductive heating of the edges to be joined, as well as optimal application of the upset pressure necessary for positive material bonding.

High-alloy austenitic steels 1.4301 and 1.4571 were selected for implementation of the modified process depicted in the present example. The dimensions of the initial semifinished goods are summarised in Table 4.

Table 4: Dimensions of the initial semifinished goods for production of the nodular element

\begin{tabular}{|l|l|l|}
\hline pipe & wall thickness: $1 \mathrm{~mm}$ & outside diameter: $33 \mathrm{~mm}$ \\
\hline sheet & thickness: $1,02 \mathrm{~mm}$ & punch diameter: $24 \mathrm{~mm}$ \\
\hline
\end{tabular}

In designing the drawing tool, special emphasis was placed on avoiding deviations in the shape of the collar, such as decreasing collar width, non-uniform collar diameter, and deviations from a rectangular edge of the joining surface. These measures are intended for ensuring that the characteristic conditions for edge welding of pipes are accurately approximated. The cross-section of a steel-sheet blank with a drawn collar is shown in Fig. 18.

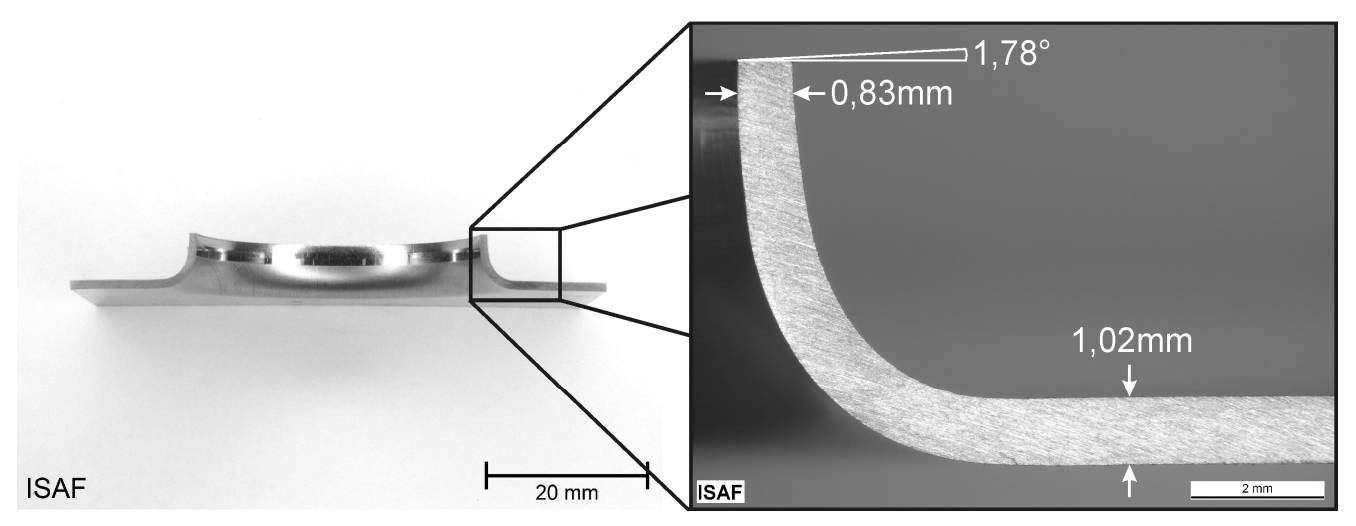

Fig. 18: Cross-section through a steel-sheet blank with drawn collar element for joining 
The slight decrease in sheet thickness as a result of the drawing operation and the nearly rectangular edge of the collar are clearly visible. Especially the rectangular edge is decisive for obtaining a weld of high quality, although slight deviations from a right angle can be compensated by the high tolerance and compatibility of the HF welding process. A polished metallographic section of the drawn collar element is shown in Fig. 19.

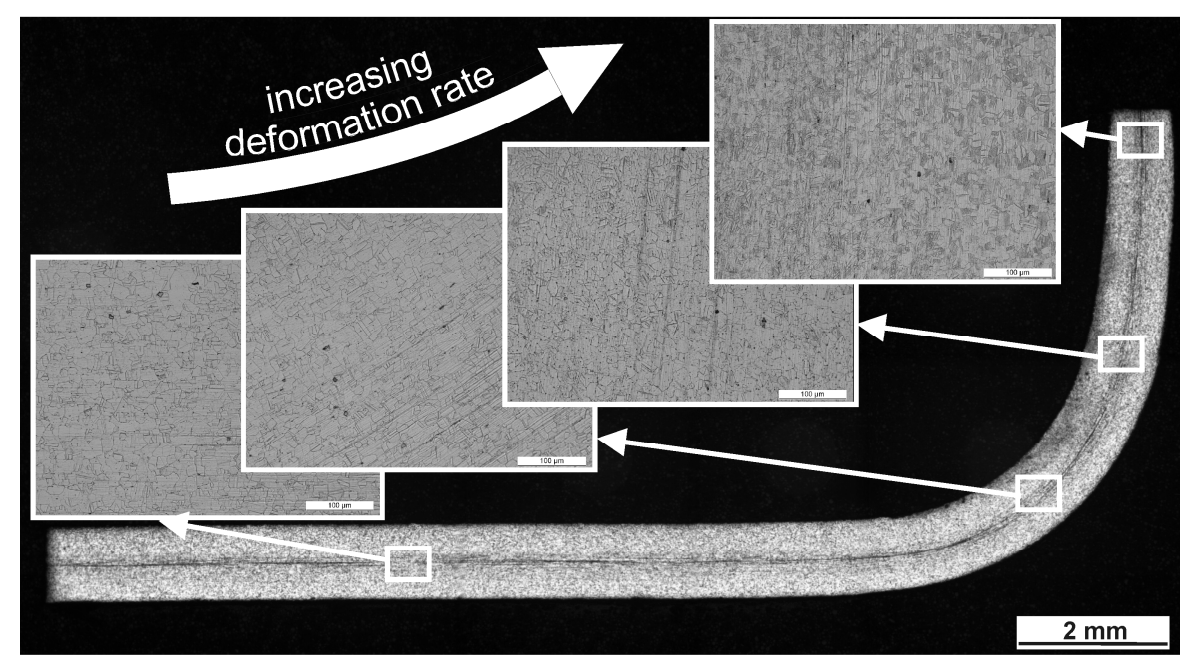

Fig. 19: Structural development in the joining collar element as a function of the deformation rate

The increasing deformation rate and the direction of drawing are clearly evident from the decreasing grain size as well as the flow-line orientation. One consequence of the drawing process is the formation of deformation-induced $\varepsilon$-martensite at the edge of the collar, that is, in the zone of highest deformation rate. The increasing strain hardening and the formation of new structural components are also evident from the increase in hardness of the material. The variation in hardness in the section of the collar orthogonal to the steel-sheet blank, that is, in the area intended for welding, is plotted in Fig. 20.

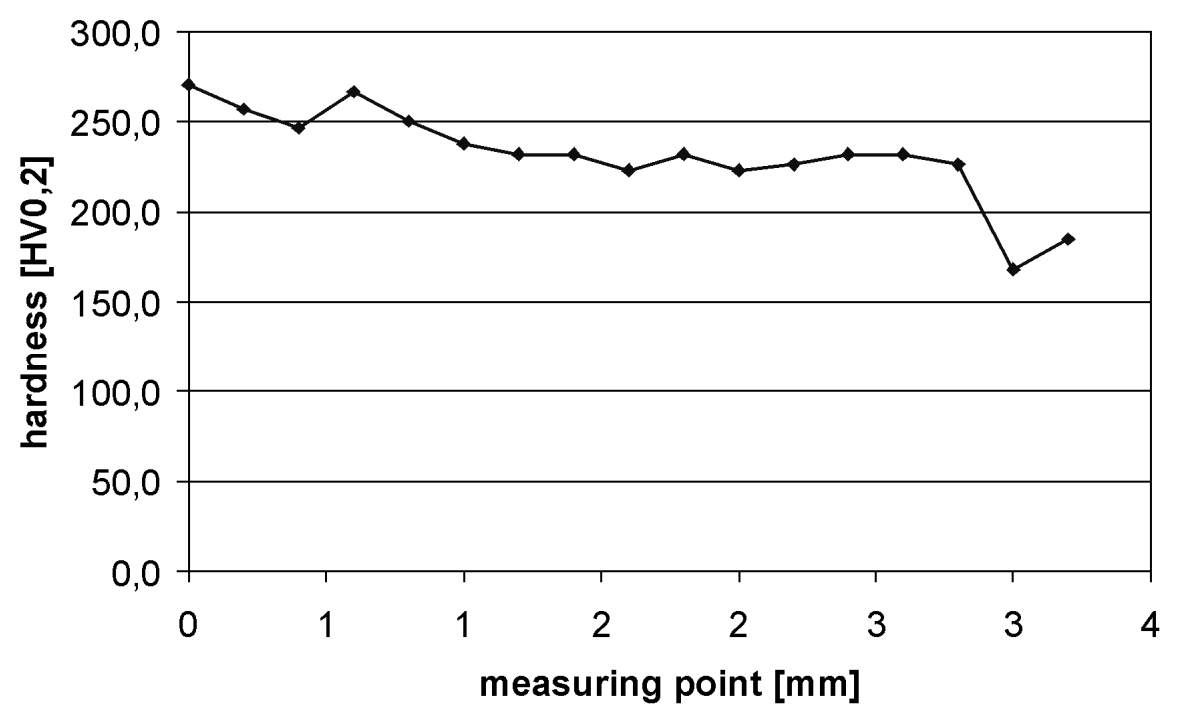

Fig. 20: Variation of hardness in the auxiliary collar element as a function of the deformation rate

As expected, the maximal hardness of $270 \mathrm{HV} 0,2$ occurs at the edge of the collar (position: $0,0 \mathrm{~mm}$ ). With decreasing deformation rate, the hardness decreases to $180 \mathrm{HV} 0,2$ without attaining the level of the base metal, that is $150 \mathrm{HV} 0,2$. The reason for this observation is the residual deformation rate at the measuring point at position $3,4 \mathrm{~mm}$. 
The set-up for producing nodular elements on the welding table and the pipe-to-steel-sheet joint thus obtained are shown in Fig. 21.

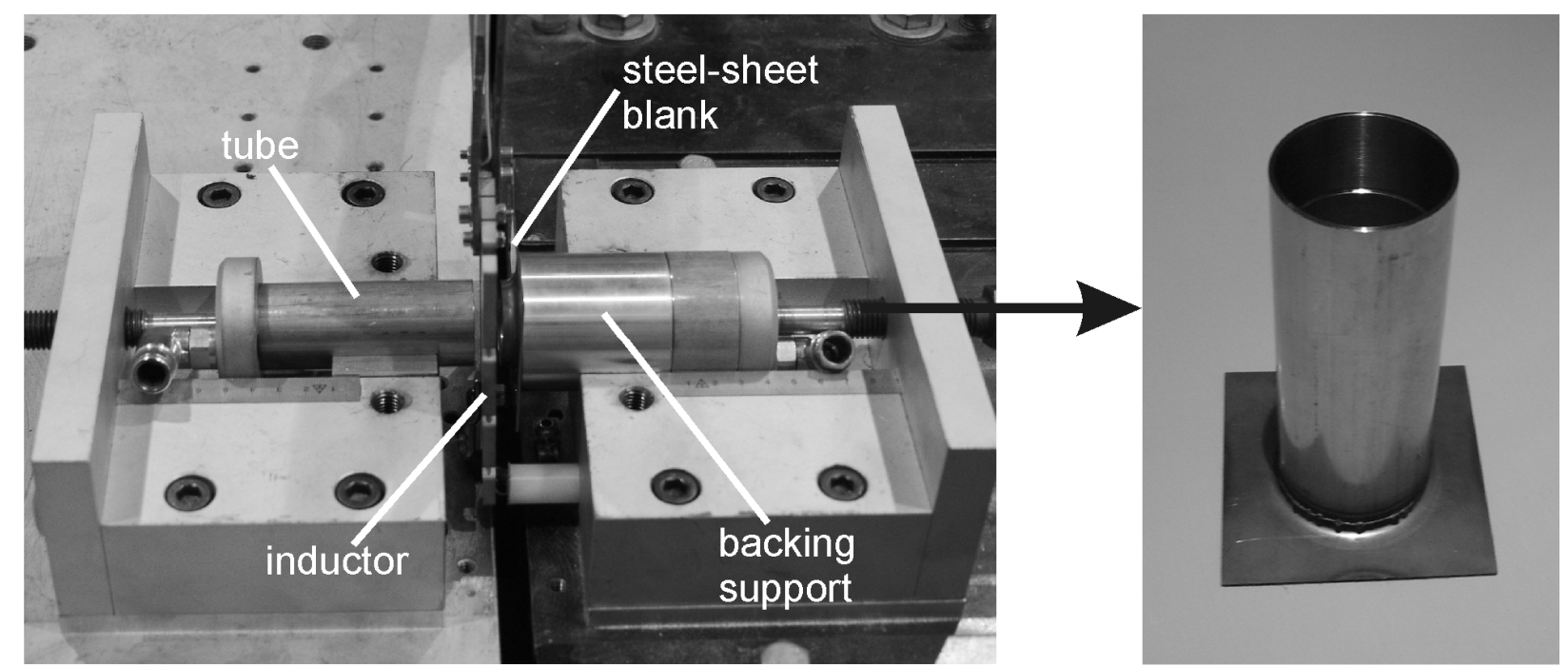

Fig. 21: Set-up for producing pipe-to-steel-sheet joints on the welding table by high-frequency welding

The nodular elements thus produced were tested by pressing the sides of the pipe toward one another at a distance of $25 \mathrm{~mm}$ from the welded joint. The object of the test was to determine whether or not the element could be subjected to these deformations without failure of the joint. A nodular element tested in this manner is shown in Fig. 22.

ISAF

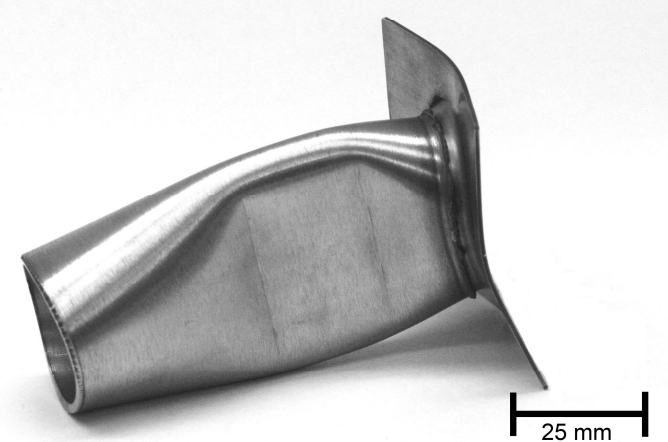

Fig. 22: Nodular element tested by deformation

The most important welding tool for producing flawless joints is the backing support, which holds the steel-sheet blank in position during the welding process. For this operation, the stabilisation of the collar by the backing support is especially decisive for preventing collapse of this auxiliary joining element during the upsetting process. Otherwise, the edges to be joined would slide past one another, and the resulting weld would be defective, see Fig. 23. 


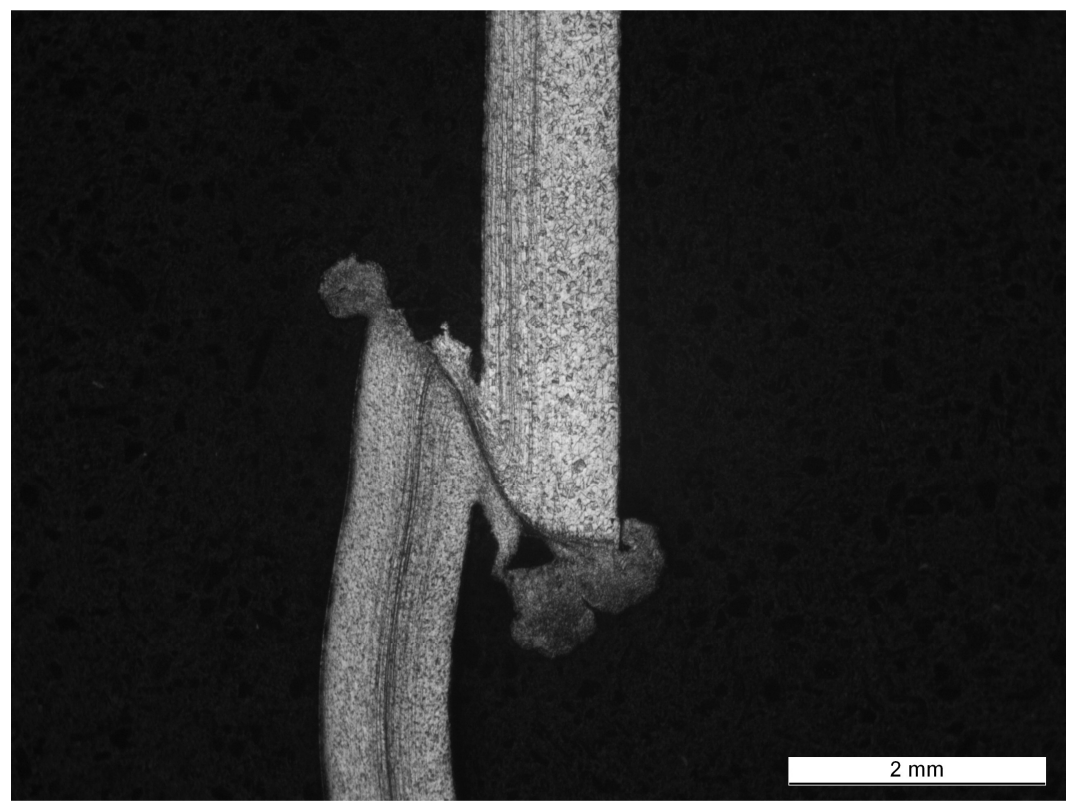

Fig. 23: Macrogeometry of a defective pipe- (1.4571) to-steel-sheet-blank (1.4571) weld, caused by an incorrectly designed backing support

A polished section of a flawless weld between materials 1.4301 (pipe) and 1.4571 (steel-sheet blank) is shown in Fig. 24.

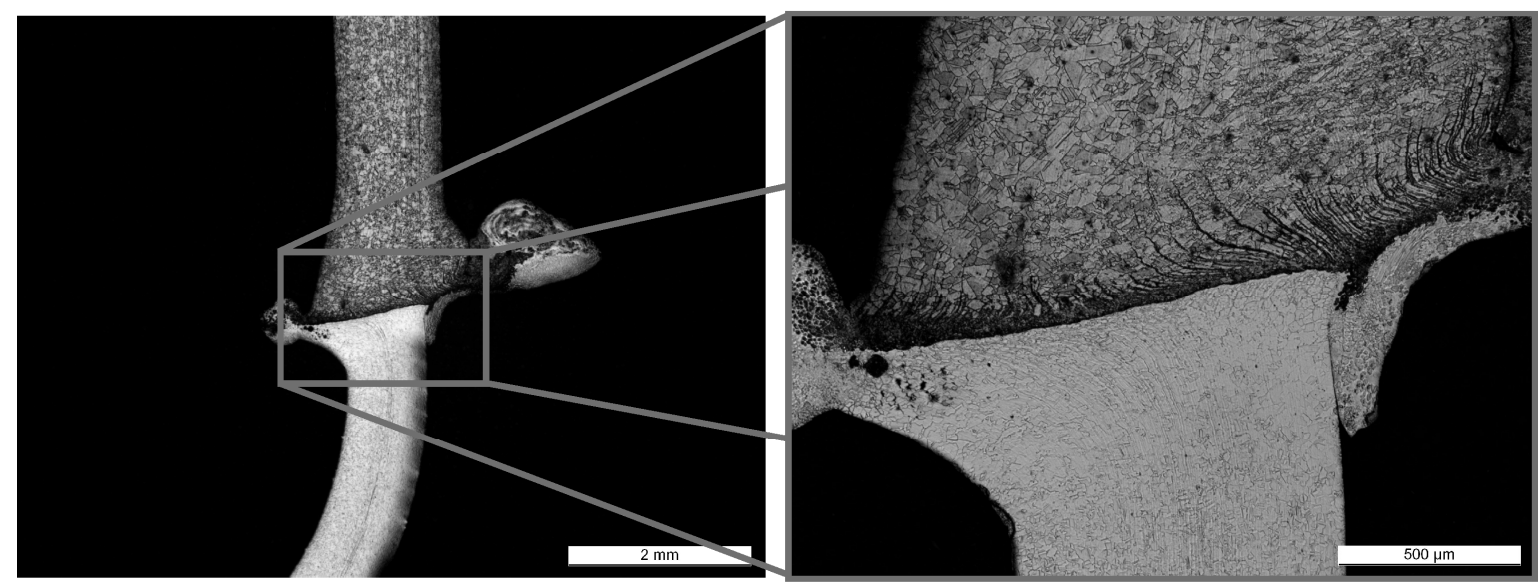

Fig. 24: Macrogeometry of a flawless pipe-to-steel-sheet-blank weld

Because of the upset shortening by $3,89 \mathrm{~mm}$, the zones which contain deformation-induced martensite on the side of the drawn collar on the steel-sheet blank have been pressed out into the excess upset metal. Hence, there is absolutely no reason to expect the occurrence of excessive embrittlement in the weld zone. Chromium carbide precipitates have formed on the side of material 1.4301. Because of the low total energy input which characterises the process, however, the quantity of precipitate is classified as uncritical.

This example shows how the use of an auxiliary joining element in the form of a projecting collar allows the production of nodular elements by inductive high-frequency welding. The type of structures which can be manufactured in this manner is by no means restricted to joining of pipes with steel-sheet blanks. Auxiliary joining elements can also be employed with curved surfaces or pipes by appropriate adaptation of the pre-punching form [11]. Furthermore, the shape of the collar is not limited exclusively to round geometry. Correspondingly, an extended range of component geometry can theoretically be welded by this method. The process limits must be determined in each individual case. However, the material must be sufficiently deformable for allowing implementation. 
Conclusions. The effect of the orthogonal upset-pressure component was taken as basis for developing a calculation concept for estimating the HF weldability of planar work-pieces with nonlinear weld geometry. Simple and economical implementation is a characteristic advantage of this concept, since the time-consuming and expensive construction of clamping elements to match the weld geometry is not necessary.

Moreover, the square-butt-joint weldability of noncircular hollow profile sections by the inductive HF method has been demonstrated. The abrupt 90-degree changes in direction which characterise this geometry do not impair the temperature distribution in the edges to be joined.

The production of nodular elements by inductive high-frequency welding has been demonstrated for the example of a pipe-to-steel-sheet-blank joint. For this purpose, the pipe-to-steel-sheet application has been transformed to square-butt joint welding of pipes. The transformation was implemented by means of a preparatory shaping operation for constructing an auxiliary joining element in the form of a projecting collar on the side of the steel-sheet blank. By appropriate adaptation of the collar shape, the production of other nodular structures by this method is also possible. Examples include T-butt joints with angular or round hollow profile sections.

\section{Reduction of the heat input during conductive HF welding of steel-sheet blanks by optimising the geometry of the clamping devices}

Initial situation. The transfer of the base-metal properties to the finished component during welding operations on semifinished goods is often not feasible unless appropriate measures are taken, especially if modern steels are involved. The cause of this problem is the effect of temperature on the thermally unstable structure of the base metal in the weld area. This question is of special importance for the use of newly developed ultrahigh-strength steels with a martensitic structure. These steels are employed for crash-relevant components in the automotive industry $[12,13]$. During welding operations on martensite-phase steels of this kind for cold forming, or boron-alloy steels which harden during hot working, cohesion loss occurs in the heat-affected zone as a result of tempering effects in the martensitic base metal.

The aforementioned problems are further aggravated during welding operations on materials with local hardening, such as those under development within the scope of the current research project, Sonderforschungsbereich 675. As a result of the subsequent exposure to high temperature during the welding process, the existing locally hardened sites disintegrate under some circumstances. However, the optimal production of components with local properties is feasible only if all previously introduced local modifications in the material are preserved in the final structure.

In both cases, a starting point for improving the properties of components produced by HF welding is the endeavour to minimise the absolute as well as local heat input into the base metals to be joined. This objective can be achieved especially in the case of conductive HF welding by selection of the appropriate geometry for the copper clamping device.

Development of the temperature distribution in the edges to be joined during conductive $\mathrm{HF}$ welding of steel-sheet blanks, as a function of the clamping-device geometry. For analysing the effect of the clamping-device geometry on the temperature distribution during conductive highfrequency welding of steel-sheet blanks, a finite-element model (FEM) has been developed for simulating the heating of the edges to be joined during the welding process $[14,15,16,17]$. For this purpose, the two-dimensional model represents a cutting plane through the steel-sheet blank to be welded, which is fixed in position by copper clamping devices. In addition, the symmetry of the welding process is utilised for shortening the computing time, see Fig. 25. 


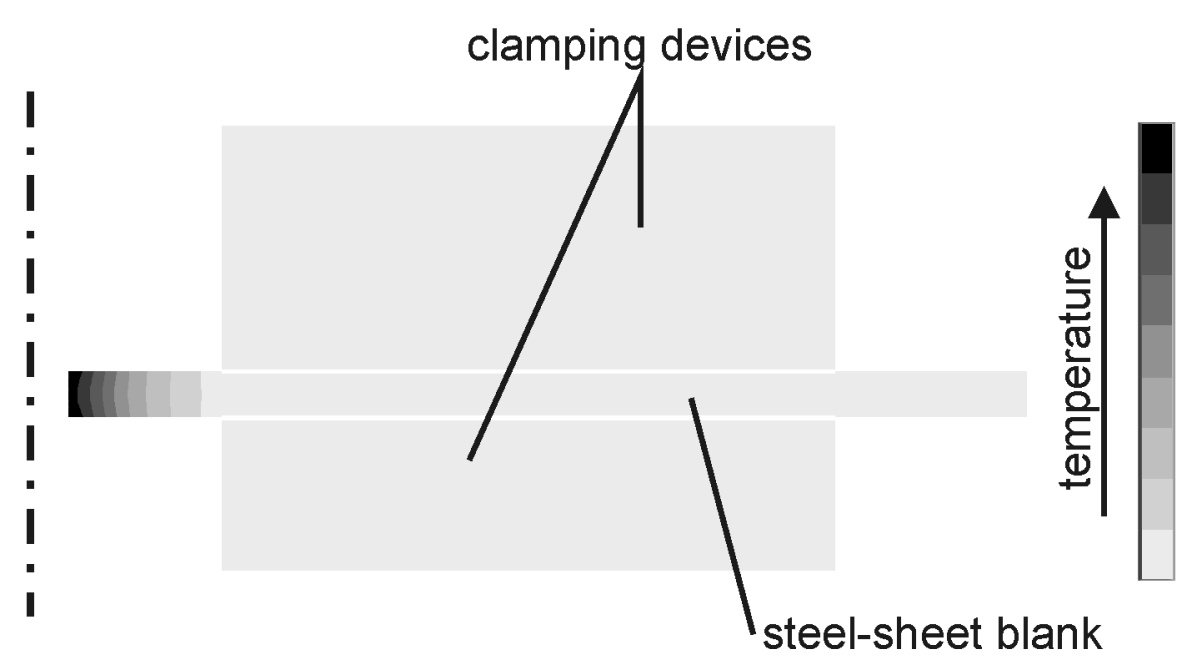

Fig. 25: Theoretical temperature distribution in the edges to be joined during high-frequency welding before the upsetting operation, calculated with the use of the FEM model developed for the purpose

Essentially, the sequence for simulating the heating process in the joining edge comprises two steps. In the first step, the current-density distribution thereby established is calculated as a function of the essential process parameters (power input, gap width, exposed work-piece length). On the basis of the electromagnetic properties of the material, the spatially resolved heat generation is determined with the use of these data. A thermal analysis is subsequently performed for determining the temperature distribution which is established as a function of the time. For this purpose, the electromagnetic and thermal properties of the material as well as the high-frequency alternating current flowing in the circuit are employed as input data for the model. The alternating current strength was determined during the real process with the use of a Rogowski-coil transducer as current sensor, see Fig. 26. For the basic operation of Rogowski Coil transducer technology and its limitations see $[18,19]$.

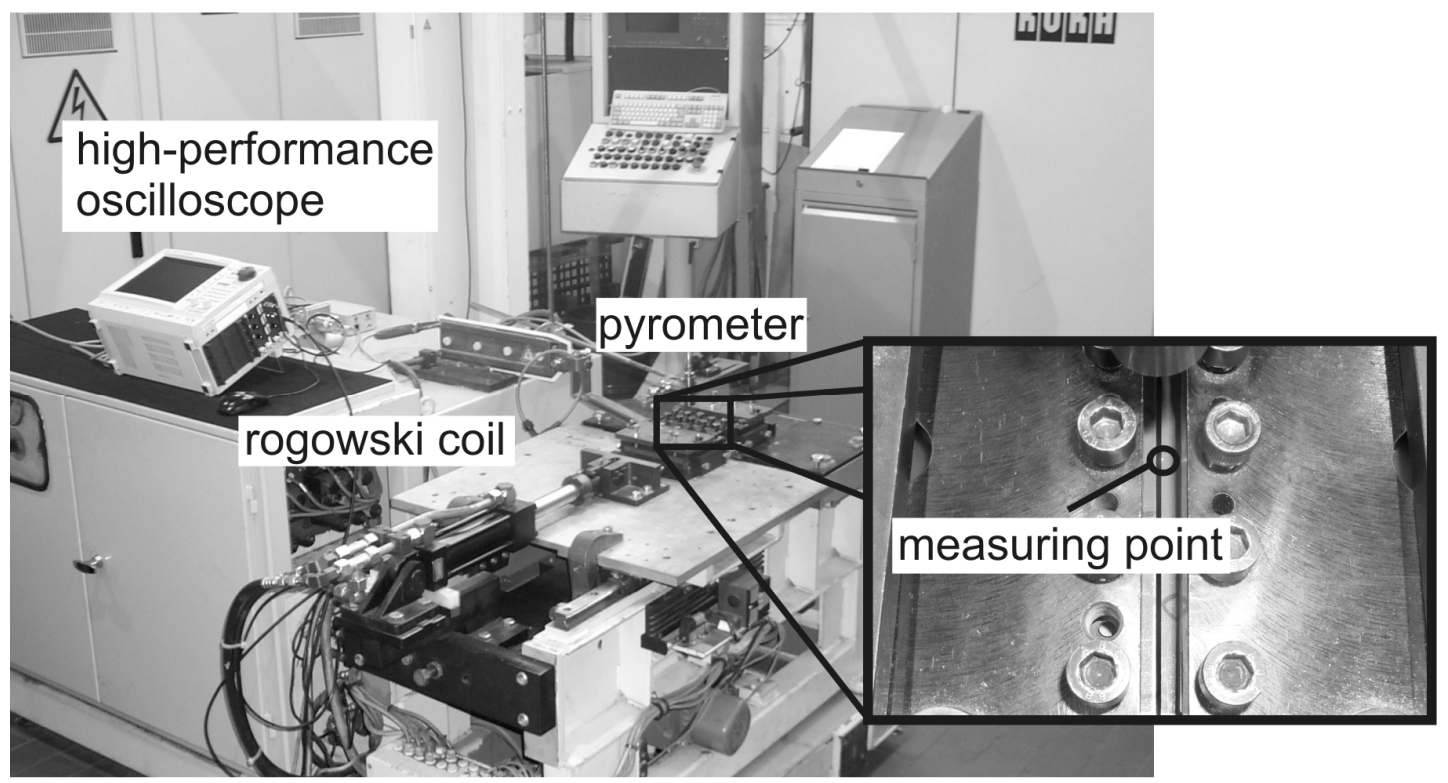

Fig. 26: Experimental set-up for measuring the welding current as well as the temperature development at the peak of the sheet edge during the conductive high-frequency welding process 
In order to allow measurement of the high-frequency alternating current with a frequency of $330 \mathrm{kHz}$, a high-performance oscilloscope with sampling rates up to 20 mega-samples per second was employed for displaying the measured data.

The FEM model thus constructed was validated by a comparison of the temperature values calculated with the use of the model over the surface of the work-piece with the surface temperature measured in the course of the process. Because of the high welding speeds involved and the poor accessibility of the welding gap, the measurements were performed on the real process with the application of a pyrometric measuring technique, Fig. 26. The measured and calculated time-versustemperature curves are compared in Fig. 27. A conspicuous feature is the mutual congruence of the two curves up to a threshold temperature of $1400{ }^{\circ} \mathrm{C}$. The deviations which occur beyond this value are due to errors in measurement on the real process. These measuring errors are caused by variations in the focusing distance between the pyrometer and the surface of the sheet edge as a result of incipient fusion of the sheet edge in combination with the steep temperature gradient which is present during the welding process. Nevertheless, the comparison demonstrates the excellent suitability of the simulation model thus developed for adequately describing the heating process during conductive HF welding. Consequently, the effect of the clamping-device geometry on the heating process and on the resulting temperature distribution can be analysed with the use of the simulation model in a further step. The geometrical parameter under investigation in this case is the height of the clamping device.

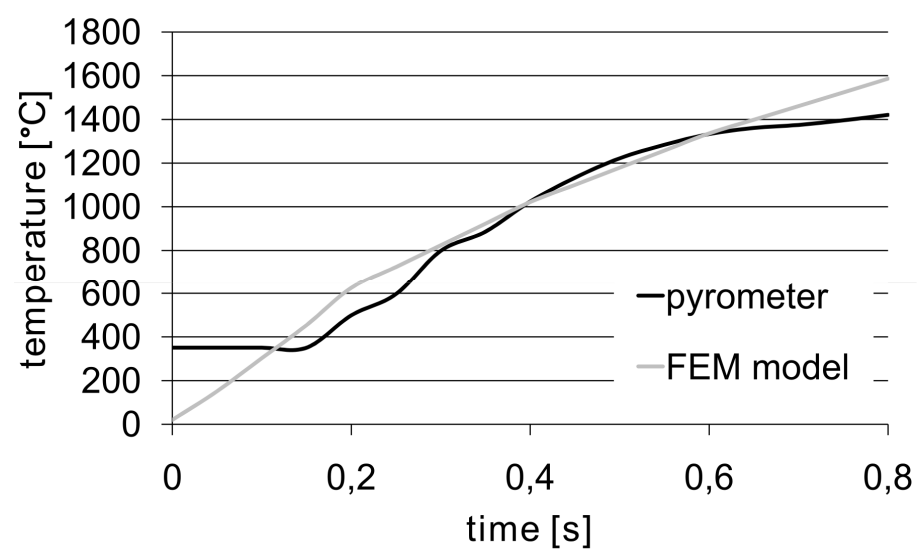

Fig. 27: Comparison of the real and calculated heating of the sheet edge during the high-frequency welding process

The temperature development at the peak of the joining edge with varying height of the clamping device was calculated with the use of the simulation model; for this purpose, the power input and the exposed work-piece length were kept constant. The results are plotted in Fig. 28.

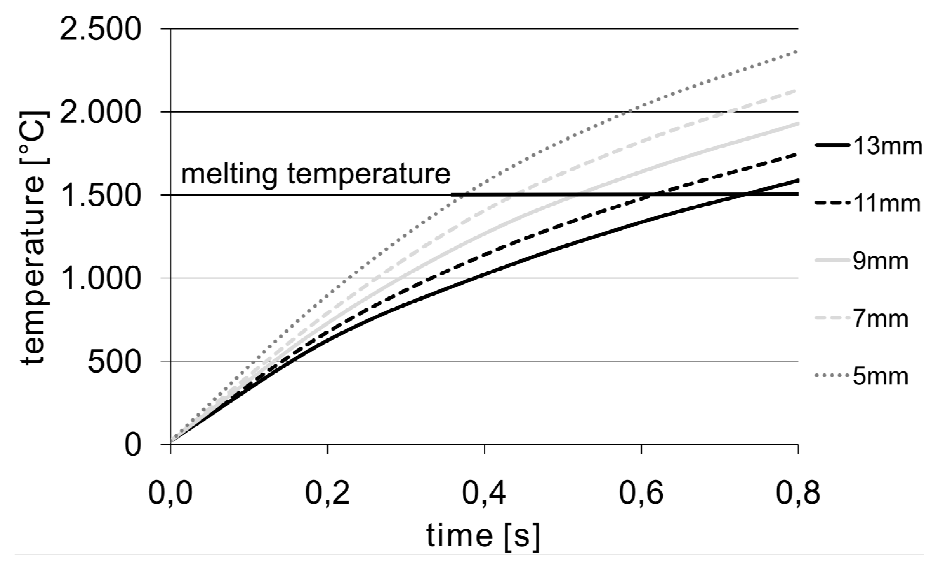

Fig. 28: Effect of the clamping-device height on the heating rate during conductive high-frequency welding 
The attainment of the liquidus temperature is shifted toward longer current-on periods with increasing height of the clamping device; this feature is clearly evident in Fig. 28. This development is caused by two factors. On the one hand, the current density in the edges to be joined decreases as a result of relative changes in impedance between the work-piece and the copper clamping devices. On the other hand, more heat is dissipated from the weld area because of the greater volume of the clamping devices.

For effectively minimising the width of the tempered zones by defined adjustment of the heat generation and heat dissipation after appropriate adaptation of the clamping-device geometry, however, the exposed work-piece lengths must be specifically adapted to match the clamping devices employed $[8,9,15,16,17]$. For this purpose, the exposed work-piece length is varied until a minimal temperature has become established at the peak of the sheet edge, for given clampingdevice geometry and for constant power input from the outside (generator output power, current-on period). In this process, the preset temperature on the joining surface helps to ensure reliable welding of the two joining partners during mutual upsetting of the sheet edges against one another under constant upset pressure. In correspondence with the conditions selected in advance, the exposed work-piece length must be decreased in order to compensate for the increasing energy input to the joining zone as the height of the clamping devices decreases. The resulting temperatureversus-distance curves in the area of the heat-affected zone are plotted in Fig. 29 for clampingdevice heights of $6 \mathrm{~mm}$ and $12 \mathrm{~mm}$ with appropriate adaptation of the exposed work-piece length.

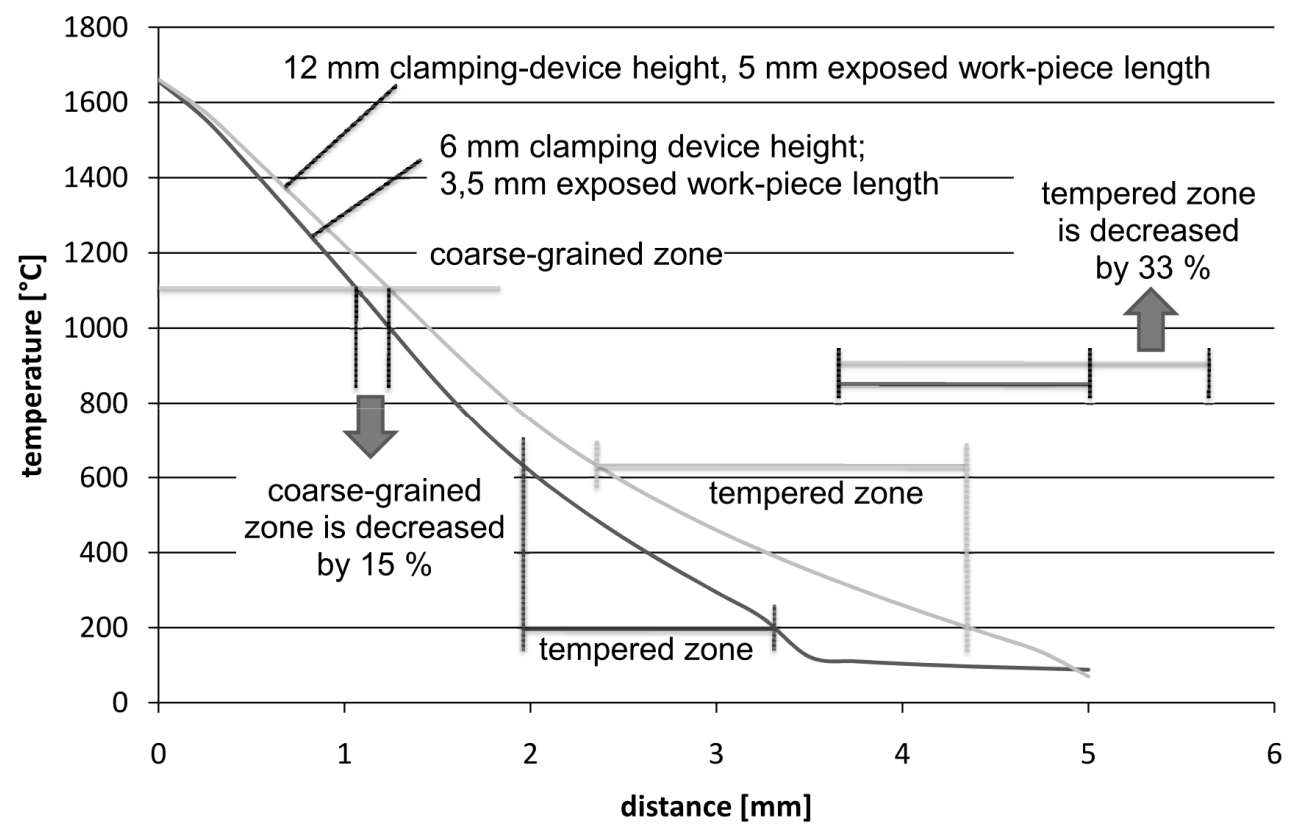

Fig. 29: Temperature-versus-time curve on the upper surface of the sheet in the direction of the exposed work-piece length for different combinations of clamping-device height and exposed work-piece length (constant: generator output power, current-on period)

In correspondence with the given conditions, equivalent peak temperatures prevail at the peaks of both sheet edges. However, the temperature variations are fundamentally different. With the use of small clamping-device heights, the temperature gradient in the heat-affected zone is decidedly decreased because of improved conditions for heat generation and heat dissipation. As a result, the area of the corresponding coarse-grained zone is decreased by 15 per cent, and the width of the tempered zone is decreased by 33 per cent. 
Improvement of the static and fatigue strength during welding operations on martensitephase steels MS1200 by adaptation of the clamping-device geometry. The geometry of the clamping device has been appropriately adapted for reducing the area of the tempered zones. The effectivity of this measure was then tested by applying the principle during the real welding process. Martensite-phase steel MS1200 with a thickness t of 1,5 $\mathrm{mm}$ has been selected for the purpose.

Table 5: Comparison of the parameter combinations employed for welding of material MS1200

\begin{tabular}{l|c|c|c}
\multicolumn{2}{c}{} & $\begin{array}{c}\text { parameter } \\
\text { combination 1 }\end{array}$ & $\begin{array}{c}\text { parameter } \\
\text { combination 2 }\end{array}$ \\
\hline \hline clamping-device height & {$[\mathrm{mm}]$} & 13 & 5 \\
exposed workpiece length & {$[\mathrm{mm}]$} & 5 & 2 \\
generator output power & {$[\mathrm{kW}]$} & 63,75 & 68 \\
current-on period & {$[\mathrm{s}]$} & 0,7 & 0,7 \\
upsetting pressure & {$[\mathrm{kN}]$} & 10 & 10
\end{tabular}

The material was welded with the use of two different parameter combinations. The corresponding details are summarised in Table 5. Parameter combination 1 is taken as standard and involves the use of high clamping devices together with large exposed work-piece lengths. With parameter combination 2, on the other hand, very flat clamping devices are employed together with short exposed work-piece lengths. The electrical parameters (generator output power, current-on time) are nearly identical, in correspondence with the FEM analyses previously performed. The same applies to the applied upset pressure. The macrogeometry of the joints welded in the manner just described is shown in Fig. 30.
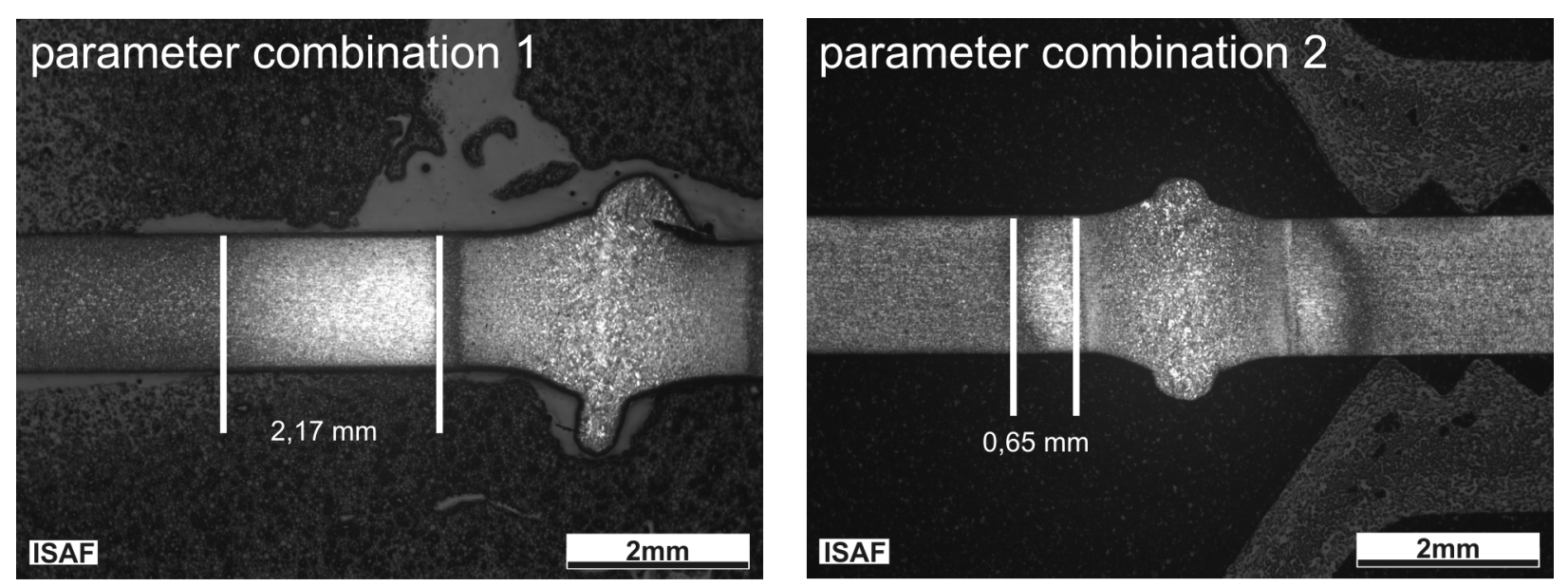

Fig. 30: Macrophotographs of the high-frequency welds obtained with parameter combination 1 (left) and parameter combination 2 (right)

In principle, three structural zones can be identified in the HF welds on steel MS1200. The finegrained zone is adjacent to the coarse-grained zone in the area of high austenitising temperature. Both zones are characterised by a martensitic microstructure. A zone of tempered martensite is present beside the austenitised area of the weld. The predicted decrease in the width of the tempered zone is clearly recognisable in the macrophotographs: The width decreases from 2,17 mm with parameter combination 1 to $0,65 \mathrm{~mm}$ with the appropriately adapted geometry of the clamping device. These conclusions are confirmed by observing the variation of the hardness in the direction transverse to the welded joint, see Fig. 31. A hardness plateau with maximal values up to $440 \mathrm{HV} 0,2$ is present in the area of the coarse-grained and fine-grained zones. The decrease in hardness in the vicinity of the joining line at large values of the exposed work-piece length is due to the formation of a ferrite seam as a result of edge decarburisation during the heating phase. This 
feature is less pronounced in the case of parameter combination 2 . In the hardness plot, the tempering zone is evident from a decrease in hardness adjacent to the hardness plateau. Beyond the hardness minimum at values from 250 to $310 \mathrm{HV} 0,2$, the hardness increases to the level of the base metal, that is, $380 \mathrm{HV} 0,2$.

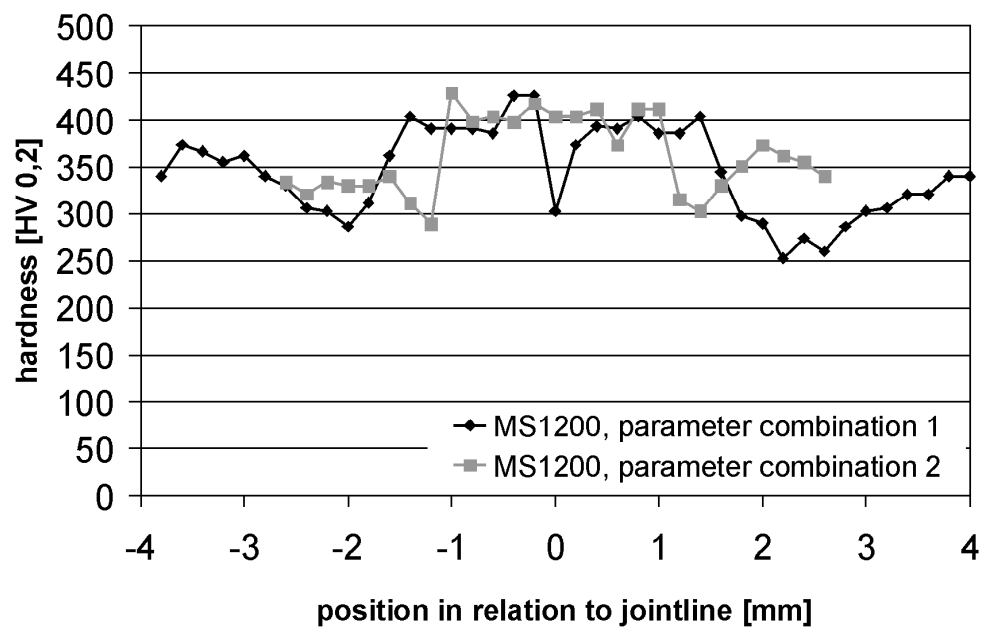

Fig. 31: Variation of hardness in the area of the HF weld with parameter combination 1 (blue) and parameter combination 2

On the whole, the conclusions reached with the use of the FEM model are mutually confirmed. Thus, the temperature gradients which occur in HF welds can be very effectively increased by appropriate adaptation of the clamping-device geometry in combination with a suitable adjustment of the exposed work-piece length. In a further step, the effect of the structures thus obtained on the static and fatigue strength of steel MS1200 must be investigated.

The static strength was determined by means of a transverse-tension test on welded samples. For this purpose, the excess upset metal was first removed by machining, in order to exclude any possible supporting action by the upset metal volume during the test. The results obtained with the welded samples can thus be compared with those obtained with the base metal. The resulting stressversus-strain curves are plotted in Fig. 32.

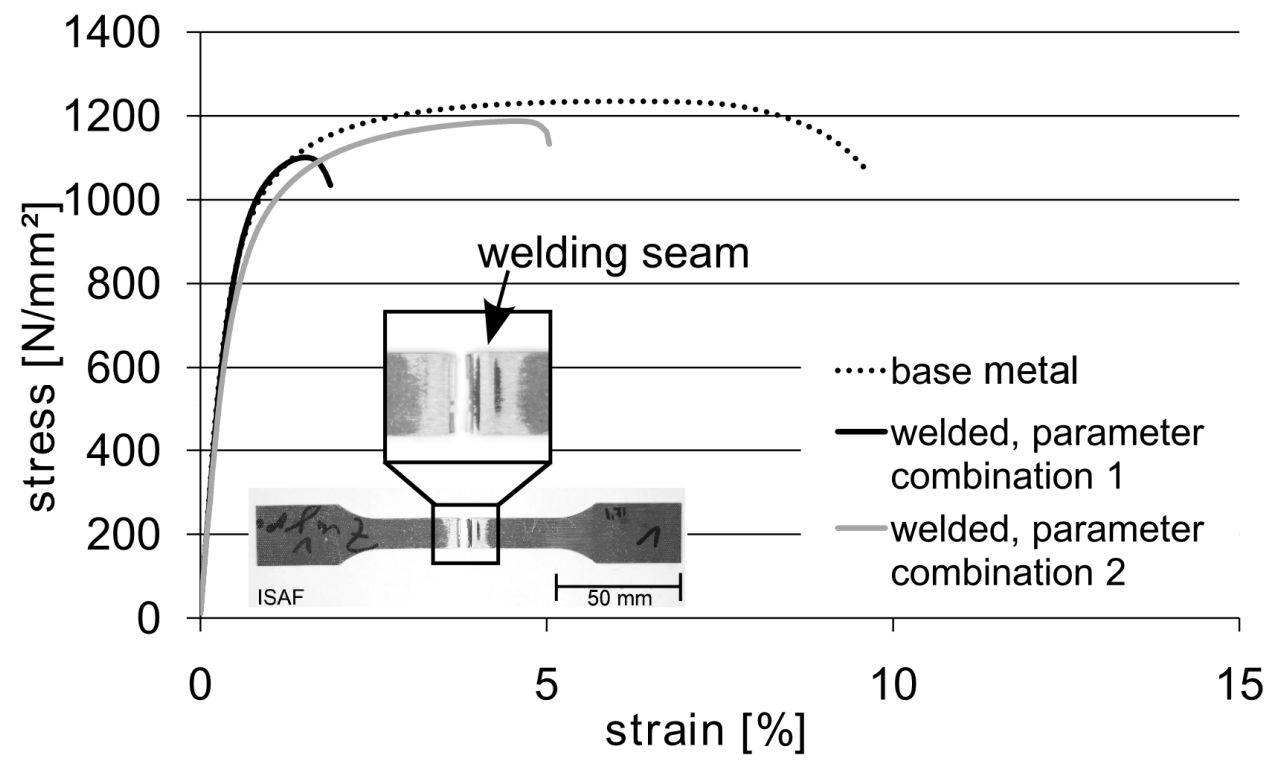

Fig. 32: Recorded stress-versus-strain curves from transverse-tension tests on welded and nonwelded samples of material MS1200 
During the transverse-tension test, failure occurs exclusively in the tempered martensite zone of the welded samples. However, the strength increases decidedly with the reduction of the tempered zone width. The average strength value is $100 \mathrm{~N} / \mathrm{mm}^{2}$. Nevertheless, the level of the base metal is not attained, see Table 6 . The observed increase in strength with decreasing width of the tempered zone is due to the improved supporting action of the surrounding structure without cohesion loss.

Table 6: Comparison of the static strength values for welded and non-welded samples of material MS1200

\begin{tabular}{|c|c|c|c|c|}
\hline & $\begin{array}{c}\text { Young's modulus, } \\
\mathrm{kN} / \mathrm{mm}^{2}\end{array}$ & $\mathrm{Rp} 0,2 \mathrm{~N} / \mathrm{mm}^{2}$ & $\mathrm{Rm}, \mathrm{N} / \mathrm{mm}^{2}$ & $\mathrm{~A}, \%$ \\
\hline MS1200 BM & 211 & 875 & 1214 & 8,6 \\
\hline $\begin{array}{c}\text { Welded, parameter set } \\
1\end{array}$ & 197 & 737 & 1072 & 4,2 \\
\hline $\begin{array}{c}\text { Welded, parameter set } \\
2\end{array}$ & 187 & 826 & 980 & 1,4 \\
\hline
\end{tabular}

In the following, the long-term stability behaviour has been investigated in the tension-threshold range with a stress ratio $\mathrm{R}=0,1$ for characterising the fatigue strength of the welded joints. For this purpose, the excess upset metal was removed from the welded samples by machining, and the results obtained with both sets of parameters were compared with those obtained with the base metal samples. The excess upset metal was removed in order to restrict the test results exclusively to the effect of the metallurgical notch on the fatigue strength. The S-N curve thus recorded is plotted in Fig. 33.

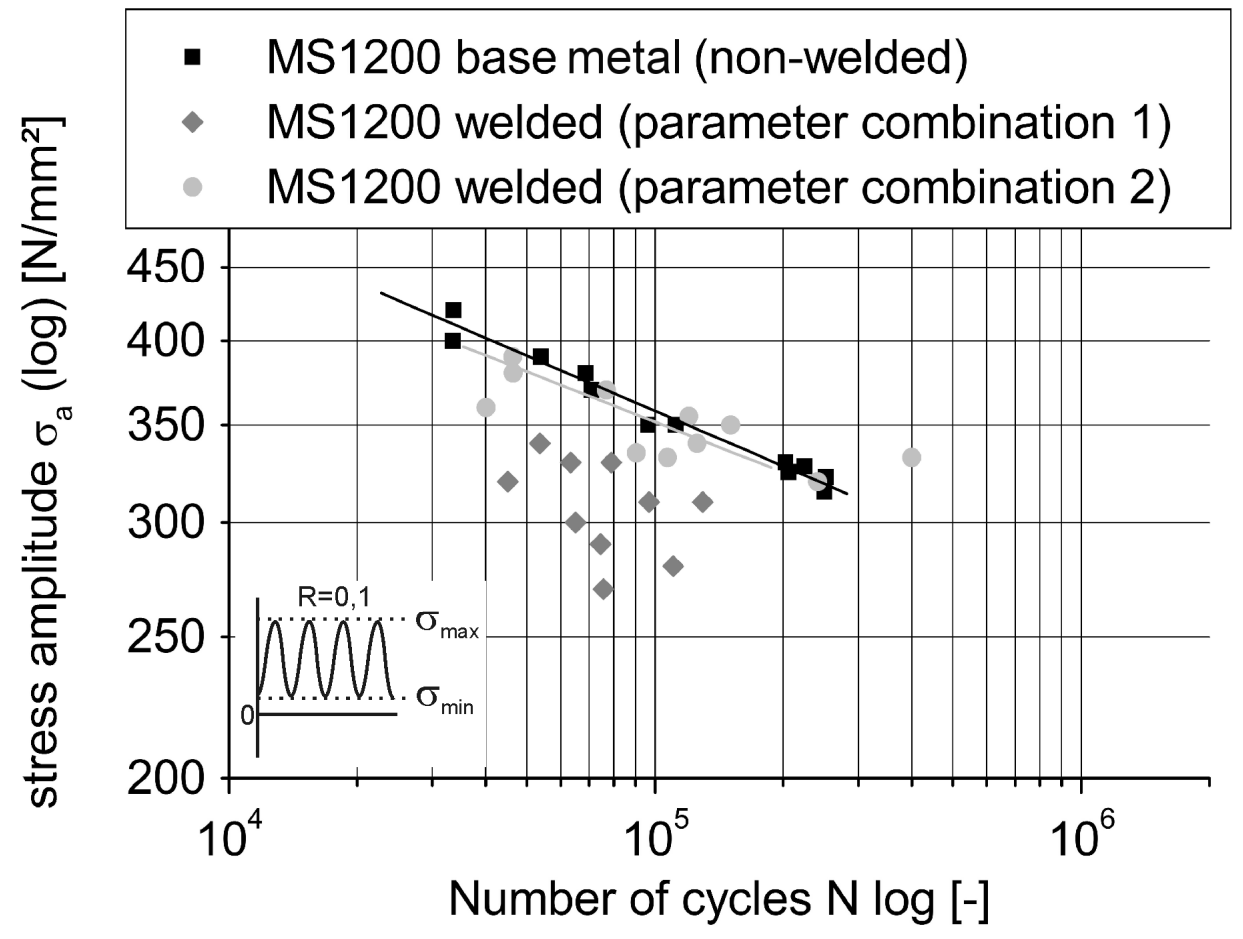

Fig. 33: S-N curve determined by fatigue-strength tests on welded and non-welded samples of material MS1200 in the tension-threshold range 
In the case of parameter combination 1, the diamonds plotted for failure of the samples are located clearly under the level of the non-welded base material. Because of the wide scatter no straight line for the long-term stability is plotted. By reduction of the metallurgical notch, the fatigue strength can be raised to the level of the base metal. Moreover, the points plotted for failure of the samples welded with parameter set 2 exhibit decidedly less scatter. Furthermore, the site of crack initiation is shifted to a different location. For samples welded with parameter combination 1, the site of failure is always located in the tempered zone, whereas the site of failure is partially shifted to the base metal for samples with a narrow tempered zone. However, no correlation can be detected between the cracking behaviour and the stress amplitude.

Conclusions. During welding operations on martensite-phase steels, tempering effects occur in the heat-affected zone of the martensitic base metal. As a result, the strength is impaired in the welded joint in comparison with the unaffected base metal.

With the use of a simulation model developed for the purpose, it has been shown that the width of the heat-affected zone in joints produced by conductive high-frequency welding can be effectively decreased by appropriate adjustment of the clamping-device geometry in combination with suitable values of the exposed work-piece length.

The resulting information has then been applied for welding of material MS1200. For this purpose, two parameter combinations have been employed. Parameter combination 1 represents the standard configuration consisting of high clamping devices together with large values of the exposed-work-piece length. With the newly developed parameter combination 2, in contrast, shorter clamping-device height has been combined with short exposed work-piece length. As predicted by the simulation model, the thermal exposure of the base metal during the welding operation has been very effectively decreased with the present process and system technology.

The decrease in the size of the metallurgical notch results in a considerable improvement of the mechanical-technological properties of the welded material MS1200. Thus, the static strength has been increased by $100 \mathrm{~N} / \mathrm{mm}^{2}$ on the average, but without attaining the level of the base metal. In the case of the fatigue strength, the properties of the welded joint can be increased even to the level of the base metal.

\section{Activation of material reactions by plastic deformation during high-frequency welding and their effects on the residual-stress state}

Initial questions. High-frequency welding is a pressure-welding method based on simultaneous heating of the joining edges along the entire length of the seam and a subsequent pressing operation for ensuring positive material bonding. During the upsetting process, the weld area is deformed to an extent which depends on the upset pressure which is applied to the edges being joined. For the present investigation, therefore, the initial objective was to determine the manner in which different deformation states affect the weld area. For this purpose, the upsetting process first had to be thoroughly analysed in an initial step for gaining a better understanding of the process involved. The objective of further, continuing investigations is the determination of the material reactions which are activated by the upsetting process, as well as the effects of these reactions on the mechanical and technological properties the welded joint. The material reactions which must be analysed as functions of the deformation state include the resulting upset shortening, the effects on the weld zone, the variation of the excess upset-metal height and width, as well as the residualstress state thus generated in the area subjected to plastic deformation. For the investigation, material DP 800 with a thickness $\mathrm{t}$ of $1,44 \mathrm{~mm}$ in the zinc-coated condition was welded by the conductive high-frequency process. For this purpose, the upsetting operation was performed with controlled force, in order to determine the upset shortening as a material reaction. The electrical and geometrical parameters which were kept constant for all tests are summarised in Table 7. 
Table 7: Summary of the constant parameter values employed for all conductive high-frequency welding tests on steel DP 800

\begin{tabular}{|l|l|l|l|}
\hline & Block 1 & Block 2 & Block 3 \\
\hline $\begin{array}{l}\text { generator output } \\
\text { power }\end{array}$ & $27 \%$ of $85 \mathrm{~kW}$ & $43 \%$ of $85 \mathrm{~kW}$ & $58 \%$ of $85 \mathrm{~kW}$ \\
\hline current-on period & $0,3 \mathrm{~s}$ & $0,3 \mathrm{~s}$ & $0,56 \mathrm{~s}$ \\
\hline $\begin{array}{l}\text { exposed work-piece } \\
\text { length }\end{array}$ & $5 \mathrm{~mm}$ & $5 \mathrm{~mm}$ & $5 \mathrm{~mm}$ \\
\hline gap width & $2 \mathrm{~mm}$ & $2 \mathrm{~mm}$ & $2 \mathrm{~mm}$ \\
\hline
\end{tabular}

During the process of heating the edges of the steel sheet, the generator output power was varied for establishing smaller temperature gradients during the heating phase. The reason for this measure is the occurrence of partial fusion phenomena at the edges of the sheet under different circumstances with the dual-phase steel under investigation.

Material reactions activated by the upset pressure during high-frequency welding of material DP 800. For establishing various deformation states in joints welded by the high-frequency process, DP 800 steel sheets were welded at different values of the upset pressure. The parameter values indicated in Table 7 were employed for these tests. For this purpose, the hydraulic pressure applied to the upsetting cylinder was varied within an interval from 35 to 115 bar in steps of 5 bar. The specific upset pressure thus applied for ensuring positive material bonding of the edges to be joined is indicated in Table 8. All joints produced in this manner were subjected to the transverse-tension test for determining their durability. The tests were performed after removal of the excess upset metal by machining, in order to exclude any supporting action of the upset material volume. In all samples tested, fracture occurred in the base metal.

Table 8: Specific upset pressure applied for conductive HF welding of steel DP 800

\begin{tabular}{|c|c|}
\hline $\begin{array}{c}\text { Hydraulic } \\
\text { pressure, bar }\end{array}$ & $\begin{array}{c}\text { Specific upset } \\
\text { pressure, N/mm }\end{array}$ \\
\hline 35 & 34 \\
\hline 45 & 44 \\
\hline 55 & 54 \\
\hline 65 & 63 \\
\hline 75 & 73 \\
\hline 85 & 83 \\
\hline 95 & 93 \\
\hline 105 & 102 \\
\hline 115 & 112 \\
\hline
\end{tabular}

The relationship thus determined between the specific upset pressure and the resulting upset shortening is plotted in Fig. 34. 


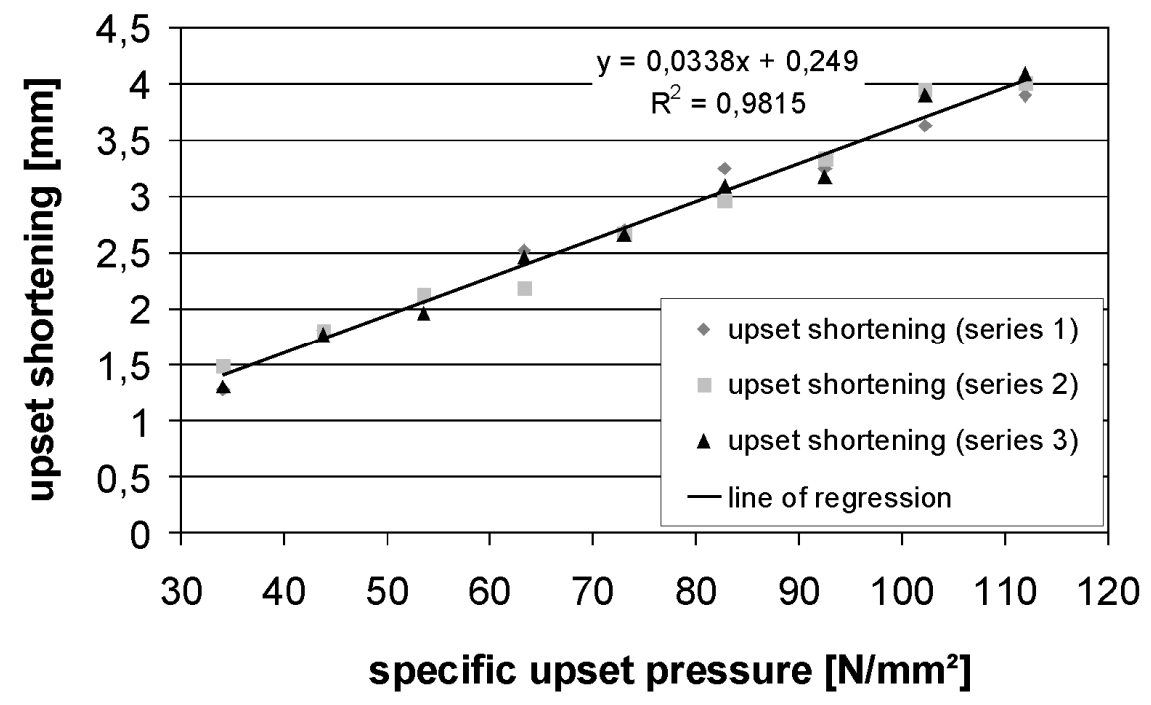

Fig. 34: Resulting upset shortening during high-frequency welding of material DP 800 as a function of the specific upset pressure

The linear dependence of the upset shortening on the applied upset pressure is clearly evident. A further conspicuous feature is the low scatter of the work-piece shortening which results from the controlled-force upset process. This observation is supported by the determination coefficient of 0,9815 for the line of regression, which is close to unity. Accordingly, it has been assumed that the plastic deformation which occurs in the joint area as a result of the welding process can be reproducibly adjusted.

For investigating the material reaction induced by plastic deformation in the weld area, transverse sections have been taken from the steel-sheet blanks after joining. Macrophotographs of the transverse sections after etching with nitric acid and picric acid are shown in Fig. 35 and Fig. 36. As a result of etching with nitric acid, structures which are established in the weld area become visible. The transverse sections are etched with picric acid for visualising the flow lines present in the material. By observing the development of the flow lines as a function of the applied upset pressure, further conclusions can be reached on the kinematics of the deformation process. 

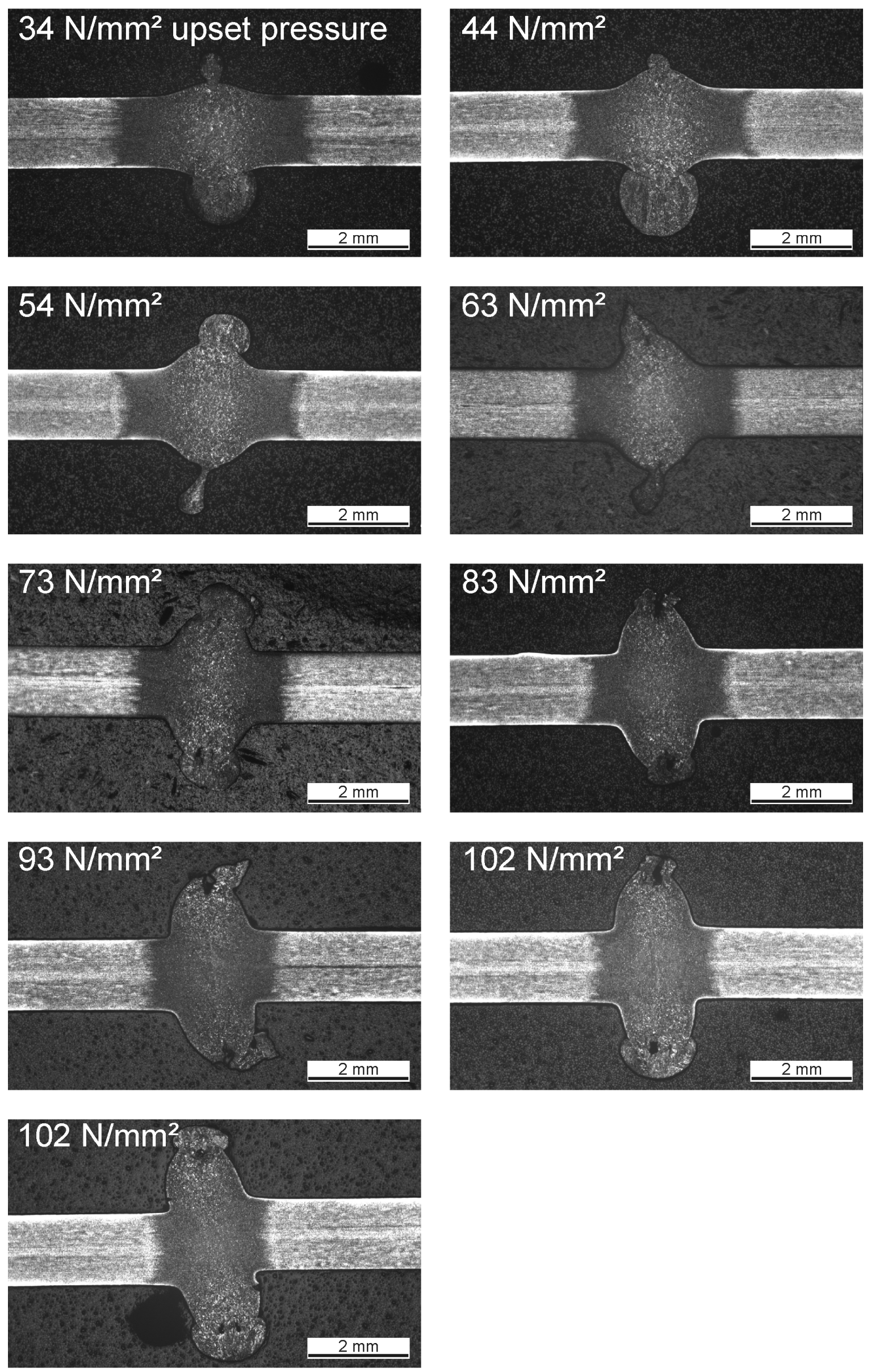

Fig. 35: Macrophotographs of the joints produced by high-frequency welding (etching agent: nitric acid) 

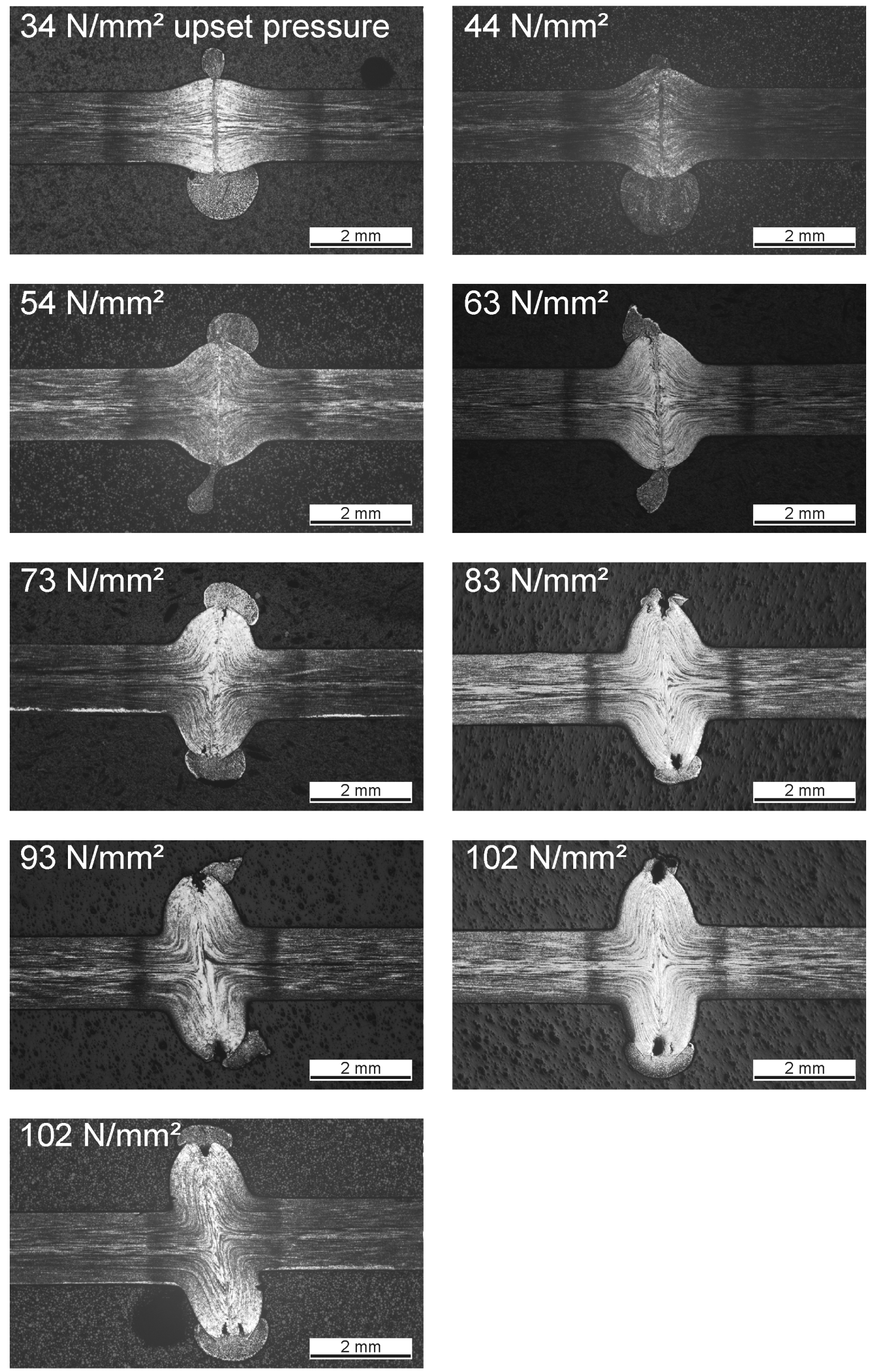

Fig. 36: Macrophotographs of the joints produced by high-frequency welding (etching agent: picric acid) 
As a matter of principle, the structure of the welded joint can be subdivided into three zones, regardless of the applied upset pressure, see Fig. 37. The fine-grained zone is adjacent to the coarsegrained zone in the area of highest austenitising temperatures. Both zones are characterised by a martensitic microstructure, although isolated ferritic structural components are visible in the coarsegrained zone. The hardness of the material is constant in both zones with a value of $450 \mathrm{HV} 0,2$, which exceeds the hardness of the base metal by $200 \mathrm{HV} 0,2$. The fine-grained zone is followed by the tempered zone, which is followed by the unaffected base metal.

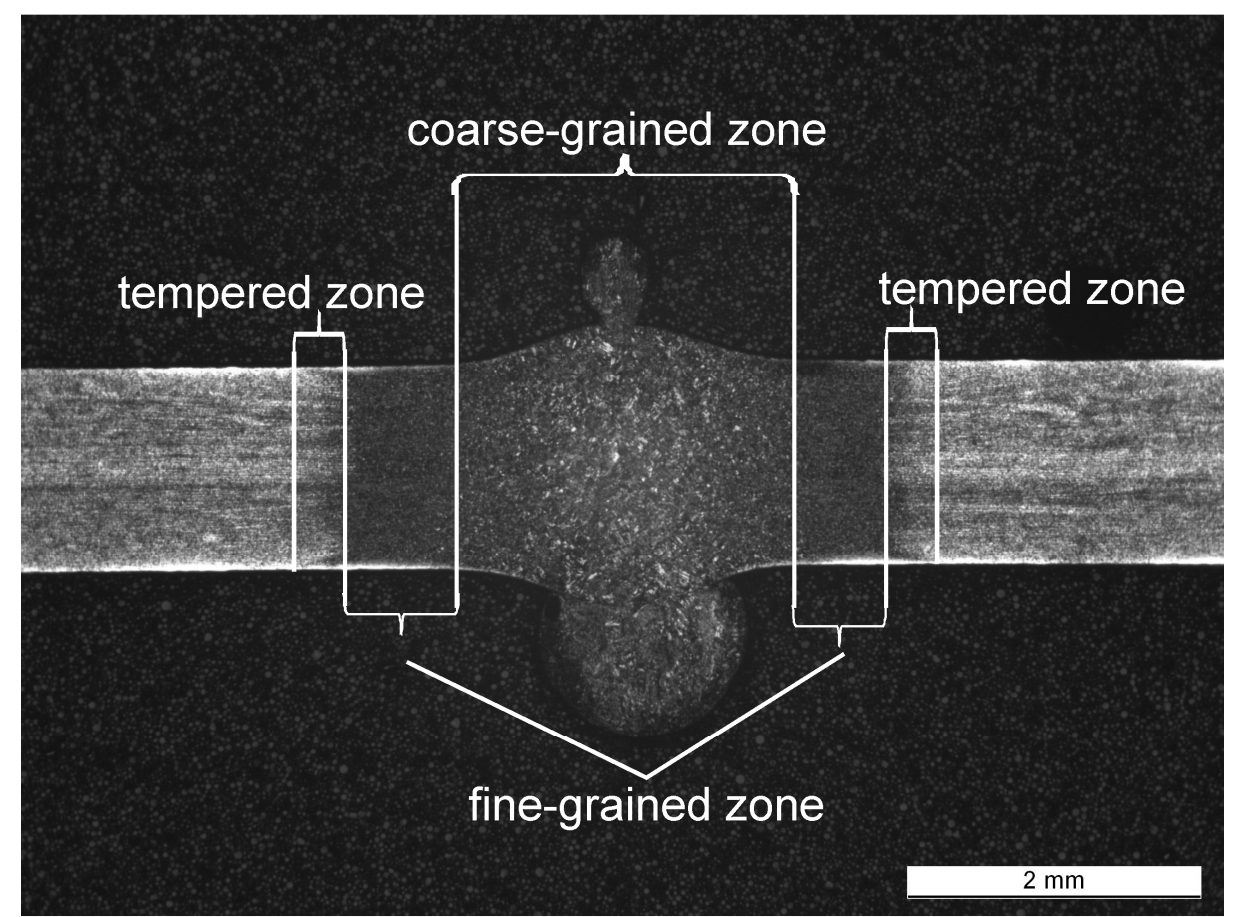

Fig. 37: Structural zones in material DP 800 joined by high-frequency welding

The material motion which occurs during the upsetting operation is visualised by means of flowline patterns on joints welded with specific upset-pressure values of $34 \mathrm{~N} / \mathrm{mm}^{2}$ and $112 \mathrm{~N} / \mathrm{mm}^{2}$, respectively, as shown in Fig. 38. In this comparison, the dots (labeled with a cross) designate identical material areas in the deformation zone for different deformation rates. The observed displacement of individual material areas during the deformation process can be explained as follows:

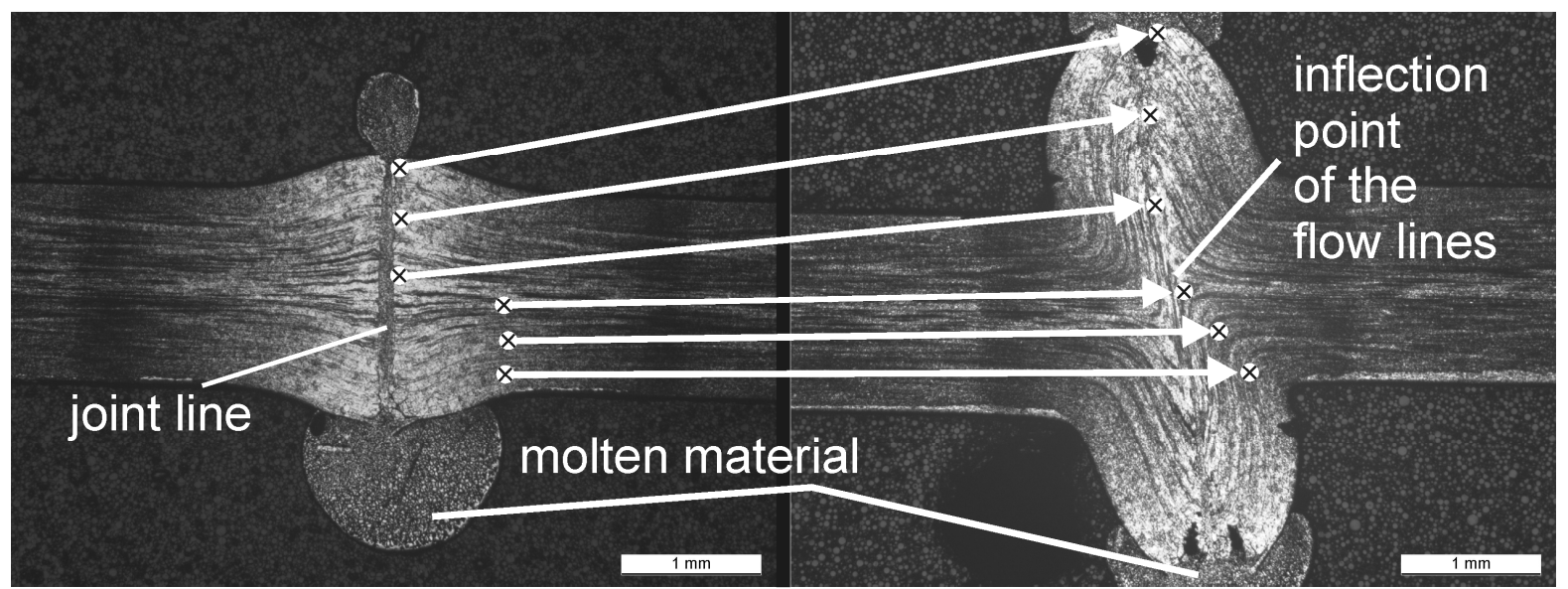

Fig. 38: Kinematics of the upsetting process during high-frequency welding 
At the beginning of the upsetting process, the molten material which is present at the peak of the sheet edge is first pinched out as excess upset metal. Subsequently, the plastified material is deformed. During this process, motion occurs essentially in two main directions. The material present at the point of impact between the two joining partners is displaced outward from its initial position in the direction orthogonal to the plane of the sheet. The resulting form of the excess upset metal is a characteristic feature of HF welding. At the same time, colder material is pressed in the direction of the joining line and thus replaces the material which has been displaced outward. Because of the superimposed transport in the direction from the inside to the outside, this effect is more pronounced in the middle of the sheet than in the outer regions. This feature is evident from the angular deflection of the flow-line motion of individual material points from the longitudinal direction to the direction orthogonal to the plane of the sheet. A consequence of the indicated material transport is the increasing constriction of the coarse-grained zone with increasing upset pressure, as shown in Fig. 39.

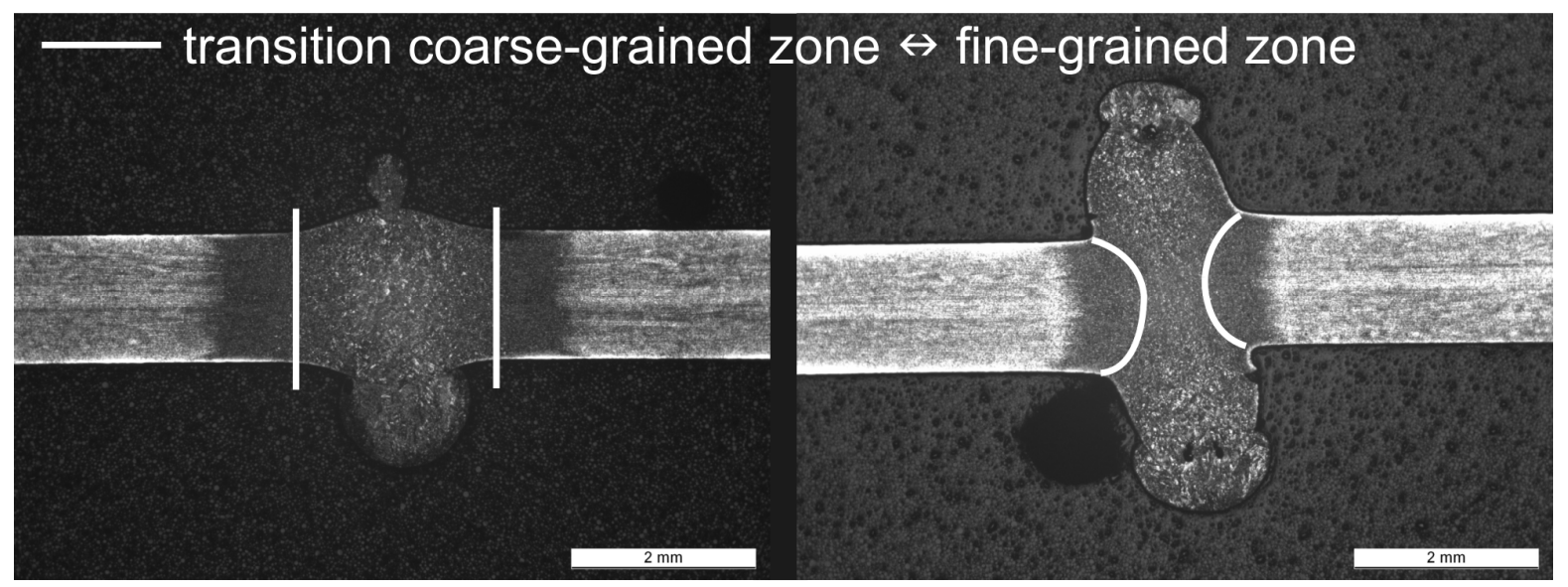

Fig. 39: Constriction of the coarse-grained zone as a function of the upset pressure during highfrequency welding of steel DP 800

Quantitatively, this effect can be described by the variation in the width of the coarse-grained zone in the middle as well as in the upper and lower regions of the weld. The relationship between the specific upset pressure and the width of the coarse-grained zone in the middle and in the outer regions of the sheet is plotted in Fig. 40.

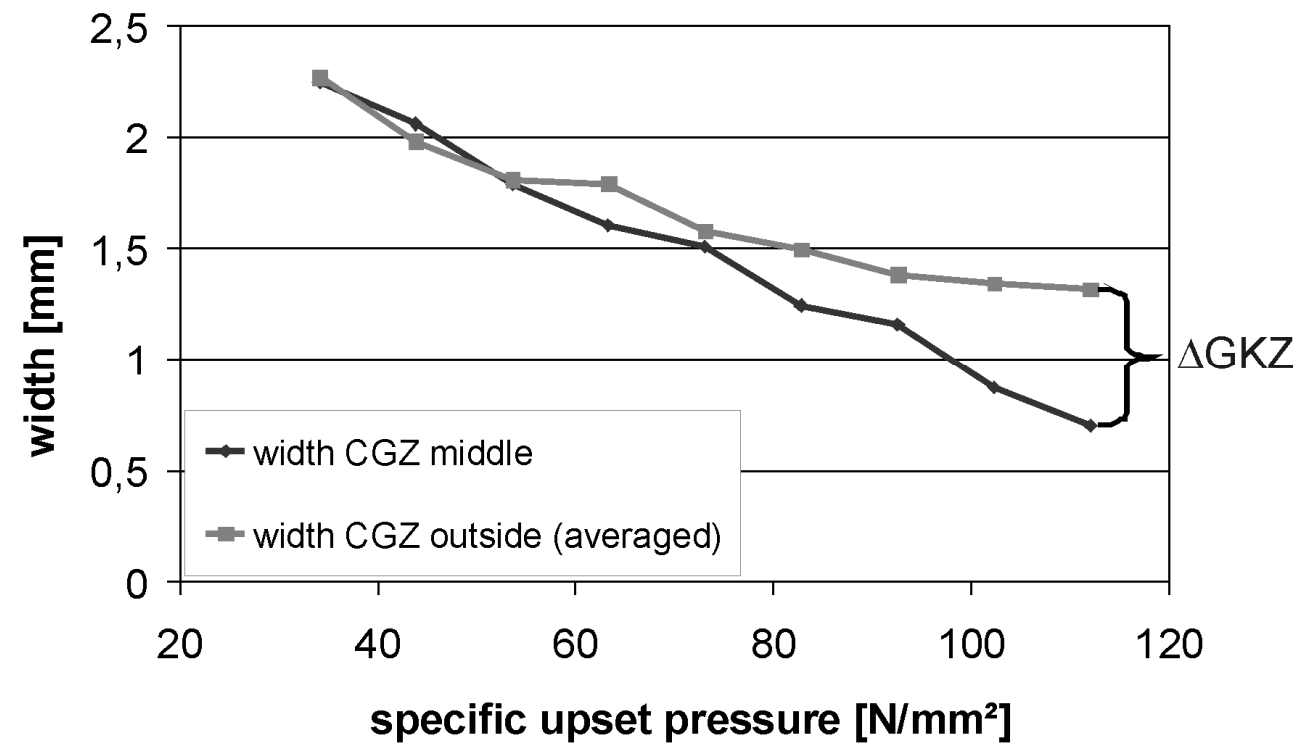

Fig. 40: Variation in the width of the coarse-grained zone during high-frequency welding of material DP 800 as a function of the specific upset pressure 
In the middle of the sheet, the width of the coarse-grained zone decreases linearly over the entire range of upset pressure under consideration, whereas the width of this zone decreases hyperbolically in the outer regions of the welded joint. Consequently, the two curves diverge to an increasing extent beyond an upset pressure value of $75 \mathrm{~N} / \mathrm{mm}^{2}$, as shown in Fig. 40. At the highest value of the applied specific upset pressure, that is, $112 \mathrm{~N} / \mathrm{mm}^{2}$, the width of the coarse-grained zone $(0,7 \mathrm{~mm})$ in the middle of the weld has thus decreased by one-half, in comparison with the width of the coarse-grained zone near the surface of the sheet $(1,4 \mathrm{~mm})$. This observation is associated with the kinematics of material displacement during the upsetting operation, as already described.

The effects of the upsetting operation on the width of the fine-grained zone and on the width of the entire heat-affected zone are plotted in Fig. 41.

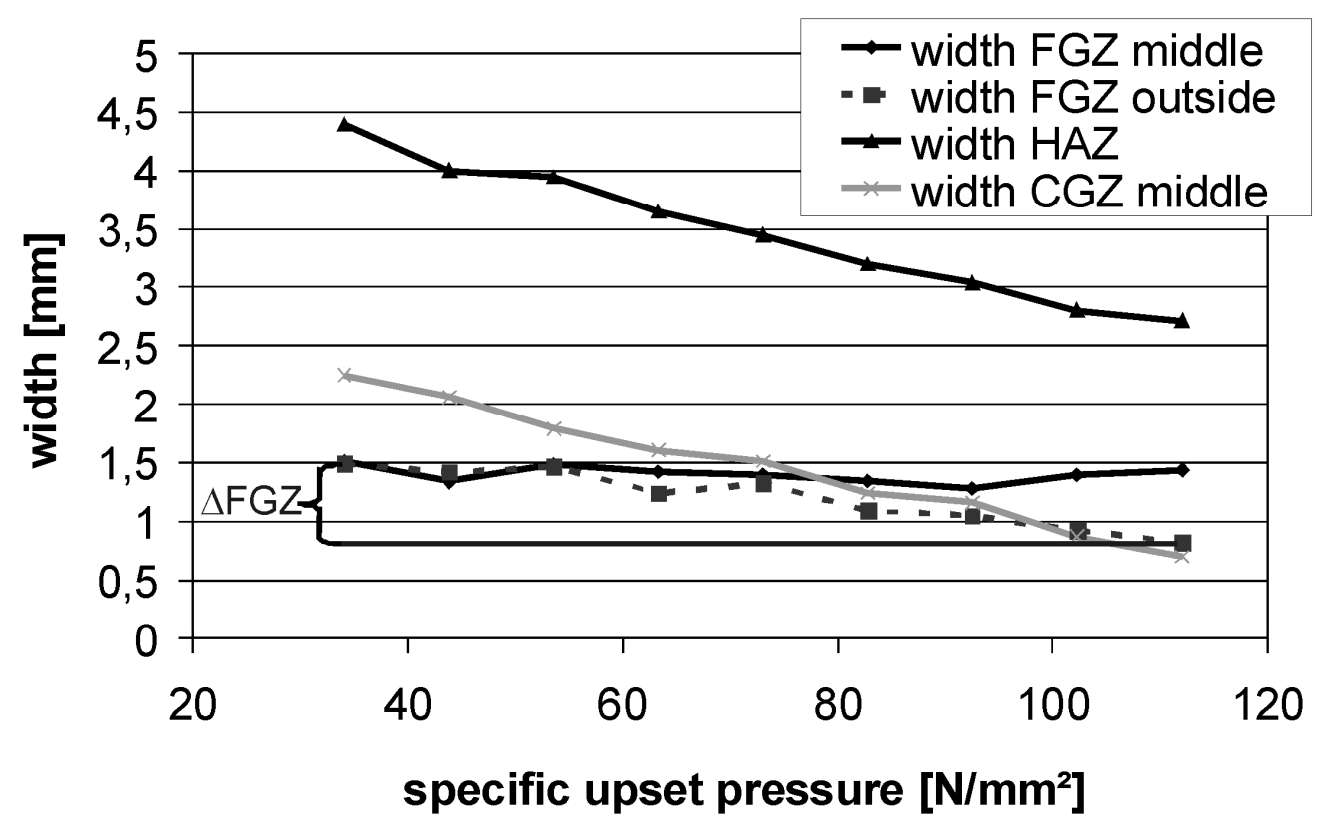

Fig. 41: Variation in the width of the fine-grained zone and heat-affected zone as a function of the specific upset pressure during high-frequency welding of steel DP 800

Since the edge areas of the heat-affected zone are far distant from the deformation region, the width of the heat-affected zone does not depend on the sheet thickness. The deformation affects the width of the fine-grained zone in a different manner. In the middle of the sheet, no material volume from the fine-grained zone is pressed outward, and its width thus remains constant, see 'FGZ middle' in Fig. 41. Correspondingly, the decrease in the width of the heat-affected zone is achieved entirely by the displacement of coarse-grained martensite, as can be seen from the parallel variation in the widths of the coarse-grained zone (middle) and the heat-affected zone, see 'CGZ middle' and 'HAZ middle' in Fig. 41. In the area of the sheet surface, in contrast, material volume from the finegrained zone is also pressed outward into the excess upset metal thus formed, see 'FGZ outside' in Fig. 41. Thus, the resulting decrease in width corresponds exactly to the difference in the width of the coarse-grained zone between the middle of the sheet and the edge area of the welded joint. That is, $\Delta \mathrm{GKZ}=\Delta \mathrm{FKZ}$, see Fig. 40 and Fig. 41 .

The effects of mutual upsetting of the samples against one another on the resulting height and width of the excess upset metal are plotted as functions of the upset pressure in Fig. 42. 


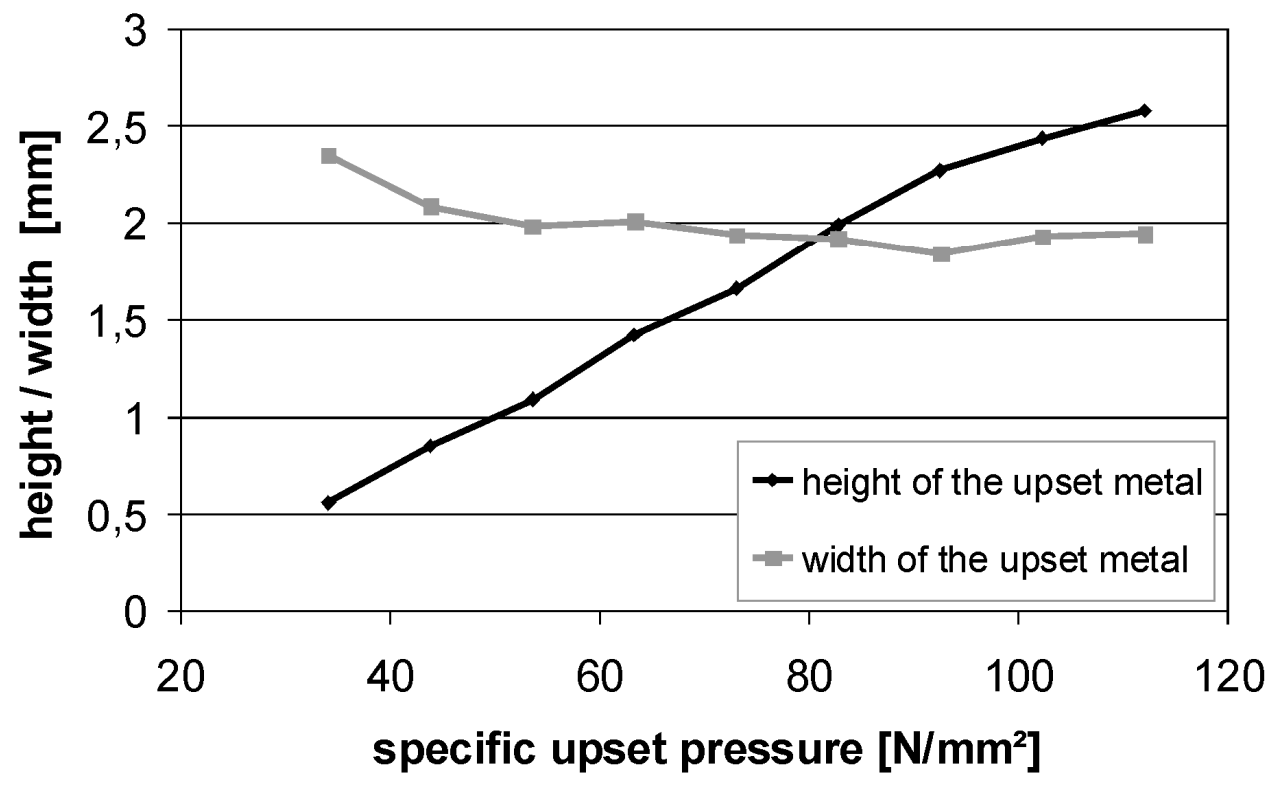

Fig. 42: Effect of the specific upset pressure on the variation in the height and width of the excess upset metal during high-frequency welding of material DP 800

A linear relationship is evident between the specific upset pressure and the height of the resulting excess upset metal. On the other hand, the width of the excess upset metal is nearly independent of the applied upset pressure.

As indicated by the results of the aforementioned investigations, the overall width of the heataffected zone as well as that of the coarse-grained zone can be very effectively decreased by an increase in the upset pressure. However, the width of the coarse-grained zone does not decrease uniformly over the entire thickness of the sheet; this observation is associated with the kinematics of deformation, as described in the preceding. The result is an hour-glass-shaped constriction in the coarse-grained zone. Consequently, an objective of future investigations is to determine the extent to which the mechanical and technological properties of the weld are affected by the decrease in zone width in combination with the alteration in the geometry of the coarse-grained zone. Moreover, the height of the resulting excess upset metal is greatly increased by the free mutual upset of the sheet edges. Hence, the activation of material reactions in the weld area by the upset pressure is beneficial only if the excess upset metal which results from the welding process is removed by an additional machining step. Otherwise, the fatigue strength under alternating stress will be severely impaired, since the excess upset metal constitutes a large geometrical notch $[10,20]$.

Effects of the deformation rate on the residual-stress state in the weld area. For analysing the effects of plastic deformation on the residual-stress state in HF-welded joints, measurements have been performed by the hole-drilling method in conformance with ASTM standard E 837, [21]. As specified in this standard, a hole is drilled completely through a thin sample at the centre of a straingauge rosette transducer. The rosette is attached to the sample with the use of an adhesive and consists of three strain-gauge transducers positioned radially around the borehole for determining the state of strain before and after drilling of the hole through the sample. From this information, the principal stresses in the plane of the sheet can be calculated with the use of Eq. 5 .

$$
\sigma_{\min }, \sigma_{\max }=-\left[\frac{p}{a /(1+v)} \pm\left\{\frac{\sqrt{\left(q^{2}+t^{2}\right)}}{b}\right\}\right] \cdot E
$$


with

\begin{tabular}{|l|l|}
\hline$E$ & Young's modulus \\
\hline$v$ & Poisson ratio \\
\hline$P$ & $\left(\varepsilon_{3}+\varepsilon_{1}\right) / 2$ \\
\hline$Q$ & $\left(\varepsilon_{3}-\varepsilon_{1}\right) / 2$ \\
\hline$T$ & $\left(\varepsilon_{3}+\varepsilon_{1}-2 \varepsilon_{2}\right) / 2$ \\
\hline$A$ & Constant conversion factor \\
\hline$B$ & Constant conversion factor \\
\hline
\end{tabular}

In this equation, the strain components $\varepsilon_{1}$ to $\varepsilon_{3}$ represent the three strain values (in $\mu \mathrm{m} / \mathrm{m}$ ) measured radially with respect to the hole. Both Young's modulus and the Poisson ratio are determined by performing a tensile test. For this purpose, the required strain values in the transverse and longitudinal directions with respect to the tension are measured with the use of the strain-gauge transducer. The following values have thus been determined: $\mathrm{E}=218000 \mathrm{~N} / \mathrm{mm}^{2}$ and $v=0,3$. The conversion factors $a$ and $b$ are dimensionless constants which are nearly independent of the material. For thin samples, these factors depend on the sheet thickness as well as the type of straingauge rosette transducer employed. The ratio of the borehole diameter and the diameter of the circle described by the strain-gauge transducers arranged radially around the hole is especially decisive for this purpose.

The conversion factors $a$ and $b$ are determined in accordance with the calibration specification given in ASTM 837. The following values have thus been obtained: $a=0,13415$ and $b=0,54517$. The experimentally determined constant conversion factors have been validated with the use of the test set-up shown in Fig. 43.

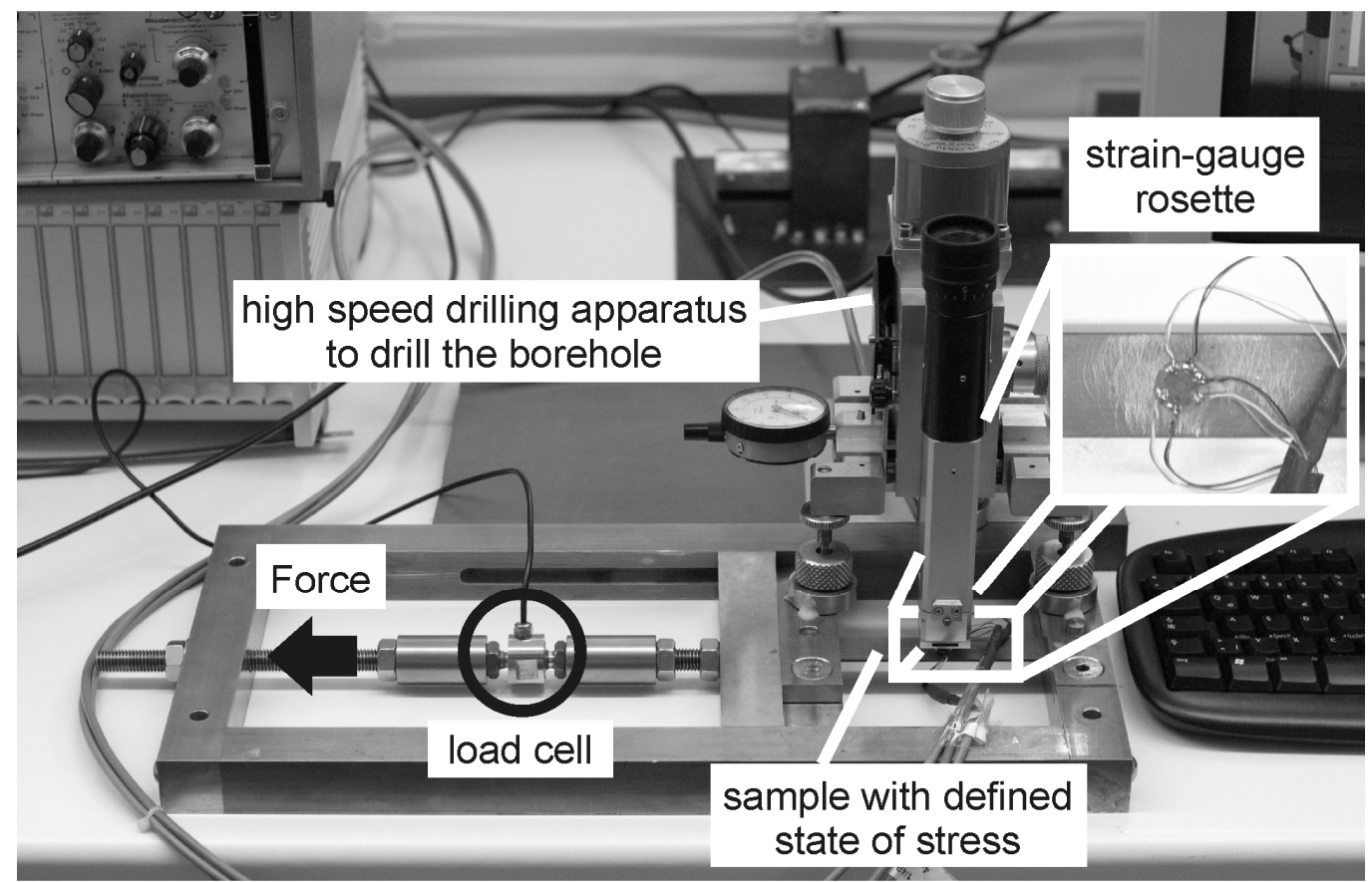

Fig. 43: Measuring set-up for determining the residual stress and for validation of the constant conversion factors by the hole-drilling method

For the validation procedure, a sample of material DP 800 was first annealed to relieve the stress and then clamped into the test frame shown in Fig. 41. Subsequently, the sample was subjected to a load in the direction of tension, in order to generate a defined homogeneous state of stress in the cross-section of the sheet. The state of stress was then determined with the above mentioned method by using the calibration constants $a$ and $b$. The values of the stress applied during the test are compared with the measured stress values in Table 9. 
Table 9: Validation measurements performed by the method just described on sheet-steel samples in defined residual-stress states

\begin{tabular}{|c|c|c|c|}
\hline $\begin{array}{c}\text { Applied stress in } \\
\text { the direction of } \\
\text { tension }\end{array}$ & $\sigma_{\mathrm{x}}$ & $\sigma_{\mathrm{y}}$ & $\begin{array}{c}\rho \text { (displacement angle } \\
\text { between the direction } \\
\text { of tension and } \sigma_{\mathrm{x}}\end{array}$ \\
\hline $100 \mathrm{~N} / \mathrm{mm}^{2}$ & $101 \mathrm{~N} / \mathrm{mm}^{2}$ & $9 \mathrm{~N} / \mathrm{mm}^{2}$ & $0,75^{\circ}$ \\
\hline $200 \mathrm{~N} / \mathrm{mm}^{2}$ & $199 \mathrm{~N} / \mathrm{mm}^{2}$ & $2 \mathrm{~N} / \mathrm{mm}^{2}$ & $0,35^{\circ}$ \\
\hline $300 \mathrm{~N} / \mathrm{mm}^{2}$ & $307 \mathrm{~N} / \mathrm{mm}^{2}$ & $-2 \mathrm{~N} / \mathrm{mm}^{2}$ & $1,33^{\circ}$ \\
\hline
\end{tabular}

As can be seen from Table 9, the specified states of stress are determined very precisely with the calibrated measuring system. The desired measuring accuracy, that is, \pm 10 per cent of the measured value (of at least $10 \mathrm{~N} / \mathrm{mm}^{2}$, however), has been achieved. The very slight deviations of the displacement angle from the ideal value of $0^{\circ}$ were caused by rotation of the principal axis directions of the strain-gauge transducers with respect to the principal stress direction of the sample. After successful validation of the constant conversion factors for measuring the residual stress, the residual-stress state in joints welded by the HF method was determined as a function of the applied plastic deformation. For this purpose, joints welded with specific upset-pressure values of 34 and $102 \mathrm{~N} / \mathrm{mm}^{2}$ were mutually compared. This comparison was performed on welded samples before as well as after removal of the excess upset metal by machining. The site at which failure had occurred in the welded samples under alternating stress was decisive for specifying the site where the residual stress was to be measured. This site was determined by fatigue tests in the pulsating-tension range at an $\mathrm{R}$ value of 0,1 , see Fig. 44.
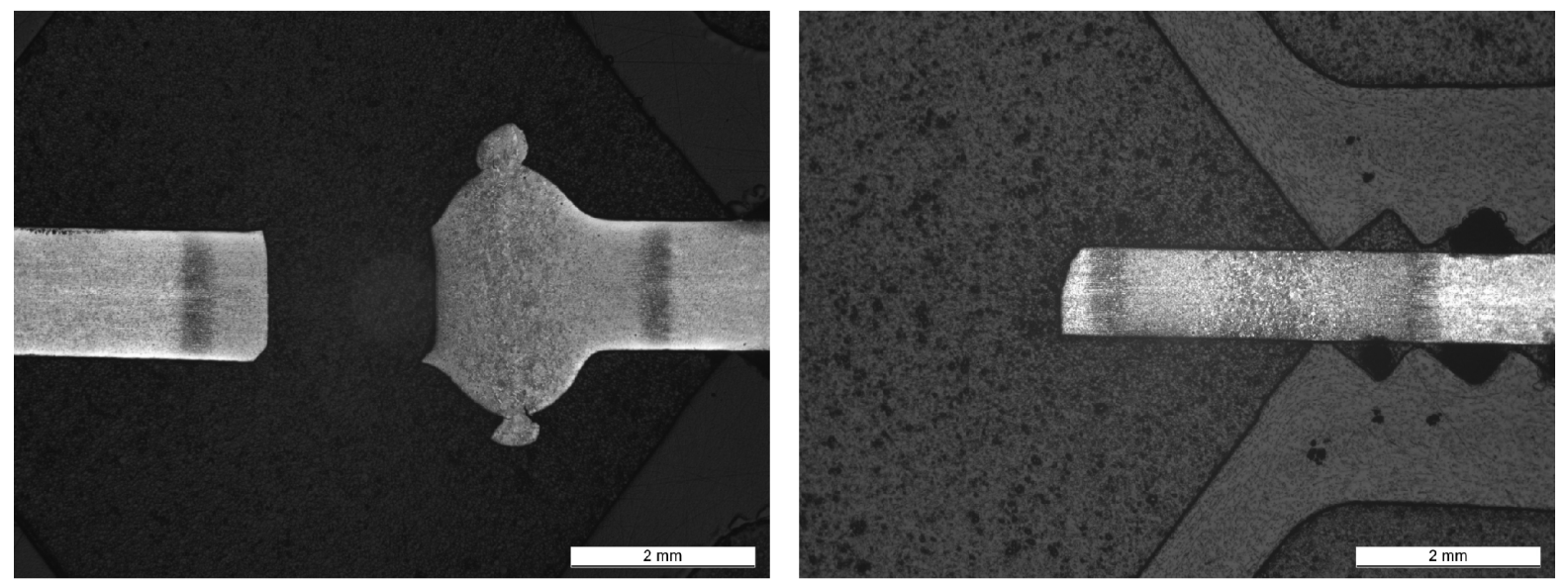

Fig. 44: Site of failure in HF-welded samples of material DP 800 under alternating stress before and after removal of the excess upset metal by machining

In welded joints of material DP 800 with excess upset metal, material failure occurs exclusively at the transition between the excess upset metal and the planar surface of the steel sheet. This effect is caused by local excessive stress at the geometrical notch formed by the excess upset metal. If the excess upset metal has been removed from the welded joint by machining, however, the principal site of failure under alternating stress is located at the transition between the heat-affected zone and the base metal. In this case, the influence of the heat-affected zone as a metallurgical notch is the decisive factor. That is, the formation of higher-strength structural components in the heat-affected zone results in a hindrance to strain in the direction of tension. The associated excessive stress is thus highest at the transition between the metallurgically altered zone and the base metal. (Compare the transition between the excess upset metal and the surface of the sheet in the case of the geometrical notch.) Consequently, the residual stress was measured at the points indicated in Fig. 45. 


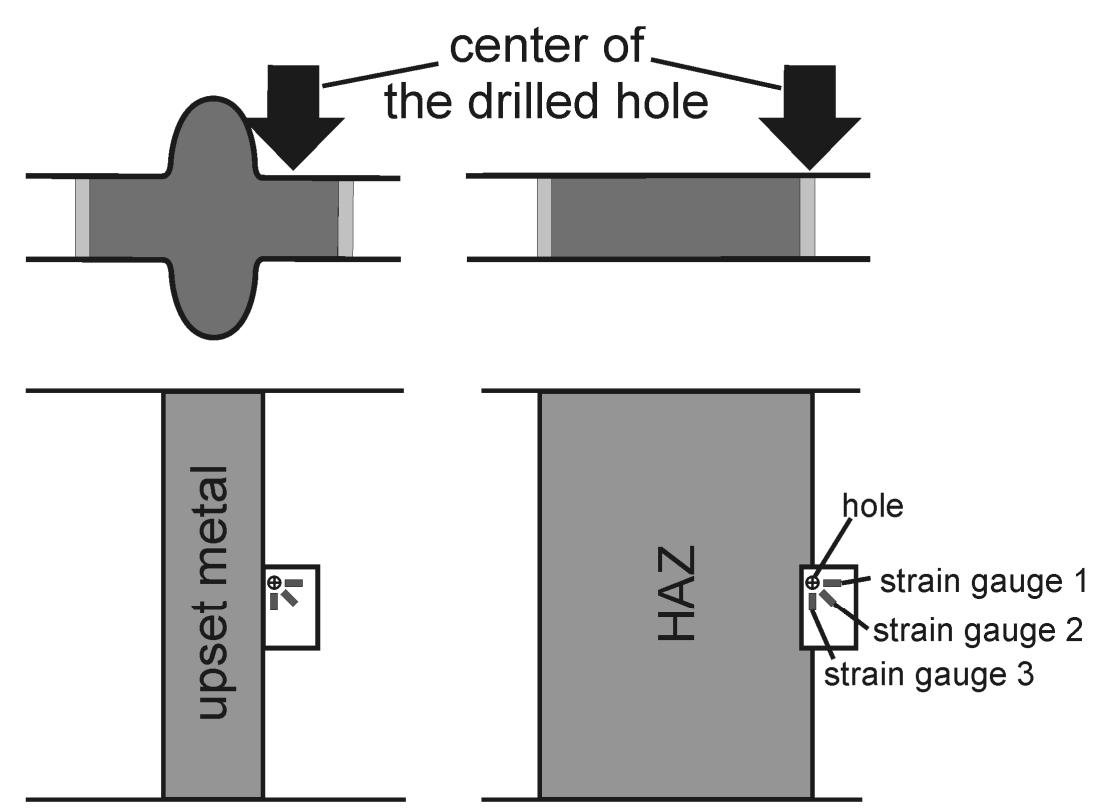

Fig. 45: Application of the strain-gauge rosette transducers for residual-stress measurement on welded samples of material DP 800 with (left) and without (right) excess upset metal

The residual-stress state determined on welded samples which had been joined at upset-pressure values of 102 and $34 \mathrm{~N} / \mathrm{mm}^{2}$ is indicated in Fig. 46 for samples with and without the excess upset metal.
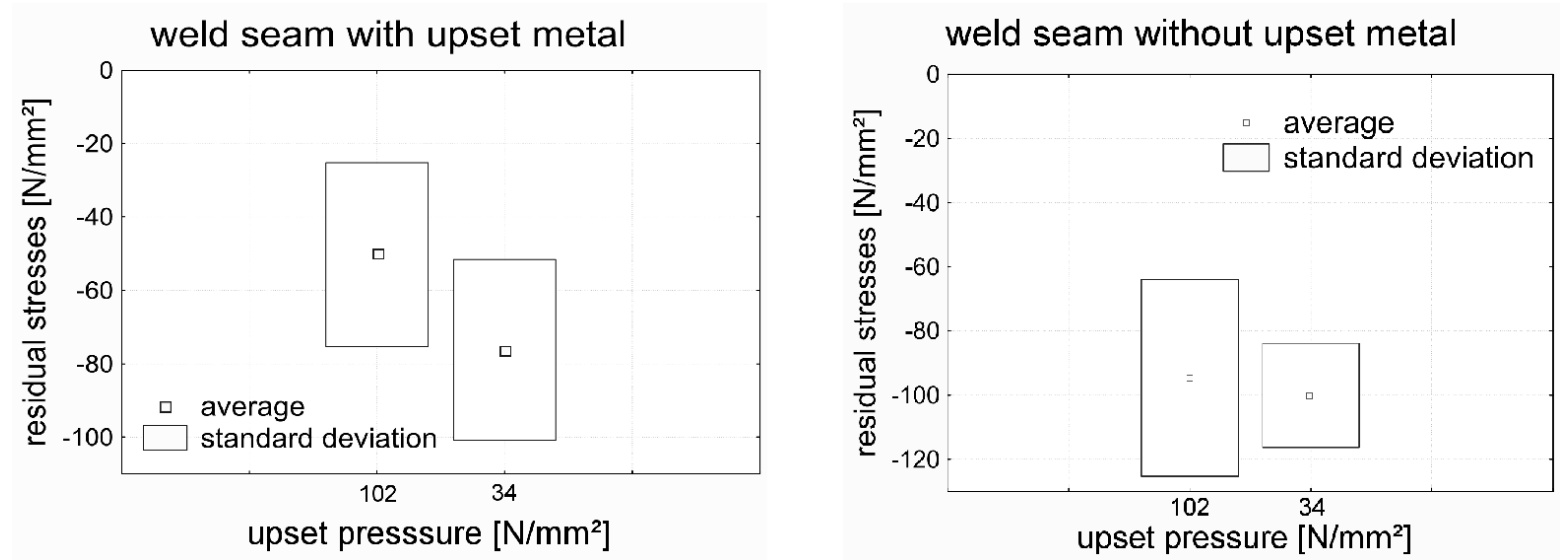

Fig. 46: Residual stresses measured in the direction transverse to the HF-welded joint, after various seam preparation

Residual compressive stresses are present in the weld area of all samples, regardless of the machining operation or applied upset force. These stresses have resulted from the deformation of heated material zones by the upsetting process. However, no such stresses are present in the unaffected base metal. In the case of joints welded with low upset pressure, the level of the residual compressive stresses is definitely higher; hence, the fatigue strength properties are considered to be more favourable. Moreover, the geometric notch which results from the upsetting process is considerably larger in the case of samples from which the excess upset metal has not been removed by machining; thus, the fatigue strength is further impaired.

Conclusions. The effects of plastic deformations caused by conductive high-frequency welding on the external material reactions, the structural developments in the weld area, as well as the residualstress state thus established have been investigated. For this purpose, steel-sheet blanks of DP 800 material were welded at constant values of the electrical parameters, but at different values of the 
specific upset force necessary for joining. For this investigation, the values of the specific upset pressure ranged between 34 and $112 \mathrm{~N} / \mathrm{mm}^{2}$.

From the analyses, a linear relationship was obtained between the upset pressure applied during the joining process and the resulting upset shortening. Furthermore the height of the excess upset metal increases linearly as a function of the upset pressure because of the increase in the material volume displaced by the upsetting process. However, the width of the excess upset metal does not change during this process.

Moreover, the width of the heat-affected zone decreases linearly as the upset shortening increases (for instance, from $4,3 \mathrm{~mm}$ at $34 \mathrm{~N} / \mathrm{mm}^{2}$ to $2,1 \mathrm{~mm}$ at $102 \mathrm{~N} / \mathrm{mm}^{2}$ ). As a result of the material transport during the upsetting process, an increasingly concave coarse-grained area is formed within the heat-affected zone.

A higher deformation rate in the weld area does not improve the residual-stress state at sites which are critical under alternating stress. A further factor which impairs the fatigue strength is the presence of a geometric notch in the unmachined condition, that is, "with excess upset metal".

In a further step, investigations are planned for determining the effect of the upset pressure on the mechanical and technological properties of the material. Among other items, the strain behaviour of the welded joint should be analysed by transverse and longitudinal tension tests with laser-optical strain measurements. Moreover, the strength of the material should be determined under alternating stress.

\section{Improving the properties of HF-welded joints by means of integrated thermomechanical treatment}

Motivation. During welding operations on materials, the heat input necessary for the welding process results in thermally activated structural alterations in the base metal. Impairment of the mechanical and technological properties in the weld area is often associated with these structural changes. Hence, the objective of the present investigation is to modify the structure which is established during the welding process in such a way that the original properties of the base metal are restored.

For this purpose, the process-specific coupling between the heating process and the mechanical pressure-welding operation should be utilised for integrating a thermomechanical treatment of the joint area into the high-frequency welding process. In a further step, appropriate temperatureversus-time deformation cycles must be developed for decisively improving the structural state and thus the structural properties of the materials in the weld area.

The option of influencing the weld properties is of special importance for joining of materials with a local property profile in the future, in correspondence with planned developments within the scope of Sonderforschungsbereich 675. In particular, the transfer of local material hardening from the initial semifinished goods to the finished component is absolutely necessary in this case.

In the following, the manner in which a thermomechanical treatment has been integrated into the conductive high-frequency welding process for the first time is described in detail, also see $[16,17,22]$. Micro-alloyed steel H340LA with a wall thickness $t$ of $1,5 \mathrm{~mm}$ was employed as test material; this steel was not zinc-coated.

Characterisation of the properties in the joint area of HF-welded micro-alloyed sheet steel. The effect of the heat input during the HF-welding process on the structural development has been investigated on material H340LA which was not zinc-coated. Moreover, a comprehensive analysis has been performed to determine the effects of the changes in the state of the material in the weld area on the static strength as well as on the fatigue strength. For this purpose, the effect of the process on the structure of the material in the weld area and the associated strength values must be determined.

After the welding operation, a structure with three characteristic zones is present in the HF-welded joint, see Fig. 47. 

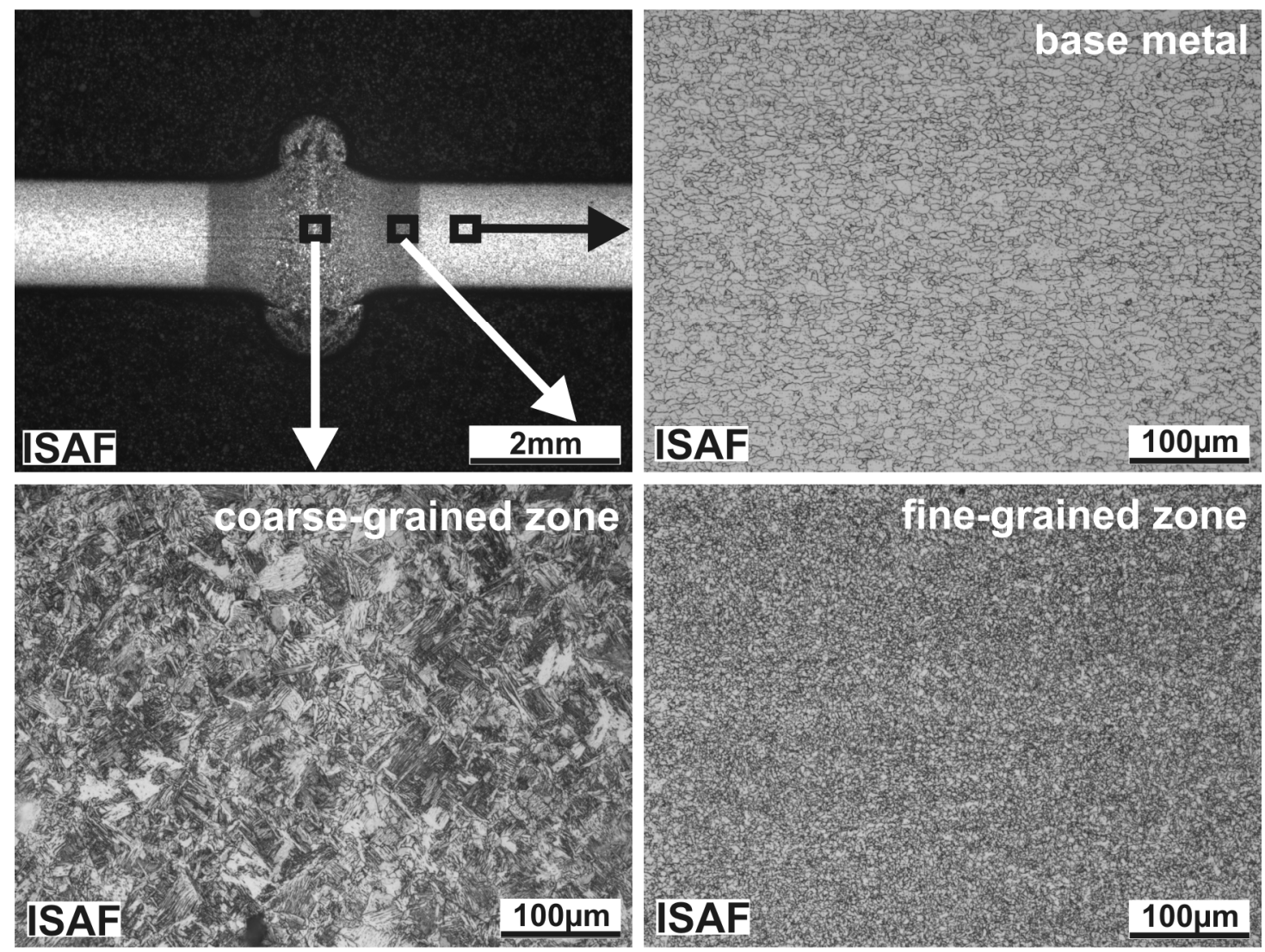

Fig. 47: Microstructure in welded joints of material H340LA

The fine-grained zone with a ferritic structure in the range of austenitising temperatures up to 80 degrees above the Ac3 temperature is adjacent to the thermally unaffected base metal. The temperatures are far higher in the middle of the weld; consequently, a coarse-grained zone is formed in this area. This zone is characterised by a martensitic-bainitic microstructure. A ferrite seam with a Widmannstätten microstructure extends along the joining line itself as a result of decarburisation effects at the edge during the heating process.

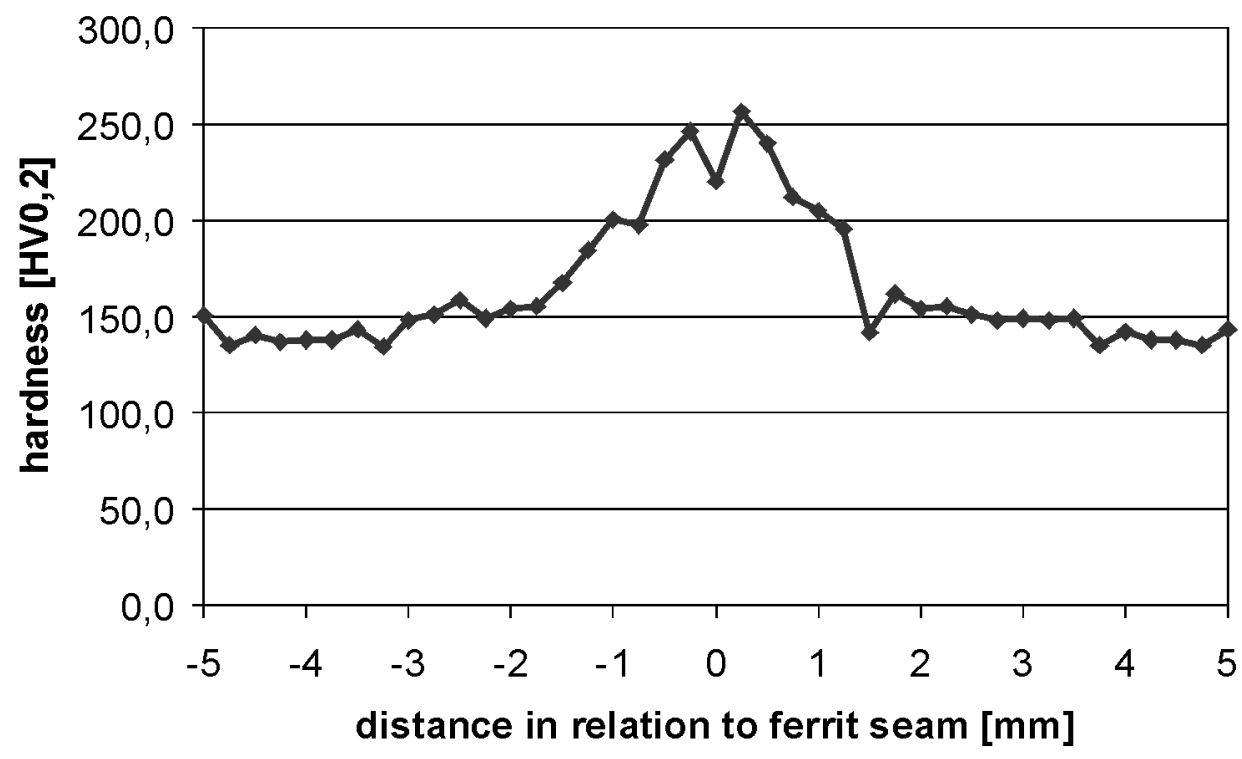

Fig. 48: Variation of hardness transverse to the HF-welded joint with material H340LA 
The indicated zones are clearly recognisable from the variation in hardness in the direction transverse to the welded joint, Fig. 48. The maximal hardness remains far below $350 \mathrm{HV} 0,2$ because of the low total energy input. The ferrite seam along the joining line is also clearly recognisable because of the decrease in hardness to $220 \mathrm{HV} 0,2$ in the middle of the hardness curve. For examining the effect of the material alterations in the weld area on the static strength, the welded samples were compared with the base metal by transverse-tension testing. Before the tests, the excess upset metal was removed by machining in order to avoid any supporting action by the upset material. Stress-versus-strain curves recorded during transverse-tension tests are plotted in Fig. 49.

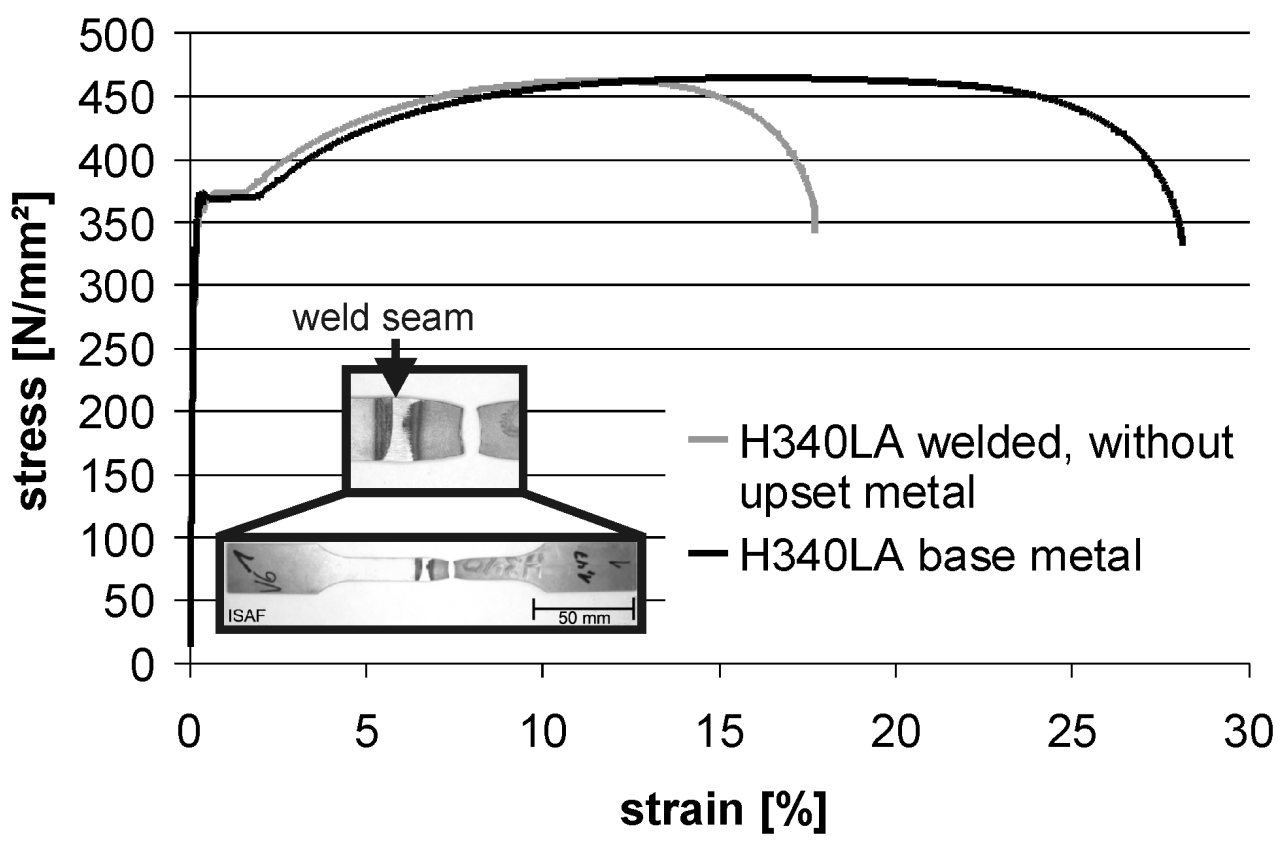

Fig. 49: Stress-versus-strain curves from transverse-tension tests on welded and unwelded samples of steel H340LA

For all welded joints tested, the site of failure was located in the base metal. Correspondingly, the average tensile strength is $455 \mathrm{~N} / \mathrm{mm}^{2}$, in analogy with the value for the base metal. The yield strength of the welds under investigation also remains unchanged, as referred to that of the base metal. The average value is $360 \mathrm{~N} / \mathrm{mm}^{2}$. However, a conspicuous feature is the considerable decrease in the elongation at rupture from 28 per cent for the base metal to 17 per cent for the welded samples. The cause of this observation is the formation of higher-strength structural components in the weld (martensite/bainite) and in the heat-affected zone (fine-grained ferrite).

The fatigue strength was determined by performing S-N tests in the pulsating-tensile range with a stress ratio $\mathrm{R}$ of 0,1 . For this purpose, the welded samples were compared with the base metal, both with and without removal of the characteristic excess upset metal by machining. In the present study, the samples with the excess upset metal were included in the analyses in order to determine the manner in which the presence of the geometrical notch affects the fatigue strength of the joint in this case. The S-N plots which resulted from these tests are presented in Fig. 50. 


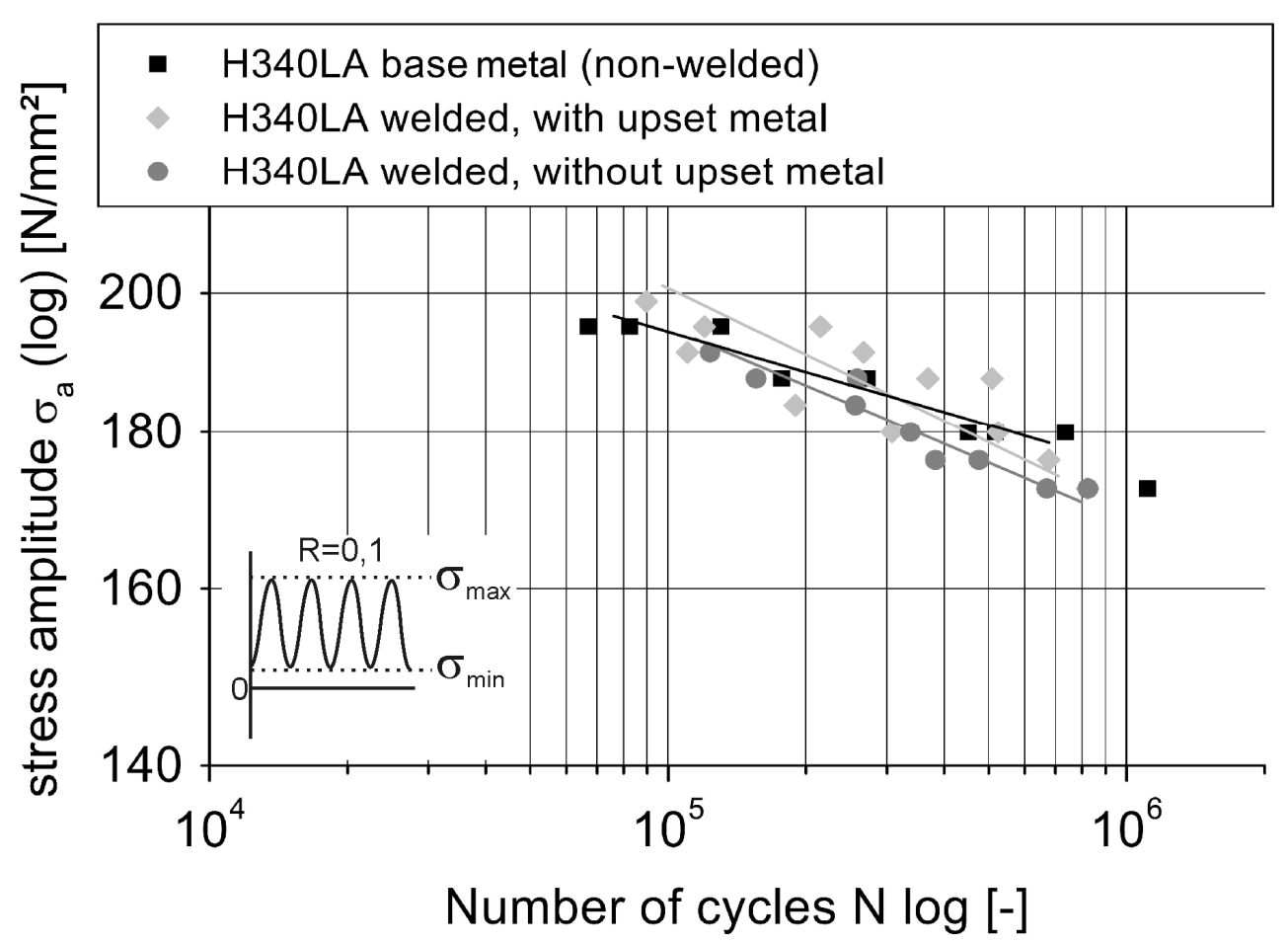

Fig. 50: S-N plots recorded during fatigue tests on welded and unwelded samples of material H340LA in the pulsating-tensile range

The welded samples exhibit the same fatigue strength as do the samples of unwelded base metal. A conspicuous feature is the fact that the slope of the recorded S-N plots is not very steep.

The material behaviour observed during the tests reflects the special features of micro-alloyed steel with an exclusively ferritic structure. Under certain conditions, plastic flow occurs in these materials under alternating stress; consequently it is no longer possible to measure the effect of the cyclic load alone on the strength.

The results of the aforementioned analyses indicate that the geometrical as well as the metallurgical notch exerts no significant effect on the fatigue strength behaviour of material H340LA. In both cases, the regression line thus determined in the S-N plot is situated at the same level as that of the base metal.

Integration of a thermomechanical treatment into the HF-welding process. As demonstrated in the preceding section, the same static and dynamic strength values have been attained with the HFwelded material H340LA as with the unaffected, that is, unwelded, base metal. Only the elongation at rupture during the transverse-tension test is decidedly lower for the welded samples than for the base-metal samples. The observed non-uniform strain behaviour results in an impairment of the deformability during subsequent manufacturing steps.

One possibility of improving the deformability in the weld area is the application of a thermomechanical treatment in the heat-affected zone. For this purpose, the most efficient alternative to the input of energy expressly for postweld heating of the joint area is the utilisation of the conductive energy input. The operating principle is illustrated in Fig. 51. 


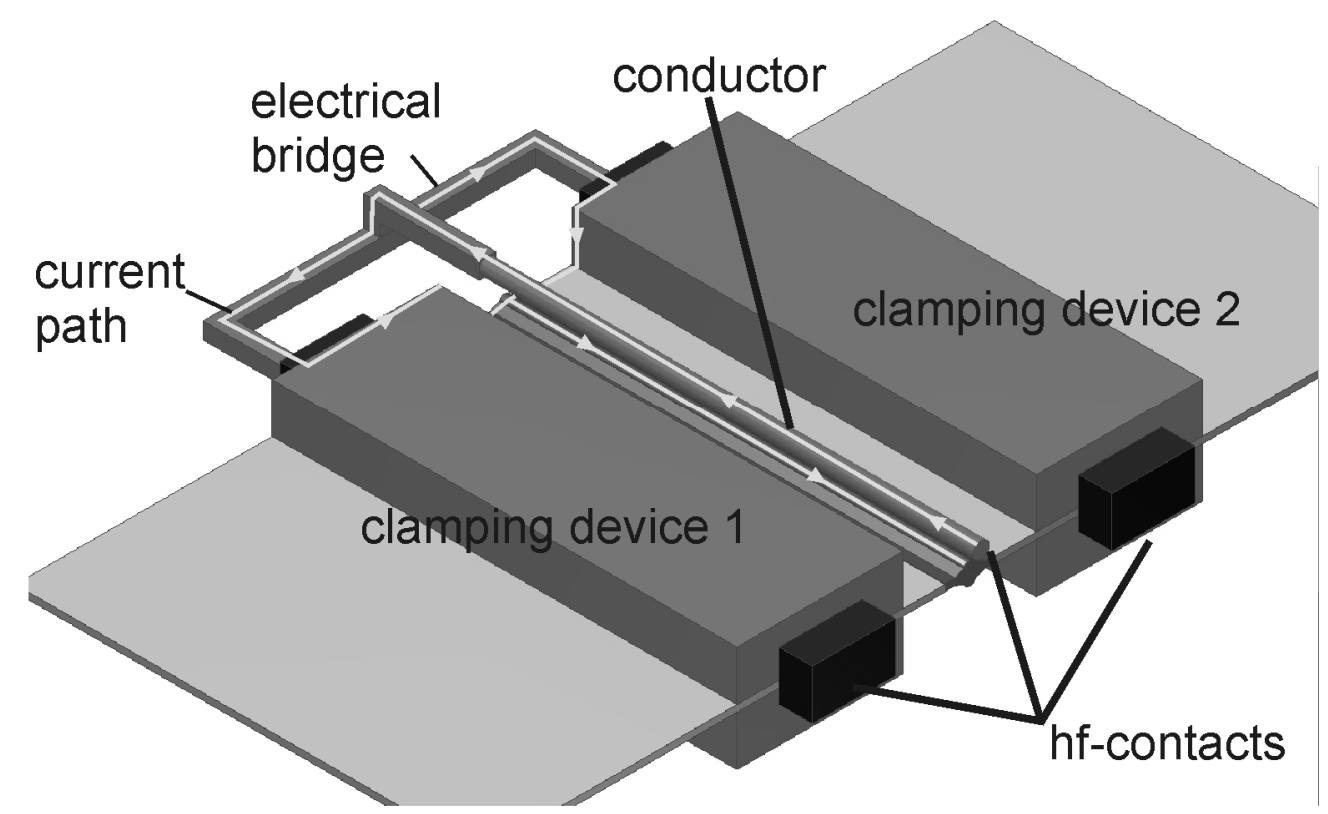

Fig. 51: Diagrammatic representation of the thermomechanical treatment integrated into the HF process

After upsetting of the two joining partners against one another for ensuring positive material bonding, the HF input voltage is switched at zero current from clamping device 1 to the conductor located over the welded joint during the cooling phase. The supply of high-frequency alternating current to the conductor results in the return flow of current through the electrical bridge and the clamping devices directly through the welded joint to the high-frequency generator. The restriction of the current flow to the weld area is due to the proximity effect between the HF current flowing in the conductor and that flowing through the welded joint in the opposite direction. The resulting temperature distribution in the joint zone, determined by the validated FEM model of the heating in the joining edge, is illustrated in Fig. 52.

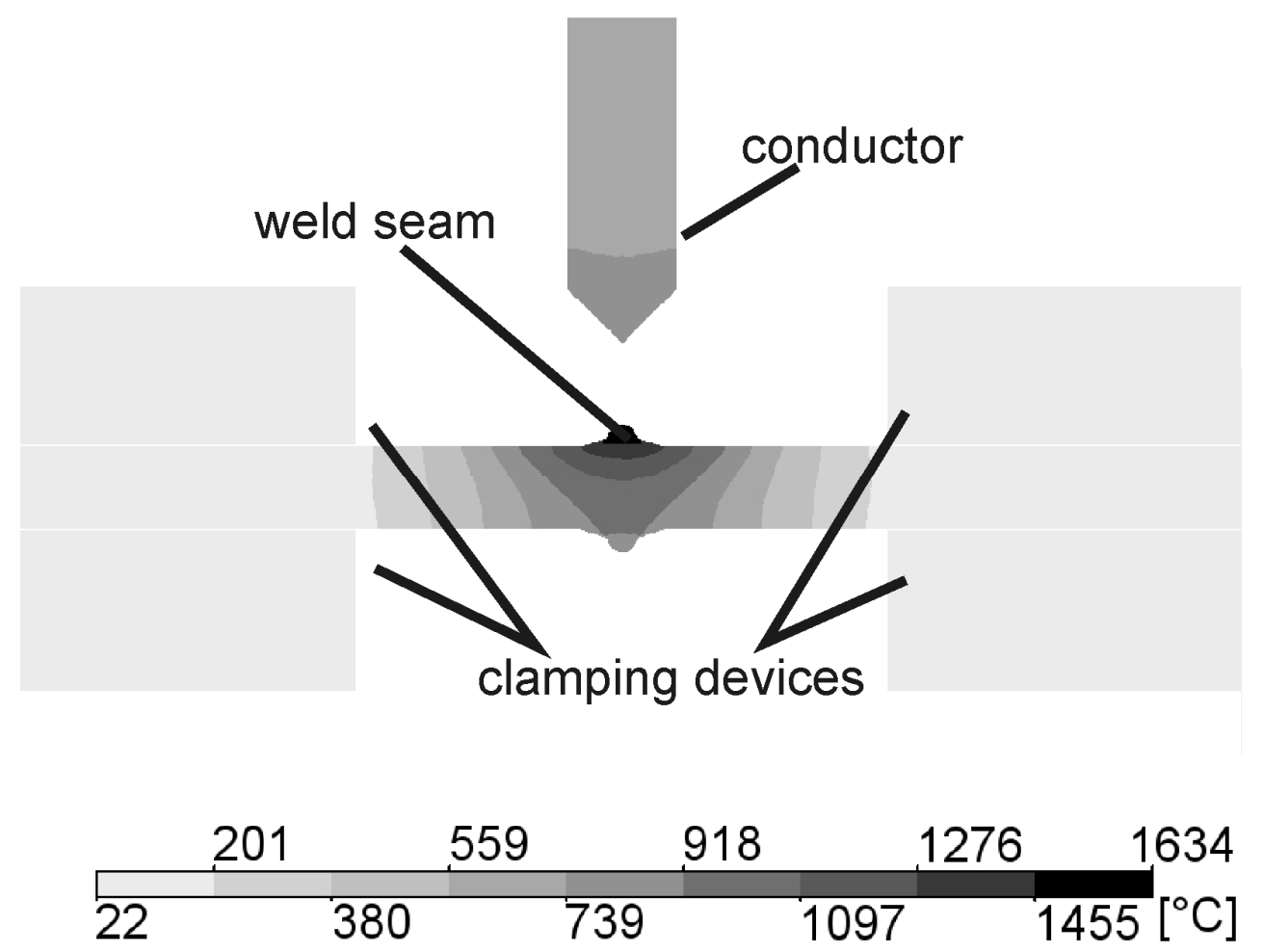

Fig. 52: Temperature distribution in HF-welded joints during the conductive postweld heat treatment 
The austenitised material zone is restricted to the area of the coarse-grained zone which results from the welding operation. As can be seen from Fig. 52, the excess upset metal which forms during the welding process absorbs the temperature peaks in the area where the concentration of current density is highest. In this manner, excessively high temperature gradients are avoided in the loadbearing cross-section of the sheet, and a homogeneous structural constitution is thus ensured. Deformation of the weld area is accomplished by subsequent upsetting of the two previously welded workpieces against one another. The selection of the time-temperature-deformation cycles depends on the desired material reaction. The time-temperature-deformation cycles employed for the thermomechanical treatment of steel H340LA are plotted in Fig. 53.
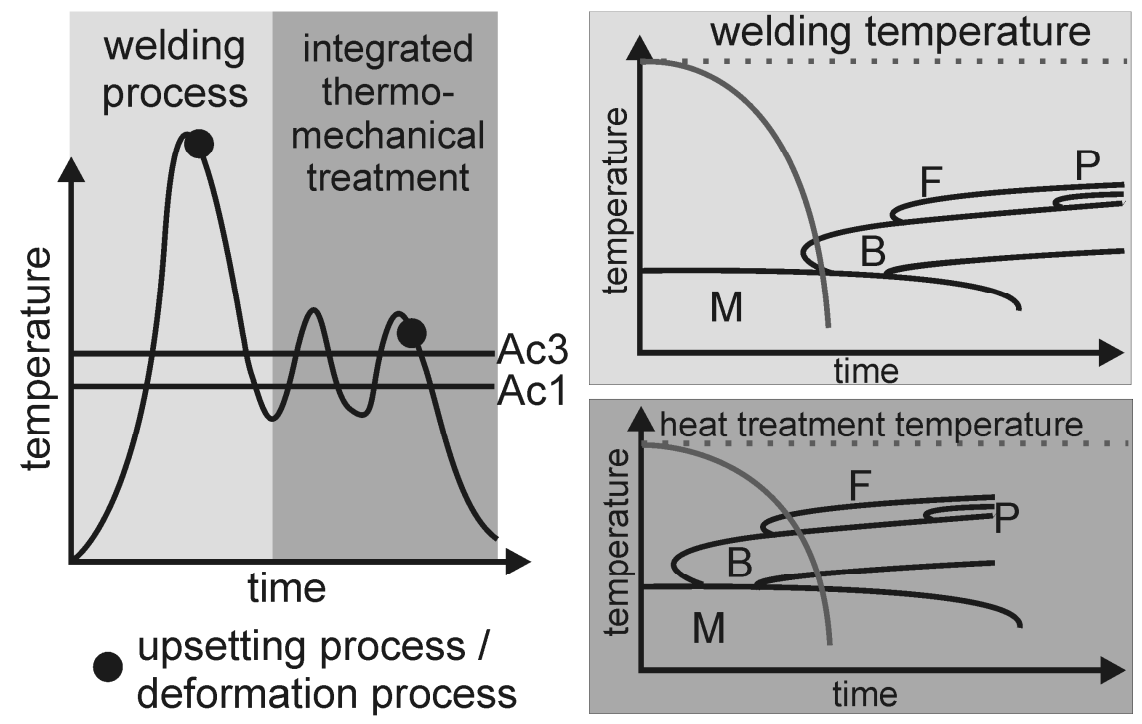

Fig. 53: Time-temperature-deformation cycles for HF-welding and for the thermomechanical postweld treatment of the joint

The thermomechanical treatment process consists of two austenitising operations on the weld structure. The selected austenitising temperatures are higher than the Ac3 temperature by 30 to $80^{\circ} \mathrm{C}$. Since the austenitising temperature is much lower than the temperature of the welding process, a ferritic structural transformation can be induced, see Fig. 53. After the second austenitising process, the weld structure is deformed during the transition to the $\gamma / \alpha$ two-phase region. The structure thus obtained in the welded joint is shown in Fig. 54. 

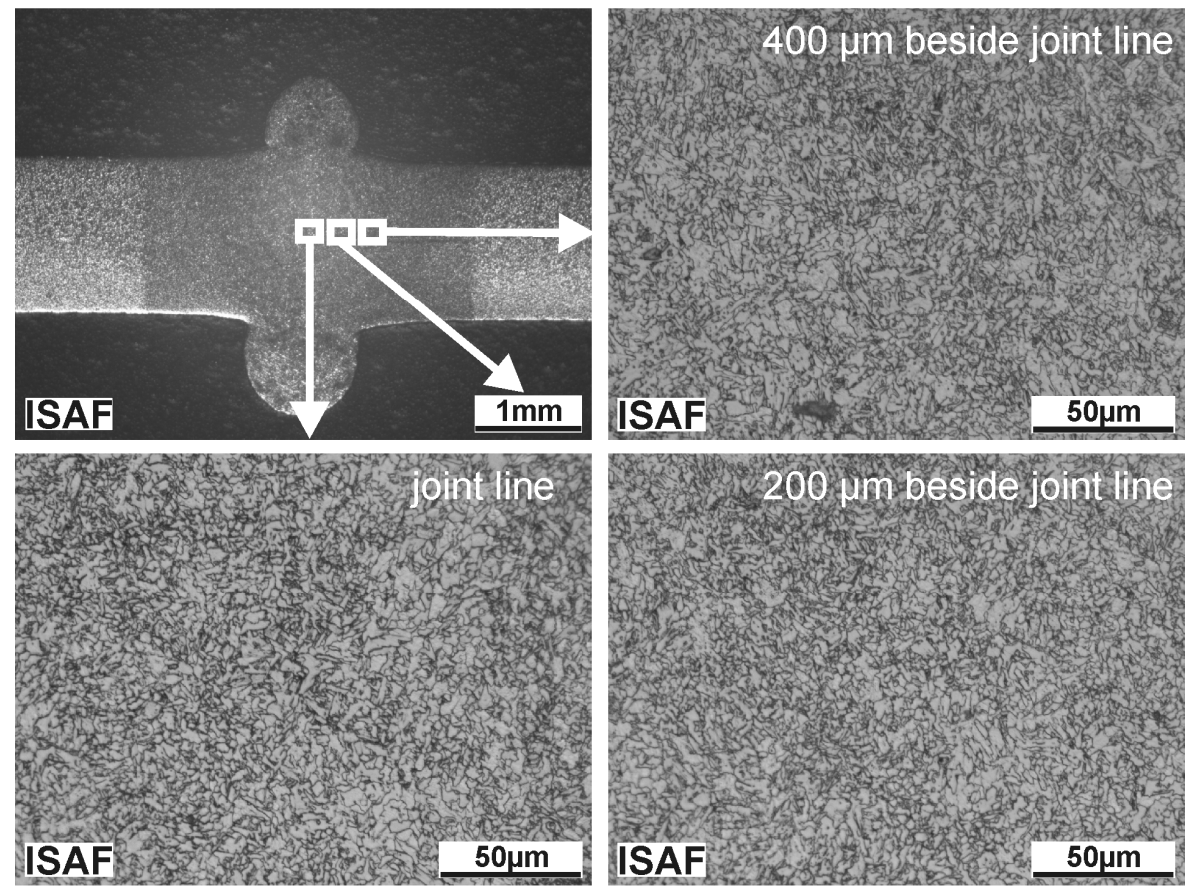

Fig. 54: Thermomechanically treated weld structure of material H340LA

The bainitic-martensitic microstructure which is present after the welding process has been completely transformed to a ferritic structure. The grain size thus obtained is comparable to that of the fine-grain zone which results from the welding process. The altered microstructure is also reflected in the hardness variation in the direction transverse to the welded joint, Fig. 55. The hardness decreases from its maximal value, but does not attain the level of the base metal. This observation is due to the considerably smaller grain size of the ferrite thus formed.

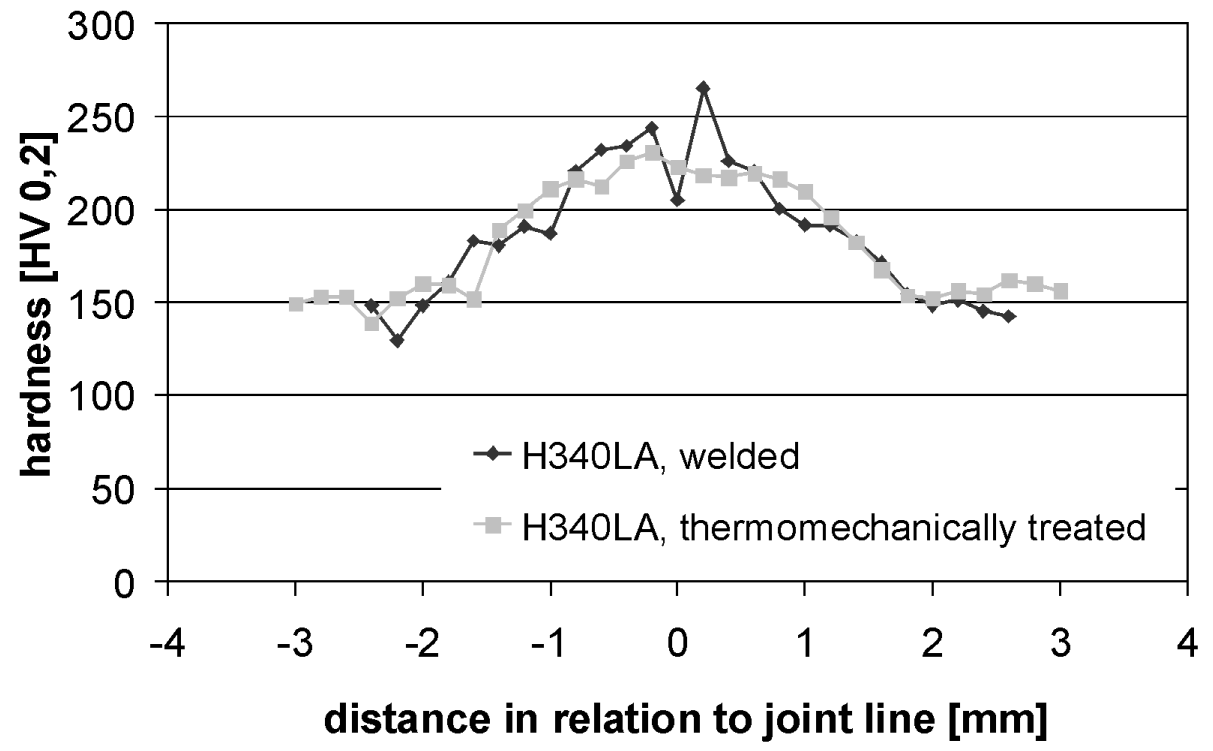

Fig. 55: Hardness variation in the joining line with material H340LA in the untreated and thermomechanically treated welds

For demonstrating the improved deformation properties of the weld as a result of the thermomechanical treatment, the joints welded with and without the integrated postweld treatment were compared with the base metal by means of longitudinal-tension tests. For this purpose, the excess upset metal was removed by machining, in order to ensure the comparability of the results. 
Stress-versus-strain curves recorded for the base metal as well as for the welded samples are plotted together in Fig. 56 for comparison.

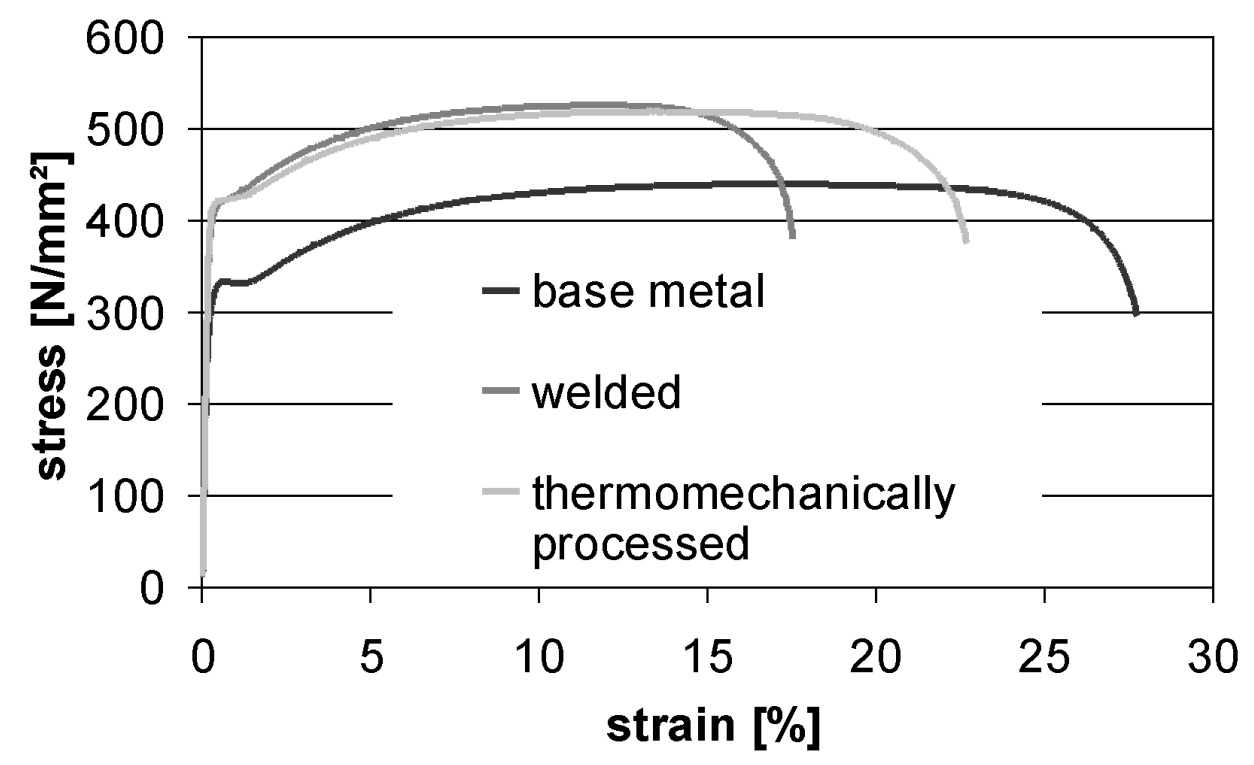

Fig. 56: Stress-versus-strain curves from longitudinal-tension tests on HF-welded joints in comparison with the base metal, steel H340LA

As can be seen from Fig. 56, the elongation at rupture in the longitudinal-tension test can be increased from 17 per cent with untreated samples to 23 per cent with thermomechanically treated samples; however, the elongation of 28 per cent for the base metal is not attained. The site of rupture is not displaced by the postweld treatment of the joint; it is still situated in the former coarse-grained zone, as with the untreated samples.

Conclusions and outlook. The properties of HF-welded joints of material H340LA have been investigated. The static and fatigue strength values for the welded samples are at the same level as those for the unaffected base metal. No geometrical notch effect has been detected under alternating stress in the case that the excess upset metal has not been removed by machining. Furthermore, the elongation at rupture has been decisively increased by integration of a thermomechanical postweld treatment into the joining process, in comparison with the lower value which results from the welding operation alone. The elongation at rupture in the longitudinal-tension test was thus increased from only 17 per cent with untreated samples to 23 per cent with samples subjected to the thermomechanical treatment.

Further time-temperature-deformation cycles for improving the weld properties are currently under development. For achieving this objective, the grain size of the weld structure should approximate that of the base metal more closely. A possible time-temperature cycle which constitutes the basis for continuing developments in thermomechanical treatment is illustrated in Fig. 57 [23]. 


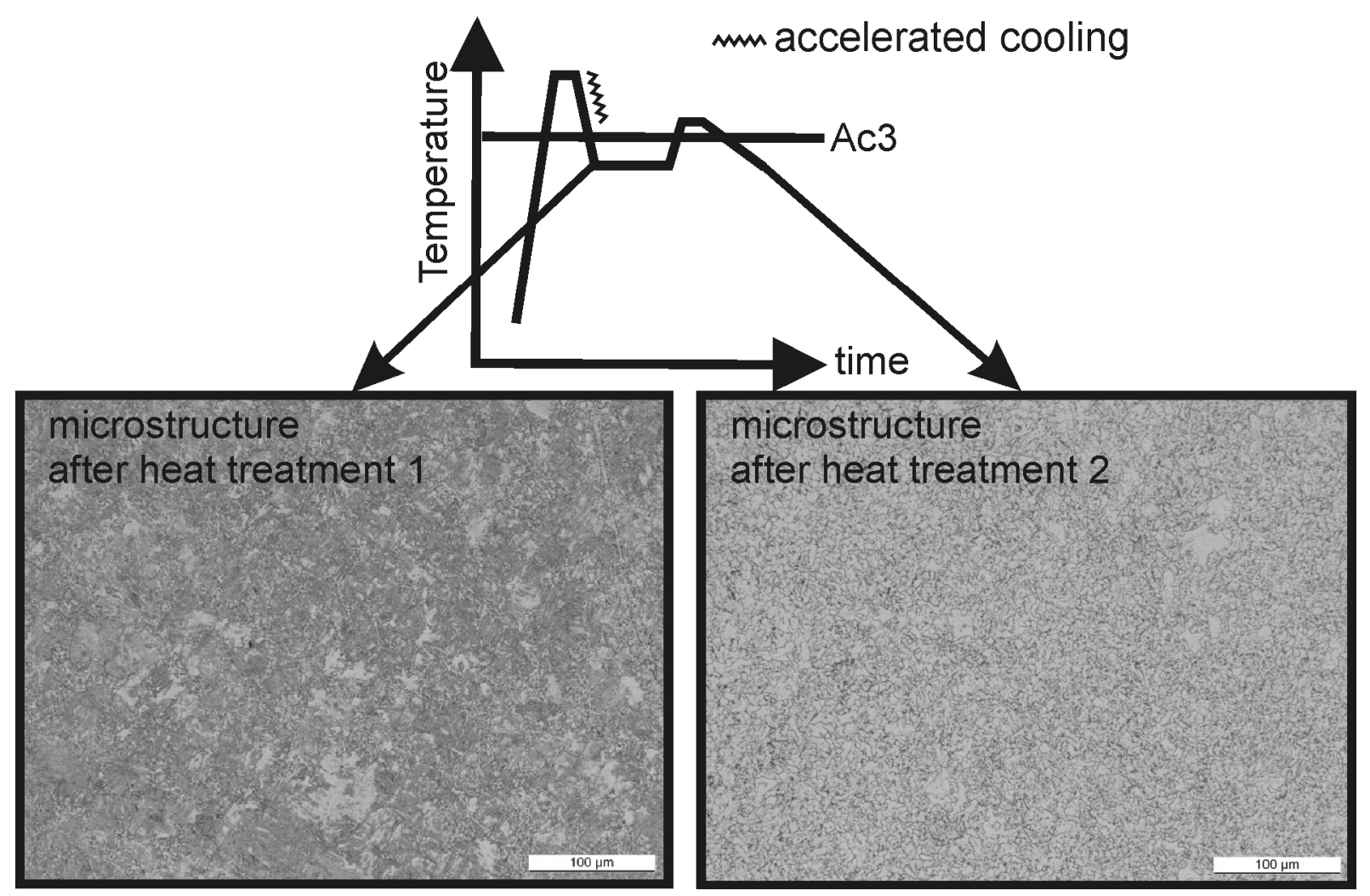

Fig. 57: Tested alternative time-temperature cycle for the thermomechanical treatment of welds on micro-alloyed steels, including a representation of the structural development

This cycle comprises two austenitising operations on the weld area. In contrast to the heat-treatment cycles previously described, the joint is heated up to $1050{ }^{\circ} \mathrm{C}$ during the first austenitising process and subsequently quenched with water. The purpose of this operation is the establishment of a homogeneous coarse-grained martensitic structure. As a result of the subsequent austenitising process in the temperature range from 30 to $80{ }^{\circ} \mathrm{C}$ above Ac3, the coarse-grained martensite is then transformed to a ferritic structure. The structure thus obtained is shown on the right side of Fig. 57. The decided increase in the grain size and a maximal hardness of $190 \mathrm{HV} 0,2$ (in relation to the first described thermomechanical treatment operation) in the weld area demonstrate the success of the measures thus implemented. The inhomogeneities visible in Fig. 57 can be eliminated by an additional deformation during the second austenitising process.

Further preliminary investigations on the possibility of applying the thermomechanical treatment to HF-welded polyphase steels have likewise yielded favourable results. Dual-phase steel DP 800 with a thickness $\mathrm{t}$ of $1,44 \mathrm{~mm}$ was employed as test material. The postweld heat treatment of the welded joints comprised furnace annealing of the samples in the $\gamma / \alpha$ two-phase region $(t=200 s)$ with subsequent deformation of the weld area in the direction orthogonal to the plane of the sheet during the cooling phase. The structural development is shown in Fig. 58 for a sample before and after the heat treatment. 


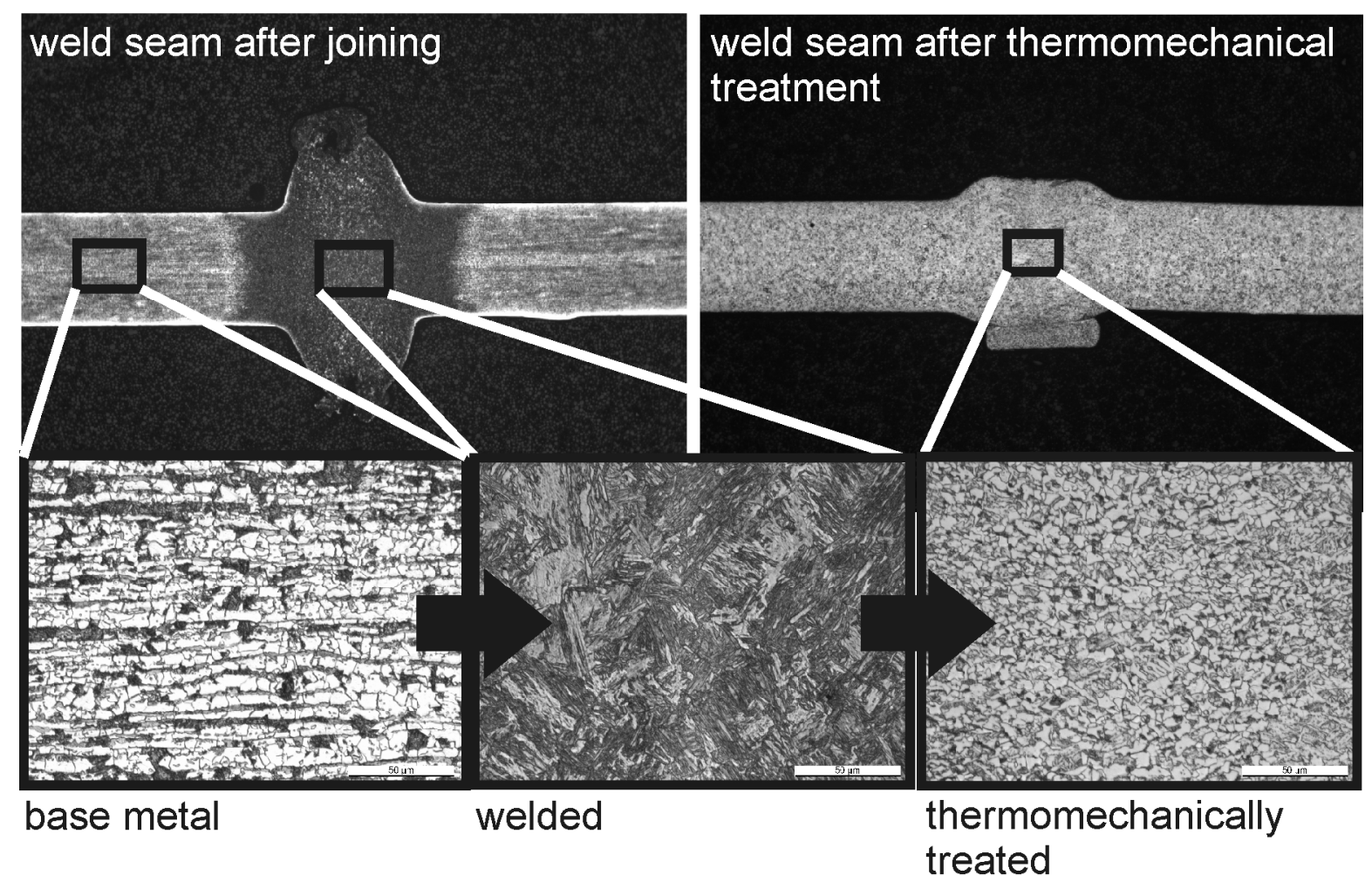

Fig. 58: Structural development in the weld area by thermomechanical treatment of material DP 800

The coarse-grained martensitic structure present after joining can again be transformed to a finegrained structure consisting of the ferrite and martensite phases. The resulting grain size is smaller than that of the initial structure. In a further step, the thermomechanical treatment process must now be integrated into the welding operation. Essential challenges imposed by this requirement include drastic shortening of the time necessary for the heat-treatment, in order to ensure economic implementation of the operating principle. 


\section{References}

[1] T. Schwetje: Untersuchungen zum Hochfrequenzschweißen von Konturbauteilen; Dissertation TU Clausthal (2002)

[2] V. Wesling: Bestimmung der qualitätsrelevanten Werkstoff- und Prozesskenngrößen für das kombinierte Umformen und Fügen von Feinblech; Arbeits- und Ergebnisbericht SFB362 „Fertigen in Feinblech“ (2006)

[3] C. Fritzsche: Untersuchungen zum Hochfrequenzschweißen von Feinblechwerkstoffen; Dissertation TU Clausthal (2002)

[4] C. Fritzsche and M. Schmidt: Hochfrequenzschweißen - Stand und Anwendungen; Konferenzeinzelbericht DVS-Berichte Vol. 213 (2001), pp. 87-92 DVS Verlag Düsseldorf

[5] T. Schwetje and K. Mazac: Hochfrequenzschweißen eröffnet Zulieferern Chancen; Blech in Form Vol. 4 (2002), pp. 74-76

[6] V. Wesling, A. Schram and H. Wiche: Hochfrequenzschweißen - Vorstellung schweißbarer Geometrien; 6. Industriekolloquium „Hochfeste Strukturen“ Clausthal-Zellerfeld (2007), pp. 69-76, Piepersche Druckerei und Verlag

[7] M. Schmidt and K. Mazac: Hochfrequenzschweißen mit konduktiver Energieeinbrinung; Konferenzeinzelbericht; 2. Industriekolloquium SFB 362 „Fertigen in Feinblech“ ClausthalZellerfeld (2000), pp. 94-110

[8] V. Wesling, A. Schram and T. Rekersdrees: Hochfrequenzschweißen von martensitischem Warmband; Schweißen und Scheiden Vol. 57 (2005), pp. 690-694, DVS Verlag

[9] V. Wesling, A. Schram and T. Rekersdrees: High-frequency welding of martensitic sheet steelprocess influences on the static strength; Steel GRIPS Vol. 5 (2005), pp. 380-384, GRIPS Media

[10]V. Wesling et al.: Schwingfestigkeitsverhalten von hochfrequenzgeschweißten Aluminiumknetlegierungen; Schweißen und Schneiden Vol. 58 (2006), pp. 408-411, DVS-Verlag Düsseldorf

[11]S. Schlagau: Verfahrensverbesserung beim Kragenziehen durch Überlagerung von Druckspannungen; Dissertation TH Darmstadt (1988)

[12]B. Engl: Warm- und kaltgewalzte Mehrphasenstähle und ihre Anwendung; KEM Vol. 1 (2000), pp. 104, Konradin Leinfelden

[13]R. Bartos: Höher-höchst-ultrahoch(fest) - Stahlsorten und Konstruktionsweisen für Bleche und Profile im Karrosseriebau; Konstruktionspraxis Vol. 1 (2008), pp. 26-28, Vogel Würzburg

[14]V. Wesling, A. Schram, T. Rekersdrees and H. Wiche: Process simulation of the heating phase during conductive high-frequency welding of low-alloy sheet-steel blanks; Steel Research International Vol. 79 (2008), pp. 202-207

[15]V. Wesling, A. Schram and H. Wiche: Einfluss der Spannelementgeometrie beim Hochfrequenzschweißen von höchstfesten Stählen; Schweissen und Schneiden Vol. 61 (2009), pp. 514-519, DVS Verlag

[16]V. Wesling, A. Schram and H. Wiche: Prozessintegrierte Verbesserung der Schweißnahteigenschaften beim Hochfrequenzschweißen von hochfesten Stählen; 7. Industriekolloquium „Potenziale metallischer Werkstoffe lokal Nutzen“ Clausthal-Zellerfeld, (2009), pp. 187-193, Oberharzer Druckerei Fischer \& Thielbar 
[17]H. Wiche: Hochfrequenzschweißen von Feinblechen aus hochfesten Stählen; DVS Vortragsveranstaltung „Young Professionals“ (2009), Hamburg

[18]W. F. Ray, C. R. Hewson and J. M. Metcalfe: High frequency effects in current measurement using rogowsgi coils; EPE Conference (2005), Dresden

[19]W. F. Ray and C. R. Hewson: Introduces the transmission line model of the rogowski coil, passive integration and the effect of assymetric coil excitation; IEEE-IAS Conference (2000), Rome

[20]V. Wesling, A. Schram, T. Rekersdrees and H. Wiche: Schweißen hochfester Stähle am Beispiel des Hochfrequenzschweißens; Aachener Berichte Fügetechnik (2007), pp. 99-110, Shaker Verlag Aachen

[21]ASTM International: Standard Test Method for Determining Residual Stresses by the HoleDrilling Strain-Gage Method (E837); in: Annual Books of ASTM Standards (2003), pp. 694-703

[22]V. Wesling, A. Schram and H. Wiche: Hochfrequenzschweißen von Feinblech aus mikrolegiertem Stahl mit integrierter thermomechanischer Nahtbehandlung; Materialwissenschaft und Werkstofftechnik Vol. 40 (2009), pp. 848-852, Wiley-VCH

[23]E. Treiß: Induktionsglühung der Schweißnaht bei der Fertigung HFI-geschweißter Stahlleitungsrohre; 3R International Vol. 20 (1981), pp. 627-630, Vulkan Verlag 